\title{
Energy Efficiency Challenges in Pulp and Paper Manufacturing: A Tutorial Review
}

\author{
Martin A. Hubbe \\ The pulp and paper industry is highly energy-intensive. In mills that use \\ chemical pulping, roughly half of the higher heating value of the cellulosic \\ material used to manufacture the product typically is incinerated to \\ generate steam and electricity that is needed to run the processes. \\ Additional energy, much of it non-renewable, needs to be purchased. This \\ review considers publications describing steps that pulp and paper \\ facilities can take to operate more efficiently. Savings can be achieved, \\ for instance, by minimizing unnecessary losses in exergy, which can be \\ defined as the energy content relative to a standard ambient condition. \\ Throughout the long series of unit operations comprising the conversion \\ of wood material to sheets of paper, there are large opportunities to more \\ closely approach a hypothetical ideal performance by following \\ established best-practices.
}

Keywords: Exergy; Pinch analysis; Process integration; Underutilized resources; Heat exchangers; Efficiency; Sustainability

Contact information: Department of Forest Biomaterials, North Carolina State University, Campus Box 8005, Raleigh, NC27695-8005 USA; *Corresponding author: hubbe@ncsu.edu

\section{Contents}

Introduction ............. 8568

General principles of energy . . . . . 8569

Simple losses ........... 8571

Energy and exergy . . . . . . . . 8573

Definitions ............ 8573

Heat exchangers. . . . . . . . 8574

Pinch analysis. . . . . . . . 8575

Converting wastes to energy ... . 8576

Exergy saving opportunities . . . . 8577

Before pulping . . . . . . . . . 8578

Biomass pellets . . . . . . 8578

Hog fuel boilers . . . . . . . 8580

Hemicellulose extraction .... 8582

Mechanical pulping . . . . . . . 8583

Chemical pulping . . . . . . . . . . 8586

Chemical recovery . . . . . . . . . 8587

Kraft recovery boilers . . . . . 8588

Gasification ............ 8588

Multiple-effect evaporation . . . 8589

Fuel value from tall oil . . . . . .. 8590

Lignin from black liquor . . . . . 8591

Lime kiln heating with biomass. 8592

Papermaking . . . . . . . 8593

Refining of chemical pulps ... . 8593

Vacuum pumping \& friction . . 8594

Additives \& dewatering rates . . 8594
Water removal in press section. . 8595

Press drying attempts . . . . . 8597

Extended nip presses . . . . . . . 8598

Drying efficiency . . . . . . . . . 8598

Size-press starch solids . . . . . . 8601

Heat exchange, paper machine. . 8602

Infrared drying. . . . . . . . . . 8602

Air impingement drying . . . . . . 8603

Through-air drying. . . . . . . . . 8603

Condebelt drying . . . . . . . . . 8604

After pulping \& papermaking . . . . . 8604

Materials from primary effluent. . . 8604

Aerated biological treatment . . . . 8605

Incineration, wastewater sludge. . 8606

Anaerobic digestion of sludge . .. 8606

Waste paper as fuel . . . . . . . . 8608

Integrative approaches . . . . . . . 8608

Increasing bioenergy usage. . . . 8608

Pinch analysis with bridges . . . . 8609

Waste heat used to dry biomass. 8611

Strategies for implementation ...... 8612

Competition, other priorities ..... 8613

Risks................ 8613

Life cycle assessment issues . . . . 8614

Closing comments .......... 8614 


\section{INTRODUCTION}

Energy is a dominant factor that affects the economics and environmental performance of the pulp and paper industry (Bajpai 2016; Lawrence et al. 2018). In broad terms, one can envision the pulp and paper industry as being in the bioenergy business. When viewed from this perspective, there are opportunities to improve efficiency and to lower environmental impacts. In this tutorial review, the goal is to cover a broad range of concepts, from elementary to more advanced, that can be important in a variety of different pulp and paper mill facilities. Principles and mechanisms will be emphasized. Other publications are available that go more deeply into certain issues, such as process audits (Gilbreath 2019; Reese et al. 2020; TAPPI TIP 0404-63, 2021) and systematic approaches to such methods as pinch analysis (Atkins et al. 2012). For example, a combined study of water and energy analysis for kraft pulp mills appeared recently (Ahmetović et al. 2021).

Pulp and paper mills not only are huge consumers of energy, in the form of power and/or fuels, but they often are huge suppliers of energy as well. In the case of kraft pulp mills, a major source of energy, the lignin removed from the cellulosic material during pulping, is mostly converted to steam during the chemical recovery process (Gong 2005; Naqvi et al. 2010; Verma et al. 2019). The generated steam can be used in running the processes. By improving the overall efficiency of operations, the industry has come somewhat closer to energy self-sufficiency (Farla et al. 1997; Holmberg and Gustavson 2007; Lundberg et al. 2014). In addition, pulp and paper processing facilities are often well situated to be able to increase their reliance on incineration of underutilized lignocellulosic materials, such as bark, knots, branches, etc. By such usage of bioenergy, pulp and paper mills can decrease their usage of purchased energy, which is often in the form of fossil fuels or electricity (Holmberg and Gustavson 2007; Costa et al. 2019).

The goal of the present work is to review the available published literature regarding ways in which energy usage within the pulp and paper can be reduced, both in terms of the current state of the art and prospects for the future. Some important reductions in energy usage will fall under the category of efficiency. Further gains continue to be achieved by application of thermodynamic principles, using such concepts as exergy (Gong 2005; Utlu and Kincay 2013; Luis and Van der Bruggen 2014; Dincer and Rosen 2021) and pinch analysis (Browne et al. 2001; Atkins et al. 2012). Such practices can avoid some of the unnecessary destruction of useful energy, as in the case where a hot stream is combined directly with a colder stream of fluid. Unnecessary destruction of exergy also happens when steam is vented directly to the atmosphere, giving up its latent heat.

Another theme that will be explored in the sections that follow will be opportunities to obtain energy or at least decrease energy expenditures related to under-utilized resources, including bark, sludge, and wastepaper. Emphasis will be placed, in this article, on approaches that have demonstrated practical success under conditions resembling an industrial process.

\section{Suggested Readings}

At the outset, it is important to recognize some important review articles and monographs, to which the reader is referred. These are described briefly in Table 1, along with citations. The existence of these publications takes away some of the burden from the present article to describe full details in the covered areas. 
Table 1. Review Articles and Monographs Dealing with Aspects of Energy Reduction in the Pulp and Paper Industry

\begin{tabular}{|l|l|}
\hline Topic & Citation \\
\hline Paper waste: recycling, incineration, or landfilling & Villanueva \& Wenzel 2007 \\
\hline Energy from biomass in pulp \& paper mills & Gavrileseu 2008 \\
\hline Black liquor gasification integration in pulp \& paper mills & Naqvi et al. 2010 \\
\hline Energy saving strategies in the industrial sector (broad scope) & Abdelaziz et al. 2011 \\
\hline Process integration in pulp \& paper mills (pinch analysis) & Atkins et al. 2012 \\
\hline Exergy analysis of energy-intensive production processes & Luis \& Van der Bruggen 2014 \\
\hline Biogas from anaerobic digestion, research achievements & Mao et al. 2015 \\
\hline Pulp and paper industry energy conservation (book) & Bajpai 2016 \\
\hline Emerging energy-efficient technology for pulp \& paper & Kong et al. 2016 \\
\hline Biomass gasification technology state of the art & Molina et al. 2016 \\
\hline Biogas from anaerobic digestion; pulp \& paper sludge & Sibiya et al. 2017 \\
\hline Drivers, barriers, success factors for energy in pulp \& paper & Lawrence et al. 2018 \\
\hline Water, energy, and carbon footprint analysis of pulp \& paper & Ma et al. 2018 \\
\hline Energy benchmarking with reference to pulp \& paper & Rogers et al. 2018 \\
\hline Energy use and carbon emissions of pulp \& paper & Sun et al. 2018 \\
\hline Energy consumption research, pulp \& paper life cycle analysis & Man et al. 2019 \\
\hline Black liquor energy optimization: modeling of evaporation & Verma et al. 2019 \\
\hline Drying of paper, featuring recent innovations and research & Stenström 2020 \\
\hline
\end{tabular}

\section{Energy Audits of Pulp and Paper Processes}

Readers of this article are urged to also study articles about energy audits at pulp and paper mills (Sweet 1991; Kong et al. 2016; Reese 2018; Reese and Deodar 2018; Gilbreath 2019; Reese et al. 2020). The largest and quickest savings in energy in pulp and paper mills usually are achieved as a result of system audits. During such audits, emphasis is placed on finding deviations from the intended functioning of operations. Independent measurements are made of flows and other parameters, often using portable flow meters (Reese et al. 2020). Such independent checking routinely reveals problems with meters, valves, pumps, and even with improper settings of devices. Audits of pulp and paper mills, which often involve a team of specialists, can reduce energy usage by about $20 \%$. In typical cases, about a quarter to a half of the identified energy savings can be achieved without capital expenditures (Reese et al. 2020).

\section{Organization of this Article}

The organization of sections of the article, after this introduction, will start with consideration of general principles, then application of these principles to the pulp and paper industry, then strategies for implementation, and finally some closing comments. A "process order" arrangement will be followed when discussing application of energy principles within a typical pulp and paper mill. In view of the many technical terms employed in this article, the Appendix contains a glossary.

\section{GENERAL PRINCIPLES OF ENERGY MANAGEMENT}

Before considering issues specific to the processing of materials by the pulp and paper industry, background is provided here regarding some fundamental and general principles. Readers not needing this background are urged to skip ahead after scanning the 
headings. Three main areas are discussed here: simple losses, energy and exergy, and converting various process wastes or byproducts into energy and exergy.

To begin, it is important to focus upon the level of carbon dioxide in the environment, which has a close connection with the consumption of fossil fuels by humans. As illustrated in Fig. 1, the growth of plants in the course of photosynthesis naturally converts carbon dioxide to oxygen and leads to the storage of cellulose and other biomolecules. The radiant energy of the incident sunlight is thus captured in the form of chemical energy. The term " $\left(\mathrm{CH}_{2} \mathrm{O}\right)_{n}$ " that is included in Fig. 1 formally represents polysaccharides (cellulose and hemicelluloses), which are the largest component in the biomass.

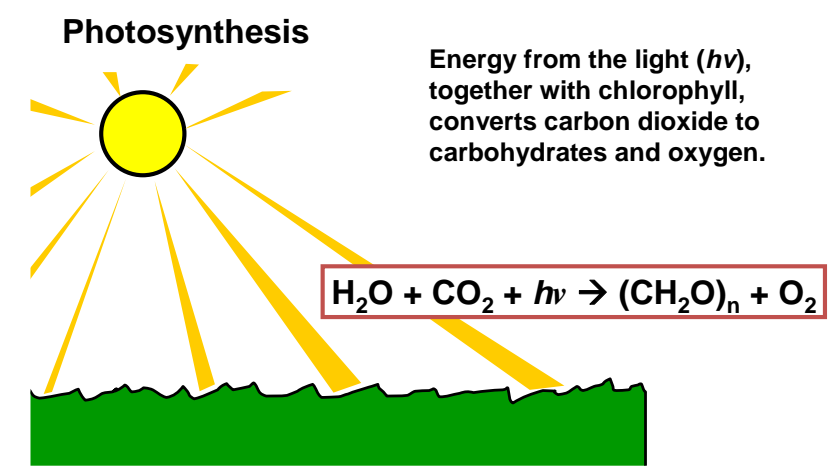

Fig. 1. Illustration of the photosynthesis process, by which carbon dioxide from the air is naturally converted to oxygen and biomaterials. Figures within this article are originals drawn by the author, unless otherwise noted.

The process of photosynthesis is essentially reversed when chemical energy stored in the organic materials, including both freshly grown biomaterials and fossil fuels such as coal, petroleum, and natural gas, are burnt. As illustrated in Fig. 2, increased levels of carbon dioxide and certain other gases in the atmosphere have the tendency to reflect back heat energy in the form of infrared radiation. Those rays initially had been reflected from the Earth's surface, thus causing a net temperature increase in the world's environments (Black and Weisel 2010).

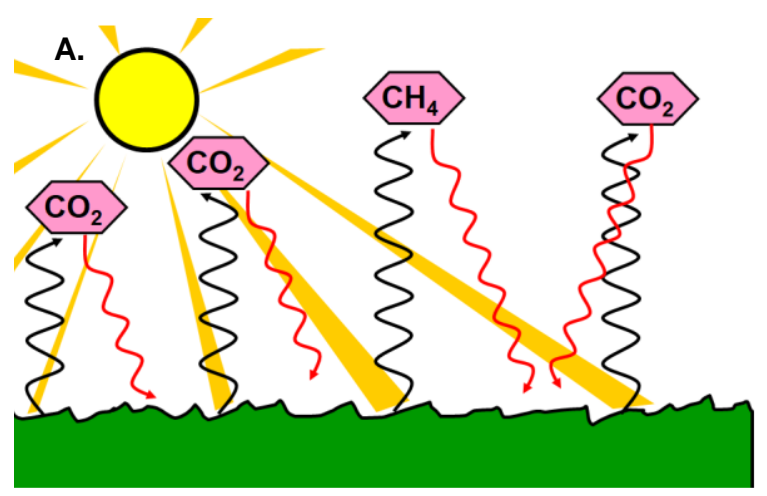

B

Fig. 2. Action of greenhouse gases such as carbon dioxide, methane, and nitrogen oxides in trapping some of the energy resulting from initial solar heating of the Earth's surface, giving rise to increased average temperatures. A: Increased reflection of infrared rays (heat) by greenhouse gases. B. Relative global warming potential (GWP) of $\mathrm{CO}_{2}$, methane, and nitrogen oxides on a molecular basis and also the warming influence of the gases at present levels in the atmosphere 
As indicated in part B of the figure, the effects in terms of global warming depend both on the tendency of each type of gas to reflect heat and their present levels in the atmosphere. For instance, although the tendency of carbon dioxide to reflect heat is only about $1 / 28$ of the same quantity for methane (when integrating the effect over time), the much higher level of $\mathrm{CO}_{2}$ in today's atmosphere than methane implies a greater effect. Another difference is that the half-life of atmospheric methane is about 8 to 12.4 years (Lelieveld et al. 1998; Balcombe et al. 2018), whereas $\mathrm{CO}_{2}$ in the atmosphere is very persistent (Ocko et al. 2018).

\section{Simple Losses}

When it comes to saving energy in an industrial facility, many of the cheapest and quickest steps are also the simplest, such as insulating hot pipes (Zaki and Al-Turki 2000; Hong et al. 2011; TAPPI TIP 0404-63 2016) and fixing leaks (Walker 1977; Sherlaw 1980; Chow 1982; Abdelaziz et al. 2011; Hong et al. 2011; Bhutani et al. 2012; TAPPI TIP 040463 2016). In an analysis of energy loss in the Taiwanese pulp and paper industry, Hong et al. (2011) estimated that in a typical manufacturing facility, equipment inefficiency accounted for an energy loss of $40 \%$, boiler and electricity generation summed up for an energy loss of $32 \%$, and distribution almost $28 \%$ energy loss. Connecting increasing energy efficiency to reducing in greenhouse gas emissions, there are opportunities to reduce emissions by 10 to $30 \%$ with "little or no investment," just by paying attention to simple losses (IPCC 1996).

Figure 3 illustrates the concept of insulation, considering the case of pipes containing a hot fluid that are immersed in stirred water media. In such cases the net flow of heat will be proportional to the gradient of temperature within the pipe walls, which are assumed to have a constant thickness.

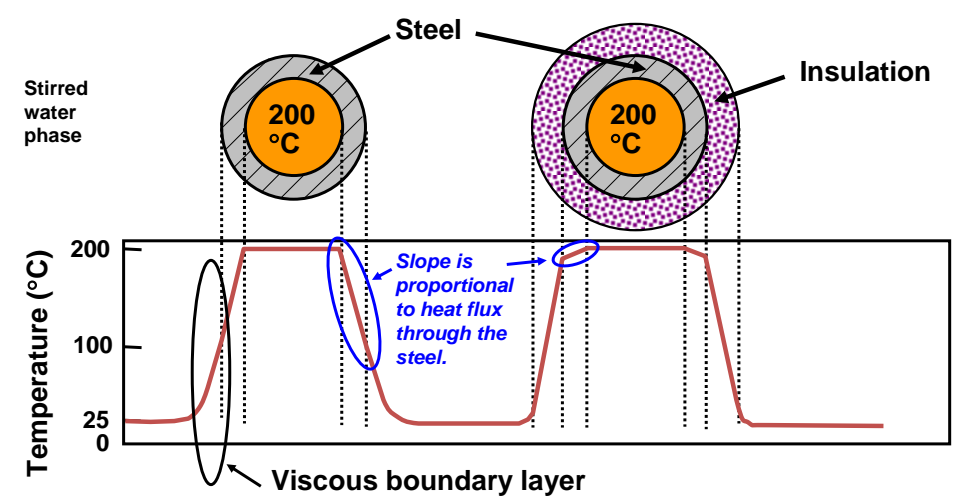

Fig. 3. Illustrative example of effect of insulation on the temperature gradients, and thus the flow of heat, in the case of pipes carrying a hot fluid through a hypothetical stirred water bath

Routine replacement of inefficient, common items is another promising place to look for potential savings. A quick pay-back, due to reduced energy usage, often can be obtained by replacing old, inefficient electrical motors with new, efficient ones (Browne $e t$ al. 2001; Abdelaziz et al. 2011; TAPPI TIP 0404-63 2016). For example, electrical energy can be saved by adding inverters to blowers (Hong et al. 2011).

Frictional consumption of energy during the running of manufacturing equipment often can be reduced by better lubrication. Figure 4 provides a schematic illustration of 
how friction affects the amount of energy required to run a continuous mechanical process, such as pulling a fabric adjacent to a surface against which it is being pressed. Among the terms in the expression that can be used to estimate frictional energy losses, it is the coefficient of friction that offers the greatest potential for savings. Savings often can be achieved by correct application of lubricants and maintenance of bearing systems.

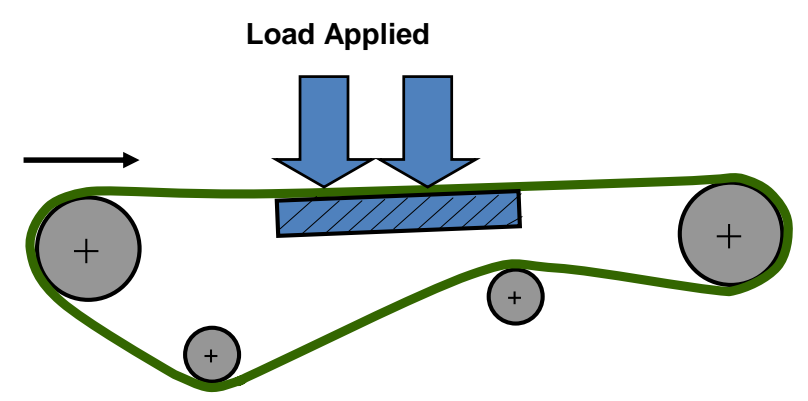

Frictional energy $=$ Load X Coef. of friction X Distance $/$ Time

Fig. 4. Illustration of a typical situation in the running of a paper machine, where motion of a continuous moving fabric is resisted due to friction as it passes over a surface, to which it is being pressed

Holmberg et al. (2013) estimated that about $15 \%$ to $25 \%$ of the energy used in a typical paper mill is due to friction. New technology for friction reduction was estimated to result in savings of about $11 \%$ in a time-frame of about 10 years and about $23.6 \%$ in the time-frame of 20 to 25 years. The reason for these relatively long-time horizons is that processing equipment in a typical paper mill can be used for multiple decades.

Large amounts of heat energy are used in pulp and paper manufacturing systems for heating and evaporation of water. Such heating requirements often can be decreased by finding ways to utilize less fresh water. Figure 5 illustrates a way to greatly decrease the amounts of water that are needed for various washing operations by applying a countercurrent washing system. As shown, the cleanest water is utilized for the final washing of the cleanest pulp. The filtrate of that operation is used for cleaning in the preceding stage of washing, and so forth.

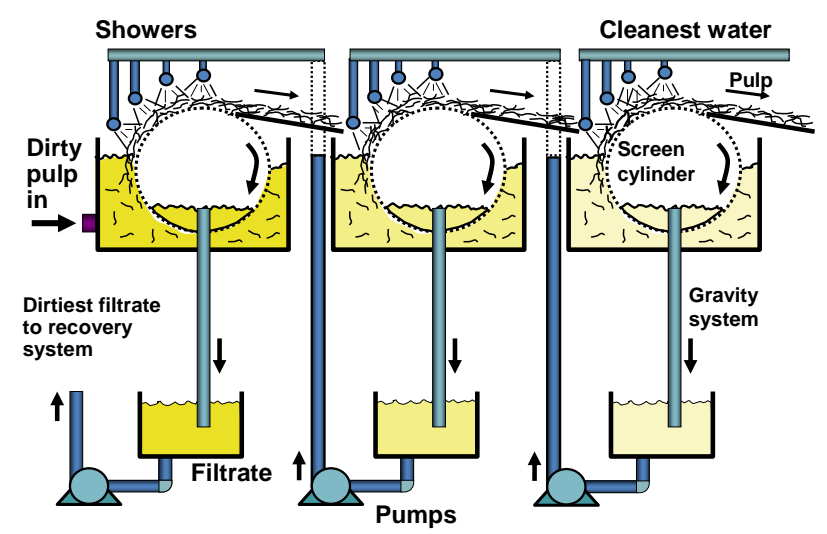

Fig. 5. Schematic view of three pulp washing deckers arranged with a counter-current flow pattern of wash solutions and filtrates 
An opportunity that is often overlooked by scholars as an energy concern, but that often is a major focus of attention for pulp and paper mill operating teams, is to increase the "up-time" of a process (TAPPI TIP 0404-63 2016). That is because various fixed and semi-variable costs, including labor, insurance, and depreciation, continue inexorably, regardless of whether or not a product is coming off the end of a process line (Hubbe and King 2009). Eliminating such process interruptions also saves energy, since most of the energy consumption in a papermaking process will be happening continuously, whether or not saleable paper is arriving at the reel of the paper machine at every minute.

\section{Energy and Exergy Definitions}

The term exergy can be defined as "shaft energy" or as "usable energy". Exergy represents the maximum work potential of a system or component at a given state in a specified environment. The reason that such energy is important is that although every material contains thermal energy, the laws of thermodynamics allow only part of that heat energy to be converted to, say, mechanical or electrical energy. The computation of the quantity of exergy always requires the definition of a reference temperature, which might be the average temperature of ambient air adjacent to the facility (Dincer and Rosen 2021). Calculations of changes in exergy make it possible to quantify any unnecessary destruction of useful energy, for instance when directly mixing hot water with cold water in an industrial process (Luis and Van der Bruggen 2014; Costa et al. 2019). Such mixing represents a lost opportunity to save exergy. Exergy analysis also makes it possible to calculate the maximum possible conservation of energy that might be achieved by future advances in technology (Gong 2005).

Pulp and paper mills are an especially appropriate focus of exergy analysis due to the fact that the processes employ large amounts of energy in multiple forms. These can include thermal energy (latent heat of evaporation and sensible heat due to the heat capacity and changes of temperature of materials), electrical energy, and mechanical energy. It is therefore important to analyze the energy and exergy flow to identify the potential areas where the energy efficiency can be improved.

The importance of latent heat is illustrated in Fig. 6, which considers the heating of water at atmospheric pressure from ambient temperature to $200{ }^{\circ} \mathrm{C}$, well above the boiling point. It is notable that in the case considered, the net energy can be estimated based on just three terms.
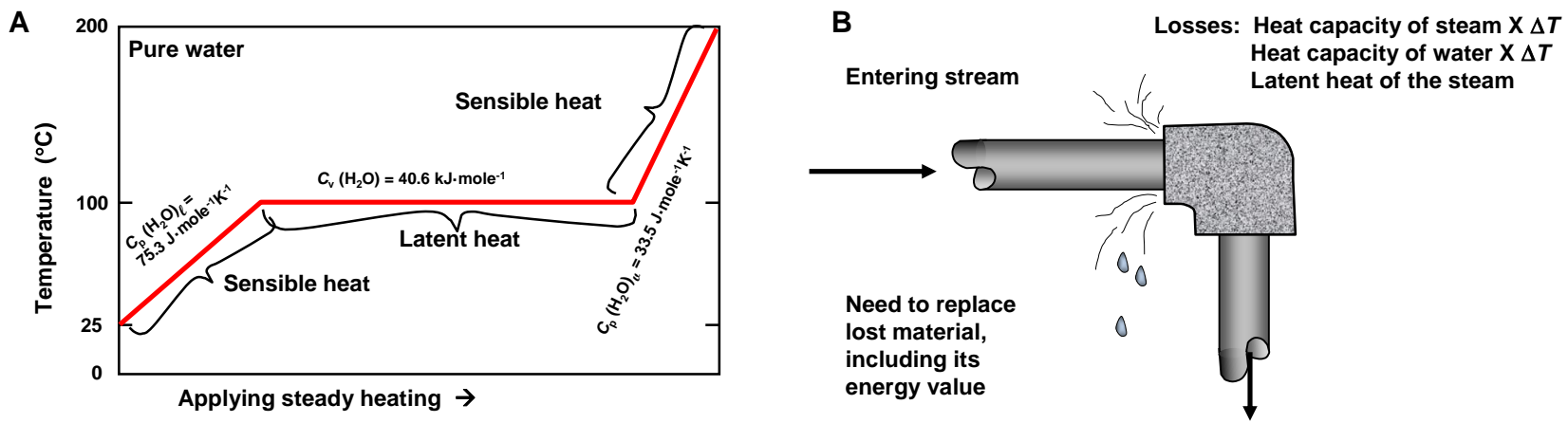

Fig. 6. A: Illustration of the relative amounts of heat required to raise the temperature of water to the boiling point (sensible heat), to evaporate the water (latent heat), and to further heat the water vapor (sensible heat) at atmospheric pressure; B: Heat losses due to steam leakage 
A first component of heat (sensible heat) needs to be applied to heat the water up to the boiling point. Next, latent heat is involved during the phase change from liquid to steam vapor. The third component of applied energy raises the steam temperature to the defined final state.

The leakage of energy is illustrated in part B of Fig. 6, which considers the possibility of escape of steam to the environment at a defective junction in piping. In the case considered, the loss of exergy includes both the latent heat and that portion of the sensible heat associated with temperatures above the reference temperature that has been assigned to the environment. Sensible heat must be included here because the leaked substances are all starting at a temperature well above the reference temperature (e.g. 25 $\left.{ }^{\circ} \mathrm{C}\right)$.

\section{Heat exchangers and recovery of heat}

Within a pulp and papermaking operation, there are simultaneously many process streams that need to be heated up and many other streams that need to be cooled down. If energy conservation were of no concern at all, then all such changes in temperature could be achieved by direct heating and by refrigeration. But exergy is unnecessarily destroyed whenever separated substances having different temperatures are allowed to form an ideal mixture (Gong 2005). Such wastage can be minimized by the use of heat-exchangers. In particular, an economizer is a heat-exchange device designed to extract heat from flue gases (i.e. smoke) so that the energy can be used for the heating of entering air and water streams (Adbdelaziz et al. 2011). Part A of Fig. 7 shows a generic heat exchanger of the tube-shell variety, whereas part B represents an economizer, which transfers heat from flue gas. The numbers shown in part B are intended to suggest a possible use of warm flue gas (for instance starting at $200{ }^{\circ} \mathrm{C}$ ) to preheat incoming air, before its usage for combustion in a boiler. Within a heat exchanger, the stream to be heated flows through a series of stainless steel tubes. The tubes can be bare or have attached fins (Wejkowski 2016), which increase the heat transfer. As a specific example, blow-line heat from a pulp digester can be used to heat incoming water, as well as preheating of the combustion air to be fed into the boiler (Browne et al. 2001). It has been estimated that the amount of heat in the moist exhaust air leaving from paper machine hoods is about six times greater than the ability of incoming dry air to absorb heat (TAPPI TIP 0404-63 2021).
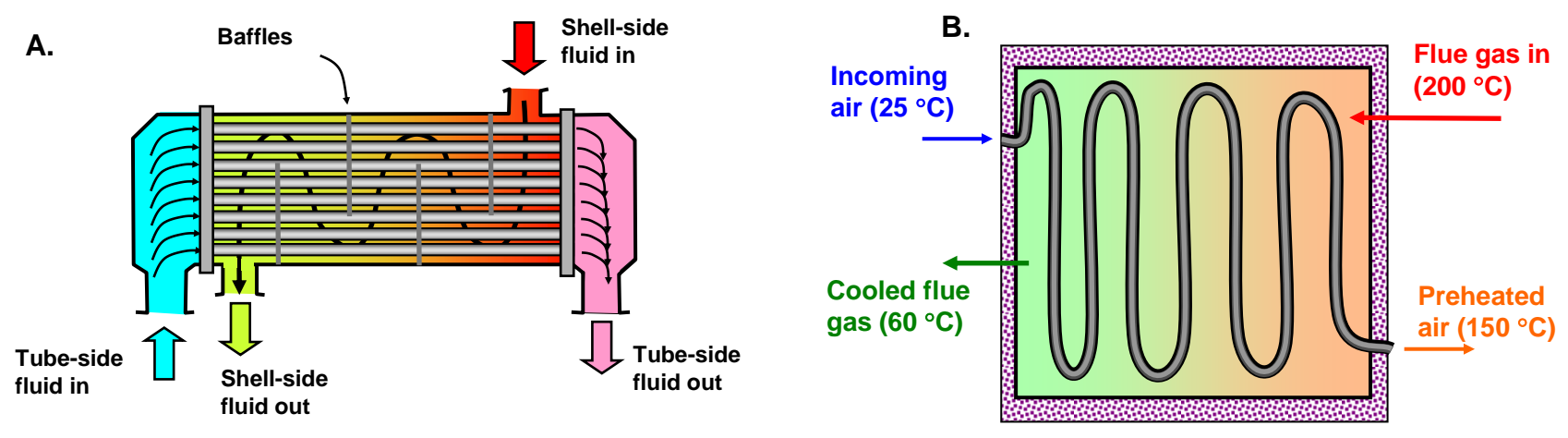

Fig. 7. A: Typical design of a tube and shell heat exchanger; B: schematic of an economizer, which transfers heat from flue gas to incoming streams of air or water to a process 
Another commonly observed wastage that occurs within pulp and paper mill systems consists of the direct venting of steam to the atmosphere. Such venting, which can either be purposeful or due to leakage of seals, should be avoided as much as possible. An exception is routinely made in the case of steam injected into dryer cans (TAPPI TIP 040463 2021). Many such systems are routinely operated with about $10 \%$ excess of steam that is "blow-through steam". The purpose of such venting of steam is to continuously displace non-condensable air and keep it from accumulating within the dryer cans. There are major savings in exergy that can be achieved by good control and minimization of blow-through steam (Walker 1977; Sherlaw 1980; TAPPI TIP 0404-63 2021).

Often within a pulp and paper mill system one encounters situations in which a certain source of steam does not have a sufficient combination of temperature and pressure to serve a particular function. Such a problem can be solved by use of a thermocompressor, which is a device that allows controlled blending of steam having different (but ideally not too different) levels of temperature and pressure (Walker 1977; Sherlaw 1980; TAPPI TIP 0404-63 2021). Though thermocompressors consume exergy, their use sometimes results in less loss of exergy (i.e. higher energy efficiency) when compared with other sources of steam having the needed pressure.

\section{Pinch analysis}

Pinch analysis is a technique that can be applied to avoid unnecessary exergy losses in an industrial process (Browne et al. 2001; Koufos and Retsina 2001; Wising et al. 2005; Atkins et al. 2012). Because pinch analysis typically considers all unit operations within the entire facility simultaneously, the term "process integration" is often applied. The term is especially used when discussing proposed process changes that come about due to pinch analysis. The general approach of pinch analysis is shown in a simplified form in Fig. 8, which is based on graphics shown by Atkins et al. (2012).

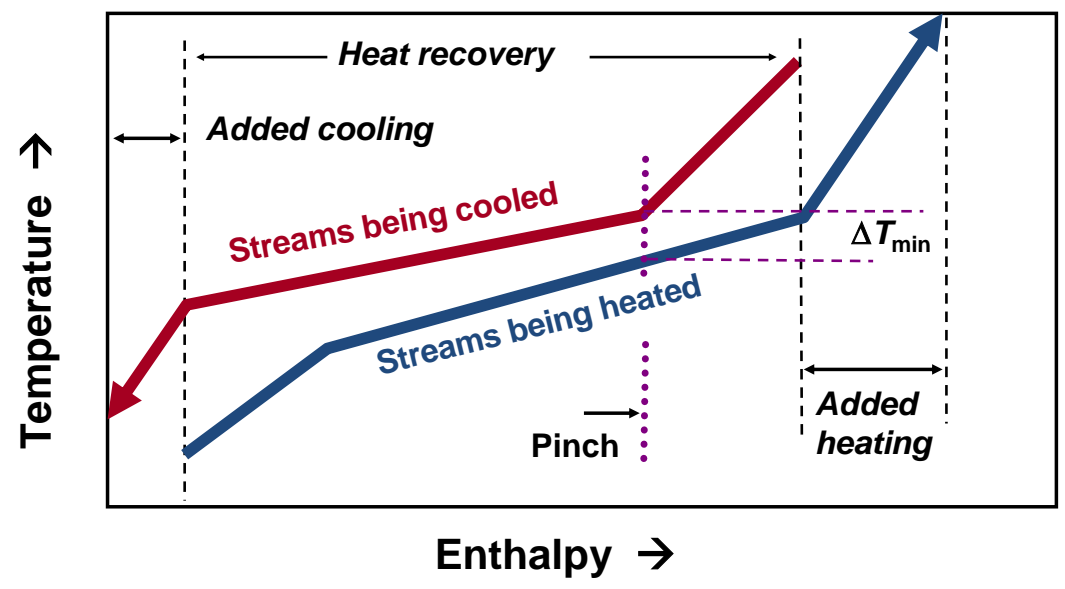

Fig. 8. Simplified diagram for a hypothetical pinch analysis, showing cumulative curves for streams being cooled (source streams) and streams being heated (sink streams). The graphic has been redrawn based on an original by Atkins et al. (2012).

The most notable feature in a typical graphic for a pinch analysis is a pair of composite curves, which together represent all of the streams being cooled and all of the streams being heated within the process as a whole (Koufos and Retsina 2001). Streams of materials being cooled (such as flue case, foul condensate, and exhaust from the hoods 
of paper machines, etc.) are called source streams. Materials being heated (such as incoming fresh air and water) are called sink streams.

In Fig. 8, the vertical axis represents temperature and the horizontal axis represents heat energy, i.e. enthalpy. In principle, energy can be saved whenever a change in the process results in the two composite curves coming closer together. Points where the composite curves come close together are called pinch points, from which the analysis method gets its name. Within such a diagram, one can envision heat exchangers functioning as bridges (Bonhivers et al. 2016). The cited work advocates the modification of bridge placements, i.e. the re-engineering of the heat exchanger network, as the most promising way to reduce energy consumption. However, there are also practical constraints to keep in mind, such as the distances between unit operations that might most efficiently exchange heat in an idealized system (Koufos and Retsin 2001). It is possible to carry out optimizations in such a way as to meet specified restrictions on heat exchange, corresponding to practical or theoretical considerations (Becker and Marechal 2012). There needs to be an evaluation of energy balance, identification of the inefficient process parts, and an optimum design of heat exchanger network. By combining pinch analysis with a techno-economic analysis of the costs of different design changes and operating costs, one can then make accurate choices between relatively cheap and convenient options (e.g. non-isothermal stream mixing and direct heat transfer), vs. more expensive retrofits to achieve a more efficient network of heat exchangers in the system (Savulescu and AlvaArgaez 2008). As another example, it has been shown that energy can be saved by changing the way in which a heat exchanger network is run during the summer $v$ s. during the winter in a pulp mill (Persson and Bertsson 2009).

Pinch analysis has been carried out to predict potential energy savings that can be achieved by various changes in processes and equipment. For instance, if the usage of steam energy in a pulp and paper mill can be decreased, then the excess steam either could be used to generate more electrical power or to enable isolation of lignin from black liquor (Axelsson et al. 2006). The lignin isolation is of interest because it can decrease the loading on an existing kraft recovery boiler, thus enabling a higher overall production rate at a pulp mill that is dependent on that recovery boiler (Hubbe et al. 2019). As another example, Marinova et al. (2009) employed pinch analysis as a way to develop strategies to save enough excess energy to enable pre-extraction of hemicellulose from wood chips prior to kraft pulping. Pinch analysis also can be applied in broader consideration of biorefinery options for redesign of existing pulp mills, allowing them to serve as sources of hemicellulose-based products, lignin-based products, and cellulose-based products (Moshkelani et al. 2013).

Beyond pinch analysis, it is important to take into account that steam-based systems comprise multiple forms of energy simultaneously, e.g. radiant energy, pressure-related energy, sensible heat (related to heat capacities), and latent heat (i.e. the heat associated with evaporation or condensation). Studies have indicated high potential for energy savings by focusing on the recovery of latent heat in the steam left over after various unit operations (De Beer et al. 1998). As an example, in paper machine drying systems it is important to efficiently return hot condensate to the powerhouse.

\section{Converting Wastes to Energy Products}

In principle, there can be a near-zero net accumulation of carbon dioxide in the atmosphere if energy is generated from burning of plant sources, since it is generally understood that such $\mathrm{CO}_{2}$ will be taken up by the next generation of a crop of biomass 
(Cherubini and Stromman 2011). Important assumptions upon which such projections depend include a maintenance of constant levels of plant growth in future years. In addition, although future forests can replace trees that are harvested today, the delay between harvesting and regrowth has consequences both on the amount of sequestered carbon and on the climate (Timmons et al. 2016). Future growth of trees and other biomass can depend on climate trends, in addition to forest management practices.

Though the pulp and paper industry sector is a major net user of energy, the industry is exceptional due to the relatively large proportion of the energy coming from consumption of renewable energy, especially biomass-based energy. Such energy comes from the incineration of the lignin present in black liquor (which is broken down and removed from the wood during kraft pulping) and also from the generation of steam energy in hog-fuel boilers, using bark and forest residuals (Blackwell and MacCallum 1983). It was reported that the US pulp and paper industry maintained a steady consumption of energy for many years, despite growth in production, mainly as a result of efficiency improvements (Koleff 1998). Opportunities to increase the proportion of plant-based energy during the production of pulp and paper will be considered later in this article. Life cycle assessment (LCA), which is based on an assumption of sustainable future growth of trees and other biomass, has become well accepted as a means to estimate and compare the expected environmental impacts of planned industrial projects.

It has been proposed that future pulp and paper facilities might achieve such high efficiency and that they will be able to use some of the excess electrical energy to actively remove carbon dioxide from the air (Mollersten et al. 2004). Such a system, if successful, would offer the industry the possibility to become an example of technology with negative $\mathrm{CO}_{2}$ emissions. The proposal is to employ captured $\mathrm{CO}_{2}$ as a raw material for bioproducts, for example in an integrated biomass gasifier system in which the syngas undergoes a $\mathrm{CO}$ shift reaction. Though such a proposal might serve to inspire useful research, most present pulp and paper facilities are very far away from generating all of their needed steam and electricity, and they are clearly not in a position to supply excess energy at present. However, as will be shown in the next section, there are a large number of unit operations that make up a pulp and paper facility, and improvements to most of them can provide opportunities to improve the mill's energy balance (Szabó et al. 2009).

\section{EXERGY SAVING OPPORTUNITIES IN PULP \& PAPER PROCESSES}

This section reviews published findings related to unnecessary loss of useful energy (i.e. exergy) in a typical pulp and paper manufacturing facility. Though, as will be seen, a pulp and paper operation can be envisioned as an interconnecting web, it is still possible to trace the main flow of materials in a linear path, and the discussion here will follow the chronological order of a typical process. Thus, the first topic involves the potential more effective usage of such materials as branches and bark during the harvesting of wood in forests. Another "before-pulping" opportunity, which pertains to kraft pulping operations, involves energy is the pre-extraction of hemicellulose from wood chips. Next to be discussed are the main pulping methods, starting with mechanical pulping, and then chemical pulping, where emphasis is placed upon use of a recovery boiler to generate steam with the burning of the lignin released from the wood material during chemical pulping. Next comes a discussion of energy savings in the paper machine system. Thereafter, the energy implications of various wastewater treatment options and sludge handling options 
are considered. In addition, some discussion points related to "whole system" integration, with a focus on energy, are left to the end of the section.

\section{Before Pulping}

Biomass pellets

Even before wood supplies arrive at a typical pulp and paper factory, already there are opportunities to recover heat value from under-utilized resources. In particular, the residual biomass, including small branches, has the potential to be converted into pellets (Miranda et al. 2015; Picchio et al. 2020). Figure 9, part A, describes a continuous process in which biomass is continuously squeezed through cylindrical holes (often about 3 to 6 $\mathrm{mm}$ in diameter) and cut to a desired length. By such conversion, the biomass becomes denser and uniform. This can be beneficial for storage, easy flowability, and convenience for metering into furnace equipment, where the materials can be converted into energy, including steam or electricity. When such material is used in place of fossil fuels, there is an expected net favorable effect on environmental impacts (Martin-Gamboa et al. 2020). Though pellet manufacture from biomass is widely practiced, it has not yet become common in the context of wood harvesting operations for pulp and paper manufacturing. Presently it is common practice to leave most branches in the forest, where presumably they can decay and return their mineral content to the soil.

A
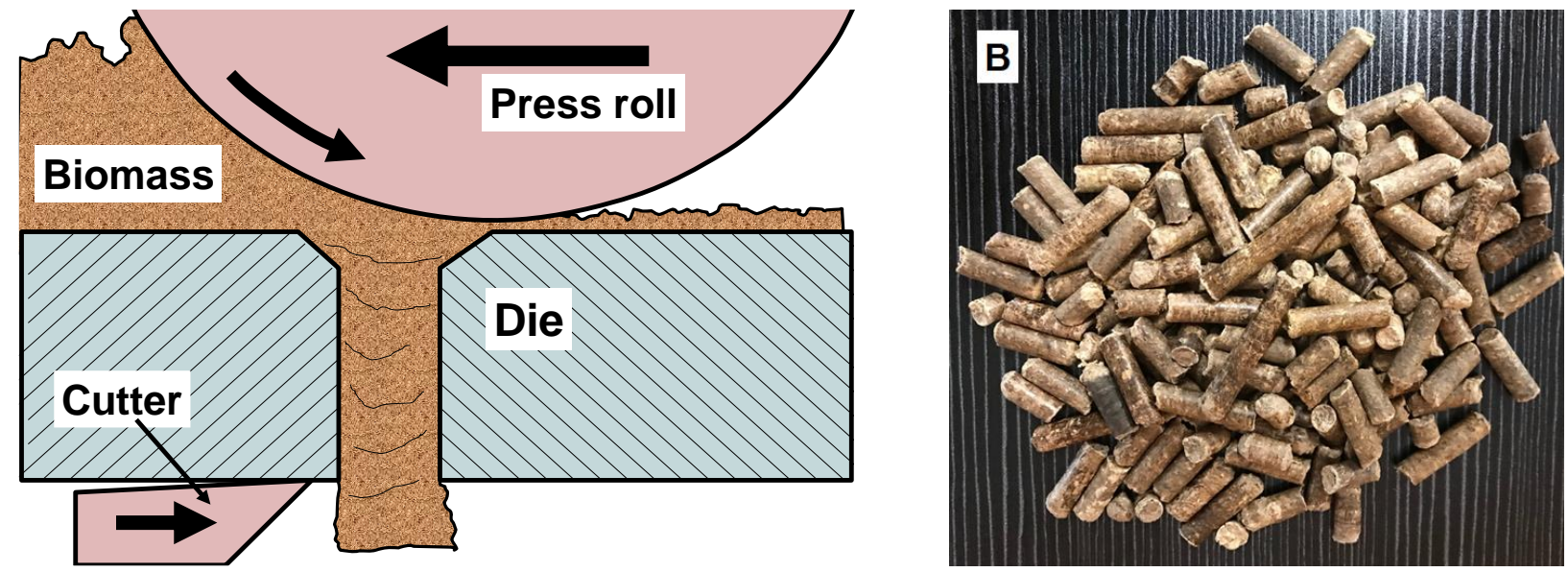

Fig. 9. A: Schematic illustration of pellet-forming process in which compressed biomass is squeezed through a small hole and cut to length using a rotating blade; B: Photo of wood pellets (courtesy of Danial Saloni, North Carolina State University, Dept. of Forest Biomaterials)

If a pelletization plant is set up at a pulp and paper mill, then a very promising option is to prepare pellets from bark, which is often removed from pulpwood at the mill site (Lehtikangas 2001; Mobini et al. 2013; Erixon and Bjorklund 2017). Although it is possible to feed bark and other forest residues directly to a power boiler (see later discussion of hog fuel boilers), the pelletization process renders the fuel suitable for use in a wide range of other boilers, including those used for district heating (Andersson et al. 2006).

Bark and wood residues, as they are collected in woods operations and at mill yards, often contain much more water than would be desirable for feeding to a power boiler. The amount of energy needed to evaporate the water becomes subtracted from the net heating value of the material (Demirbas 2005). The effects of moisture content and ash content on 
the effective heating value of various biomass types is shown in Fig. 10 (Zhao et al. 2017). The area in the plot below the horizontal dashed line defines conditions in which the net energy production is negative. Note that the highest positive value is shown at the upper left of the plot for bituminous coal, which is generally quite dry and has a low ash content. By contrast, at the lower right, the least desirable feedstocks for recovery of energy by combustion are the wet sludge samples (fermented sludge and sewage sludge). Unless these waste materials could be pre-dried using available waste heat, it would be advisable to seek other ways to recover their energy content. For instance, anaerobic digestion with recovery of methane gas is considered later in this review.

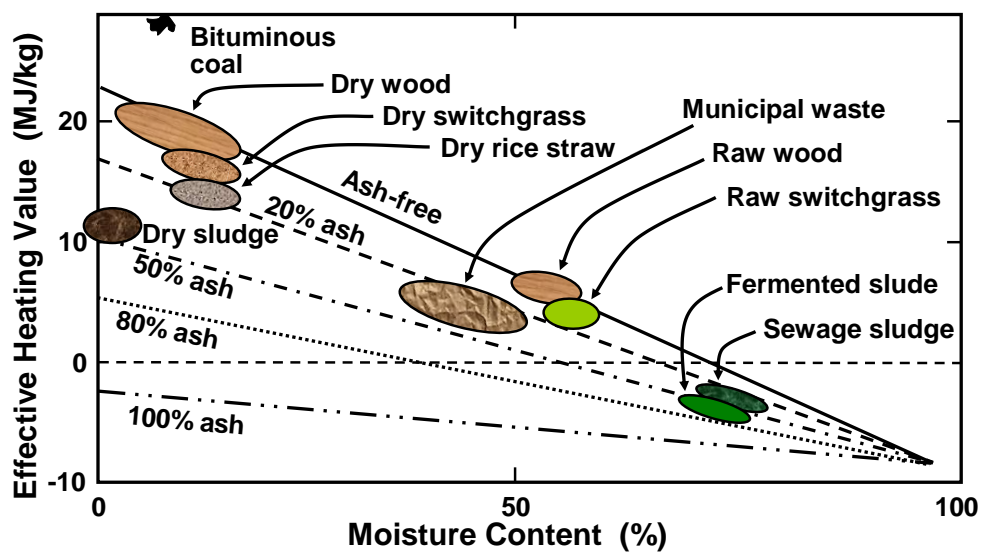

Fig. 10. Effects of different moisture contents and ash contents on the effective heating values of various biomass materials, compared to bituminous coal. Replotted from a version presented by Zhao et al. (2017)

Ash content represents the minerals (e.g. $\mathrm{SiO}_{2}$ or $\left.\mathrm{CaCO}_{3}\right)$ that may be present in the raw material. Ash content is regarded as undesirable, not only because it detracts from potential for energy production, but also due to the residue generated during combustion. Many existing boilers have limited tolerance for ash.

A net boost in energy production can be achieved when some of the low-grade waste heat, e.g. from flue gases, can be utilized for pre-evaporation of water in the biomass. For example, the material could be dried before its conversion to pellets (Wolf et al. 2006; Andersson et al. 2006; Erixon and Bjorklund 2017). Greater improvement can be achieved by steam treatment under pressure, followed by rapid expansion. The resulting steamexploded "black pellets," which resemble Masonite, are denser, stronger, and more waterresistant than ordinary pellets, and these are regarded as positive attributes. Another option is to use low-grade steam for a pulp and paper mill system to achieve partial drying of the biomass (Erixon and Bjorklund 2017). A related option to consider is torrefaction (Nosek et al. 2017; Mostafa et al. 2019; Wang et al. 2020), which entails heating up of the material to a range of about 200 to $300{ }^{\circ} \mathrm{C}$ (Picchio et al. 2020). Torrefaction, which can be carried out either before or after compressing the material into pellets, results not only in water removal, but also in partial decomposition of hemicellulose, yielding higher density and lower tendency of the material to absorb moisture from the air during storage. These changes render the material more valuable as a fuel. In addition, byproducts from the pulp and paper industry, such as lignosulfonate, can be used as binder for the production of pellets (Kuokkanen et al. 2011). Another potential source of material for pellet production 
is the sludge from wastewater treatment (Matúš et al. 2018). Additional energy-related options for utilization of such sludge are considered in a later section.

The higher effective heating value of bituminous coal, in comparison to dry wood, can be attributed to its elemental composition. As shown in Fig. 11, biomass in general has a much higher ratio of oxygen to carbon in its molecular structure in comparison to coal, in either its anthracite or bituminous forms. The covalent bond connecting carbon and oxygen is not available for combustion, and this difference means that oxygencontaining compounds are at a disadvantage in terms of their energy contribution, even when dry and having a low ash content.

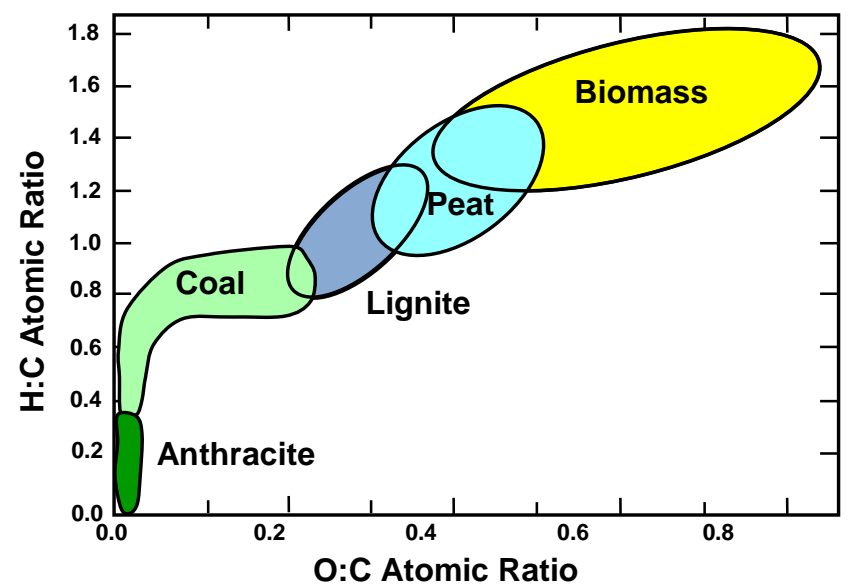

Fig. 11. A so-called Van Krevelen diagram, showing typical ranges of molecular composition for various solid fossil fuel and biomass resources. Redrawn based on a version reported by Grønli (2021)

The higher heating value (HHV) of a fuel can be defined as the maximum amount of heat released during the complete combustion after complete drying of the material of interest. The HHV of bituminous coal has been reported to be in the range 20 to $33 \mathrm{MJ} / \mathrm{kg}$ (Fernandez et al. 1997), whereas that of biomass is generally within the range 15 to 20 $\mathrm{MJ} / \mathrm{kg}$ (Chen et al. 2015).

\section{Hog fuel boilers}

To take advantage of forestry residues present at the mill wood yard, many pulp and paper facilities will run an additional power boiler, which is often called the hog fuel boiler or hogged fuel boiler (MacCallum 1983; Costa et al. 2019). The term has been used traditionally to denote the mixture of biomass that has been chopped up to enable more uniform burning. By running such a system, paper companies can generate electricity that either displaces purchased electricity, or they can sell energy back to the grid (Marshman et al. 2010). Heat can be generated from biomass according to the approximate relationships shown in Eqs. 1 and 2.

$$
\begin{array}{ll}
\mathrm{CH}_{2} \mathrm{O}+\mathrm{O}_{2} \rightarrow \mathrm{CO}_{2}+\mathrm{H}_{2} \mathrm{O} & \Delta H=-9.1 \mathrm{MJ} / \mathrm{kg} \\
\text { Lignin }+\mathrm{O}_{2} \rightarrow \mathrm{CO}_{2}+\mathrm{H}_{2} \mathrm{O} & \Delta H=-22 \mathrm{MJ} / \mathrm{kg}
\end{array}
$$

In these equations, $\mathrm{CH}_{2} \mathrm{O}$ represents the carbohydrates, which can approximate the elemental composition of cellulosic material. 
As was noted earlier, with reference to pellet production, the moisture content of hogged fuel has a major influence on the potential for steam production from the boiler. More energy can be generated if waste heat is used to pre-dry the material before its addition to a power boiler (Blackwell and MacCallum 1983; Sweet 1991; Costa et al. 2019). Boiler efficiency decreases at an increasing rate with increasing percentage moisture content of the hogged fuel (Linderoth 1986). The solid red curve in Fig. 12 shows how heat release at the grate of a power boiler was found to depend on the moisture content of the hog fuel. The dashed blue curve indicates the steam production as a function of moisture content (compared to the reference moisture content of 30\%). Incoming material that is drier burns faster, which helps to maintain a high rate of energy production in the boiler. In addition, the temperature of incineration will likely be higher when the incoming biomass has a lower moisture content. The drying process of hogged fuel generally happens in two stages: In an initial rapid stage, the rate of drying is controlled by the rate at which heat can be supplied to the outsides of the particles, which are wet. In the later stage, the rate of drying depends on diffusion of moisture to the surface of the particles (Blackwell and MacCallum 1983).

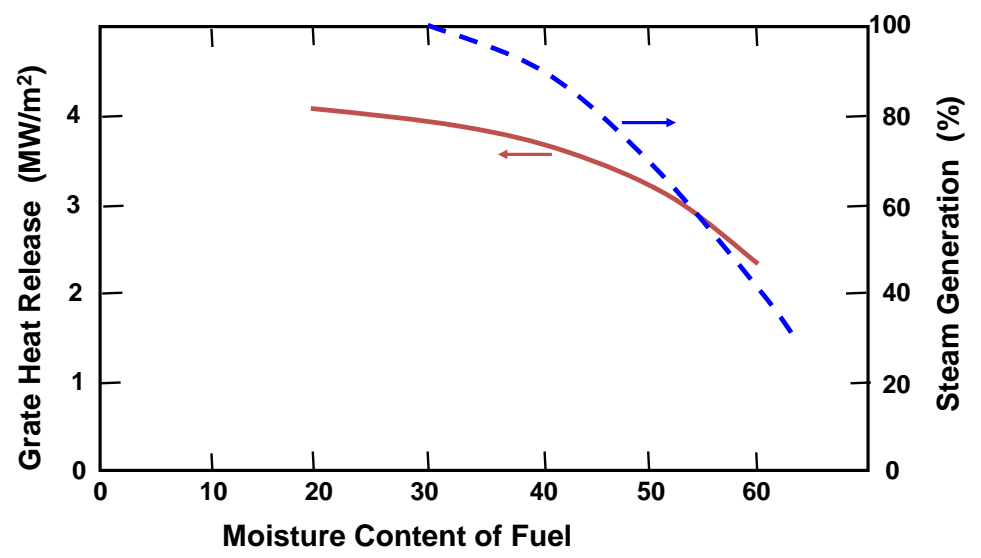

Fig. 12. Boiler efficiency as a function of moisture content of hogged fuel (replotted from Linderoth 1986)

Figure 13 illustrates a hypothetical concept in which the remaining heat content of flue gas is used to decrease the moisture content of biomass before it is fed to a hog-fuel boiler. The numbered yellow circles shown in the figure correspond to various pyrolysis gas-cleaning operations described in an earlier review article (Nelson et al. 2018). The figure has been modified by addition of a hopper at the upper left. By adding such a device, it would be conceivable to feed a controlled stream of medium-temperature flue gas near the base of the hopper. Thus, by the time the biomass has arrived at the base of the hopper, some of the moisture content has been evaporated.

Whether systems such as that illustrated in Fig. 13 can be used in practice will depend a lot on whether measures are taken to reduce the possibility of fires. Uncontrolled fire is an inherent danger during the drying of biomass, especially if direct contact with flue gas is used. Such danger can be avoided by usage of low-pressure steam rather than flue gas (Bruce and Hulkkonen 1998). Fortunately, the moisture content of hogged fuel can be really measured by means of a calibrated infrared-sensing device (Sayegh et al. 1983). There is a need for process control systems that can enable safe operation of biomass drying equipment. Power boilers suitable for hogged fuel can be grouped into two 
main types - grate-fired boilers, and fluidized bed boilers. A fluidized bed system has some advantages when handling particles that are relatively wet (McDermott et al. 1981), and it also has more flexibility with regard to fuel characteristics.

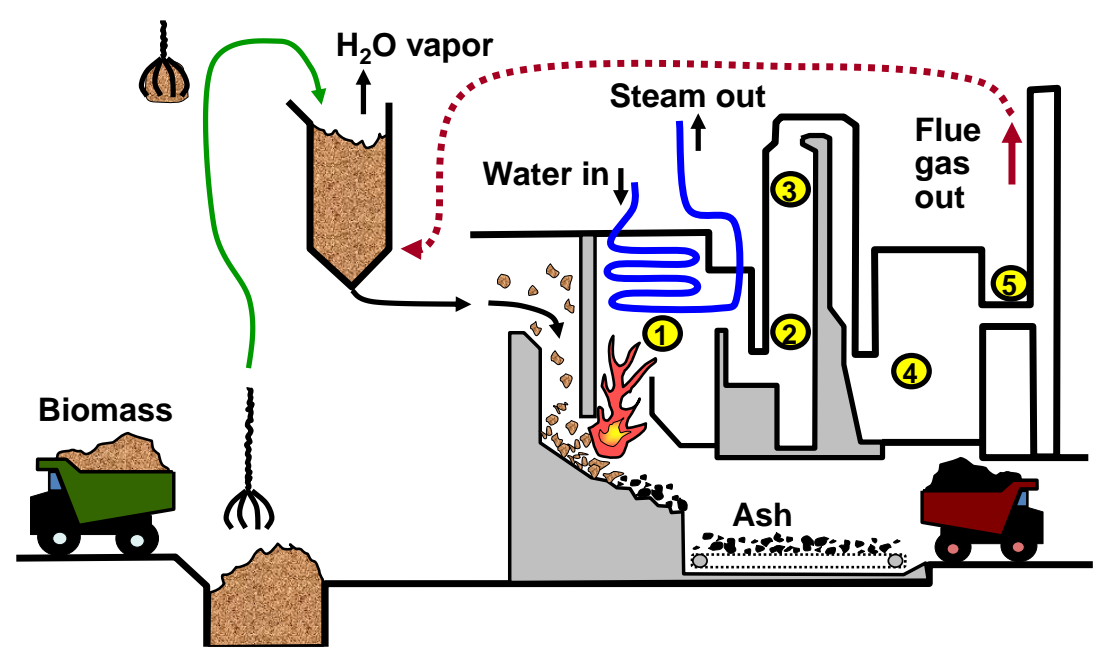

Fig. 13. Hypothetical scheme for pre-drying of hog fuel before its combustion by means of spent flue gas, after its use for steam generation and cleaning procedures. The figure is a modified version of what was original presented by Nelson et al. 2018). The numbered gas-cleaning steps are for (1) nitrogen oxides, (2) mercury and dioxin, (3) acid gases, (4) particulates, and (5) pollution control testing.

\section{Hemicellulose extraction before kraft pulping}

The next situation to consider pertains to kraft pulping. Hemicellulose is an energycontaining component that can be obtained from woody material before the pulping process. In conventional kraft pulping technology, the understood goal typically is to retain as much of the hemicellulose as practical in the pulp fibers. When present within the fibers, hemicellulose contributes positively to inter-fiber bonding within paper (Bai et al. 2012) and it renders the fibers less susceptible to irreversible loss of inter-fiber bonding ability when the paper is recycled (Oksanen et al. 1997). Though some of the hemicellulose becomes dissolved during delignification during kraft pulping, such hemicellulose and its byproducts contribute to energy generation in the recovery furnace (see later discussion). The pre-extraction of hemicellulose from wood chips prior to kraft pulping has been shown to have a negative effect on paper strength (Al-Dajani and Tschirner 2008; Yoon and van Heiningen 2008).

Sometimes there are persuasive reasons to extract at least part of the hemicellulose from the chips before they are added to the kraft digester. For instance, such pre-extraction can lead to savings in costs of bleaching the resulting pulp (Al-Dajani and Tschirner 2008; Yoon and van Heiningen 2008). In addition, the hemicellulose that becomes extracted is likely to be of relatively low molecular mass and therefore less effective as an inter-fiber bonding agent. Most often it is proposed to remove the hemicellulose by steam treatment, though a steam explosion process has been shown to be even more effective for its solubilization (Martin-Sampedro et al. 2014). The steam explosion option is not recommended when the fibers are to be used for papermaking, due to adverse effects on paper strength. However, such treatment might make sense if the kraft fibers were being 
converted to chemical products such as glucose, ethanol, furfural, or carboxylic acids (Xing et al. 2011; Moshkelani et al. 2013).

Another reason in favor of pre-extraction of hemicellulose before kraft pulping is that the amount of energy that can be produced by the combustion of hemicellulose is much lower than that of lignin (Marinova et al. 2009; Hamaguchi et al. 2013). For example, the higher heating value (HHV) that can be obtained by pyrolysis of hemicellulose to bio-oil is only about $60 \%$ of what can be obtained from the same mass of lignin (Zhao et al. 2017). This difference is consistent with the earlier discussion related to the oxygen content of the biomolecules. Hemicellulose has an O:C ratio of about 1:1 (from the chemical formula for carbohydrates), whereas that of lignin is about 0.3:1 (Robert et al. 1984). When hemicellulose has been pre-extracted, a promising option then is to use enzymes (e.g. xylanases or other hemicellulases) to convert it to sugars (Dhiman and Mukherjee 2018). Yeast can be used to convert such sugars to ethanol, which is a valuable fuel.

Implementation of hemicellulose pre-extraction in an existing kraft pulp mill can be expected to disrupt the balance of materials, steam, and energy (Marinova et al. 2009; Moshkelani et al. 2013). The extraction decreases the energy content of the wood chips being fed to the digester (Hamaguchi et al. 2013). However, the freed-up capacity of the digester might make it possible to feed a greater quantity of wood chips, depending on compression of the material, thus possibly enabling an increase in production rate at the mill. A higher production rate implies a greater flow of burnable material in the black liquor being sent to the recovery furnace. In a favorable case, such changes were projected to enable the separation of some of the lignin from the black liquor, which also decreases the amount of energy produced in the recovery boiler, putting the system back in balance at a higher production rate (Hamaguchi et al. 2013).

\section{Mechanical Pulping}

High amounts of energy are required to separate uncooked wood fibers from each other when using mechanical pulping procedures. The type of equipment utilized to separate the fibers is illustrated schematically in Fig. 14

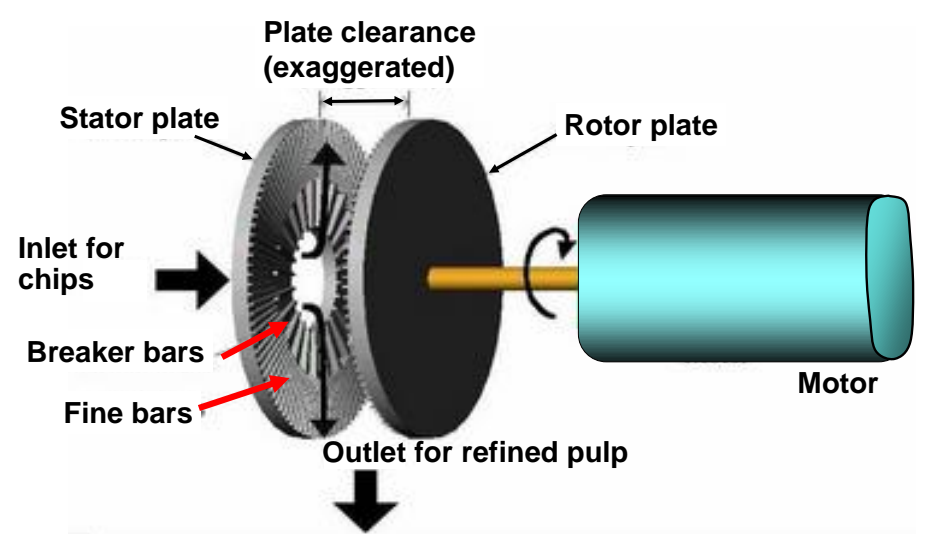

Fig. 14. Schematic view of a pulp refiner of the type often used for mechanical pulping. (Commercial refiners are more often configured as "double-disc" units, in which a central rotor is associated with two stators.)

- As shown, the wood is introduced in the form of chips, starting at the central area between a rotor and a stator. The rectangular bars on the adjacent surfaces give rise to repeated compression and shearing of the cellulosic material as it passes toward the outer 
perimeter. In the innermost part, nearest to the axis of rotation, the bars are widely spaced, i.e. breaker bars. Progressively finer bars, with closer spacing, are used on the rotor and stator surfaces as one progresses outwards towards the circumference of the refiner plates. The product of mechanical pulping is often called defibered or fiberized pulp.

One of the ways to decrease the amount of energy required for refining is to heat up the wood chips while they are moist. This can be done by steam pretreatment, where the goal is to exceed the softening points of the lignin and hemicellulose. Such a strategy is aided by the fact that the glass transition points of lignin and hemicellulose are depressed by the plasticizing effect of moisture (Back and Salmén 1982). In the plasticized state, shearing of the material causes the separation between fibers to occur mainly in the ligninrich middle lamella region, i.e. between the fibers. As a result, the full fiber length is preserved to a greater extent than in other mechanical pulping processes, such as unheated refiner mechanical pulping (RMP) and stone groundwood pulping (McDonald et al. 2004; Sandberg et al. 2020). Thermomechanical pulping of spruce, pine, cedar, and a blend of chips in two-stage refining was found to require about 2 to $10 \mathrm{GJ} /$ tonne to achieve optimal fiber quality (Miles et al. 1991). Another study gave ranges of 10.6 to 12.1 and 7.7 to 10.5 GJ/tonne for spruce and fir, respectively (Johal et al. 2006). Sabourin et al. (1997) reported that savings in energy can be achieved by optimizing the temperature of processing.

A further way to decrease the energy of mechanical pulping is to apply alkaline peroxide medium ahead of the mechanical treatment (Yuan et al. 2006; Johansson et al. 2011). As illustrated in Fig. 15, the combination of oxidation and alkaline conditions induces swelling of the wood material, which contributes to easier separation during the refining (deGroot et al. 1997; Chang et al. 2012). Such effects can be further enhanced by treatment with carboxymethyl cellulose (Cheng et al. 2013) or supplementary alkali (Xu et al. 2016). For alkaline peroxide mechanical pulping (APMP) of poplar, the specific refining energy required to achieve Canadian Standard Freeness levels in the range of 200 to $350 \mathrm{~mL}$ is about 3.3 to $4.3 \mathrm{GJ} /$ tonne (Hart et al. 2009).

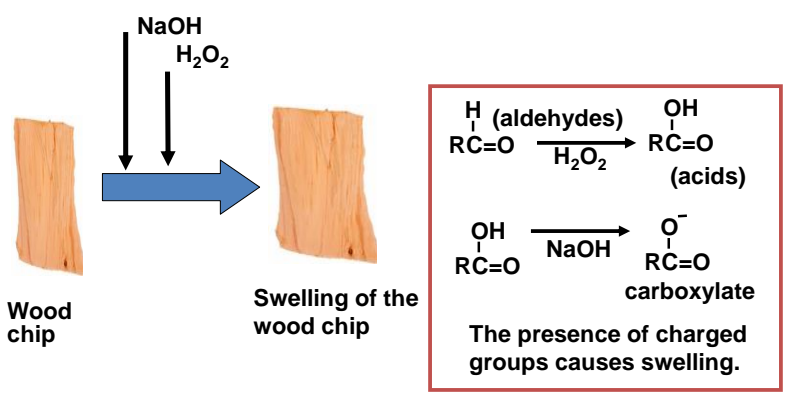

Fig. 15. Conceptual illustration of the combined effects of alkali and hydrogen peroxide in tending to swell wood chips, leading to their separation into fibers with lower application of energy in refiners. Note that the degree of swelling of a chip is greatly exaggerated in the figure.

By pretreatment with various blends of cellulase and xylanase, it was possible to further reduce the refining energy about by about $18 \%$ to achieve the same freeness (Hart et al. 2009). Related work by Yang et al. (2011) achieved a decrease in refining energy in APMP poplar pulp by $12.5 \%$ to $22 \%$ on account of enzyme pretreatment. As illustrated in Fig. 16, enzymatic treatment prior to refining of pulp can reduce the energy requirement, whereas application of a similar enzyme treatment after refining can be used as a way to 
increase the rate of water release during paper forming. Reductions in refining energy also have been observed when enzymes are used to treat kraft pulp fibers (Kim et al. 2006; Lecourt et al. 2010), which is the next topic to be considered.

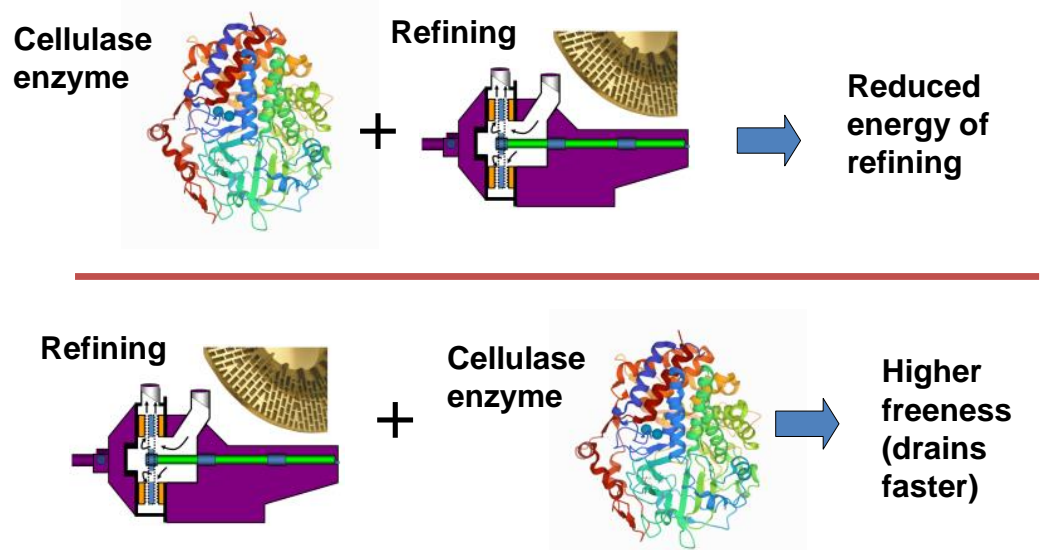

Fig. 16. The effect of cellulase enzyme treatment of pulp can have different effects, depending on the sequence of treatment. Treatment before refining can reduce the energy required to separate and fibrillate the fibers. Treatment after refining can solubilize the smallest fines, thus allowing water to be drained more rapidly as paper is being formed.

The action of an enzyme in bringing about decomposition of a target molecule is illustrated schematically in part A of Fig. 17. The detailed chemical structure of the enzyme, involving coiling of their protein macromolecules, allows for a precise fit to the target molecule. Once the enzyme and target molecule are coupled together, flexing motions within the enzyme can facilitate the cleavage or assembly of covalent bonds (Bhabha et al. 2011). Part B of the figure indicates certain bonds within a cellulose structure that can be cleaved with the help of different enzyme components that are released by bacteria.

A

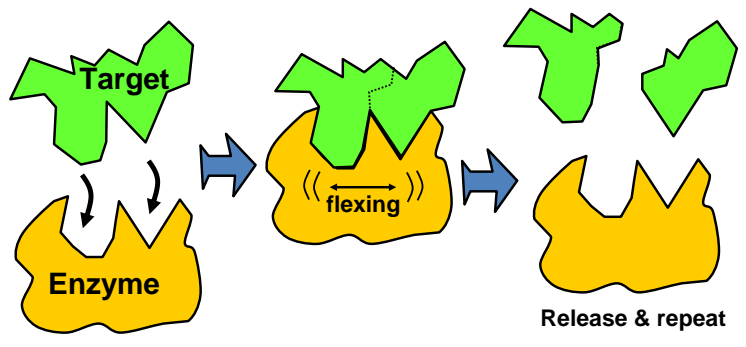

Cellobiohydrolase attacking

B end of a cellulose chain

Endoglucanase attacking the

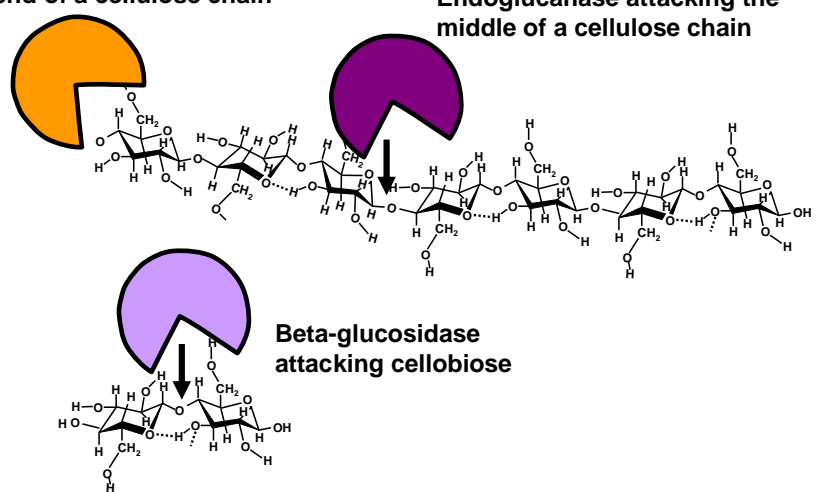

Fig. 17. Representation of the work of cellulase enzymes. A: Generalized mechanical concept for the action of enzymes in cleaving covalent bonds of target molecules; B: Positions in the cellulose molecule and its fragments that are susceptible to different classes of cellulase ( $A$ version of Part B previously appeared in Hubbe et al. 2018b). 


\section{Fractionation to Save Energy in Mechanical Pulping}

Another approach to saving energy associated with mechanical pulping involves screening or the use of hydrocyclones after the first or second passes through a refiner (Amiri et al. 2010; Miller et al. 2017; Sandberg et al. 2019). The over-size rejects from the fractionation steps, which represent only a minor fraction of the pulp, are sent back for an additional pass.

\section{Chemical Pulping}

Quite unlike mechanical pulping, the kraft process, which is the dominant variety of chemical pulping, has been characterized as being close to self-sufficient in energy (Holmberg and Gustavsson 2007). But that near self-sufficiency is achieved at a cost of a much lower yield. Compared to the original dry-weight of the wood chips, the dry mass of bleachable-grade kraft fibers falls in the general range of $43 \%$ to $55 \%$, depending largely on the lignin content of the wood (MacLeod 2007). Most of the lignin and much of the hemicellulose originally present in the wood ends up in the spent pulping liquor, which then goes through processes of evaporation and incineration, with the generation of steam in a recovery boiler.

The type of equipment used for the chemical pulping of wood chips is shown in Fig. 18. Part A shows a batch pulping digester system, whereas part B shows a continuous process. In each case, chips are combined with the pulping liquor (a mixture of $\mathrm{NaOH}$ and $\mathrm{Na} 2 \mathrm{~S}$ solutions in the case of kraft pulping) under pressure. The pressurized conditions make it possible to reach suitable temperatures $\left(\right.$ e.g. $\left.170^{\circ} \mathrm{C}\right)$ to achieve favorable rates of delignification.

A

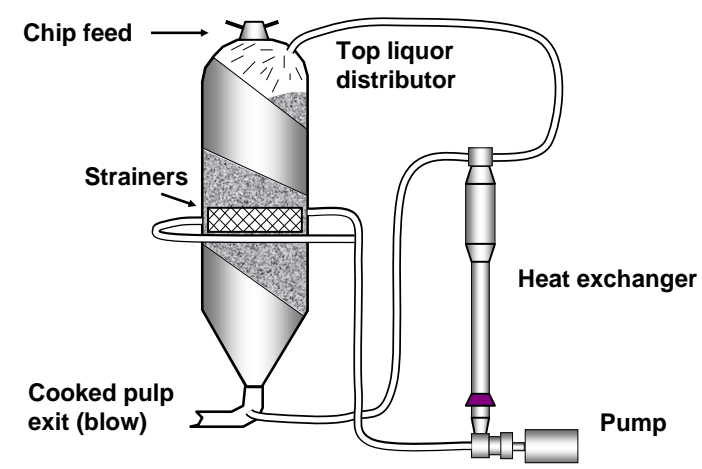

B

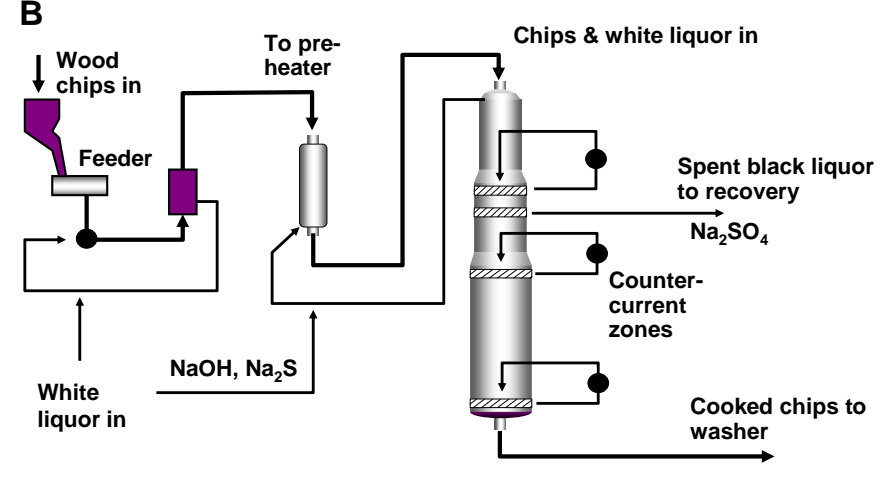

Fig. 18. Representation of (A) a batch process for chemical pulping (such as kraft pulping), or (b) continuous pulping

The rate of delignification reactions has been found to follow an Arrhenius relationship (Johansson et al. 1984),

$$
\frac{\mathrm{d} L}{\mathrm{~d} t}=A \exp \left[\frac{-E_{a}}{R T}\right]\left[\mathrm{OH}^{-}\right]^{a}\left[\mathrm{HS}^{-}\right]^{b} L
$$

where $L$ is the amount of lignin, $A$ is a coefficient, $E_{a}$ is the activation energy, $R$ is the gas constant, $T$ is absolute temperature, and $a$ and $b$ are exponents. The major energy input is thus the heating of the pulp liquor to reach the target temperature. As illustrated in part A of the figure, the temperature of a batch digester can be controlled by use of a heat 
exchanger and the circulation of pulping liquor. Likewise, part B shows a preheater system in the case of a continuous pulping system.

\section{Chemical Recovery}

Kraft recovery boilers

Recovery boilers and lime kilns, which are designed to recover the pulping chemicals and to produce steam and power, are understood to be the largest points of exergy loss within a typical pulp and paper manufacturing facility (Gong 2005). For instance, Ramos et al. (2019) developed a mathematical model of the process and derived an efficiency of just $42.5 \%$, based on an exergy analysis. The difference in temperature between the combustion process and the water to be evaporated is very large, leading to irrecoverable loss of exergy. Ramos et al. (2019) estimated that of $47 \%$ and $30 \%$, respectively, of the loss in useful energy were associated with the furnace and with the water-walls, i.e. locations where there is contact between media having very large temperature differences.

The overall chemical recovery system for a typical kraft pulp mill is summarized in Fig. 19. As shown, the process can be understood based on a pair of circular processes involving sodium and calcium. The details of these processes have been well described elsewhere (Empie 2009). Briefly stated, the pulping process begins when wood chips are combined with a concentrated solution of sodium hydroxide and sodium sulfide, which are the active cooking chemicals in white liquor. Once cooking temperatures are reached within a pressurized digester, the chemicals break down and solubilize much of the lignin and some of the hemicellulose. The spent liquor, called black liquor, is washed from the fibers and sent to a series of evaporators, about which more will be said later. Once the black liquor solids have become high enough, the mixture is fed to a specialized power boiler, where it is the main fuel. Because of the amounts and distribution of air that is injected, reducing conditions are established in the lower part of the boiler system, and this allows for any sulfate ions within the mixture to be converted to the sulfide form. Meanwhile, calcium carbonate is present in the mixture coming from the base of the digester. Green liquor is obtained when these solids are combined with water.

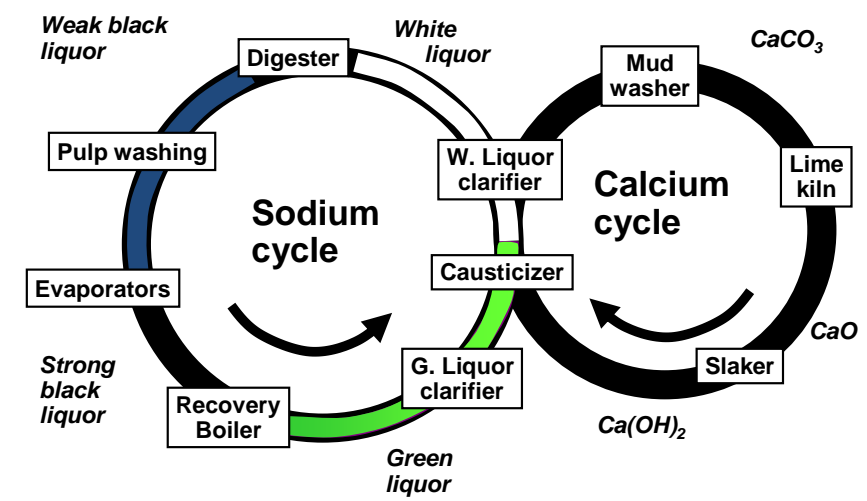

Fig. 19. Summary of the kraft pulping chemical recovery process, based on circular reprocessing of chemicals associated with sodium and calcium

As a means to be able to restore $\mathrm{NaOH}$ as the active cooking chemical, the calcium carbonate is washed and subjected to very high temperatures within a lime kiln (as shown in the right-hand side of the figure). The products are carbon dioxide gas and $\mathrm{CaO}$, which 
is called either lime or burnt lime. Addition of the lime to water yields $\mathrm{Ca}(\mathrm{OH})_{2}$, which is milk of lime. When the milk of lime is combined with the clarified green liquor (meaning that the calcium carbonate had been removed from it), $\mathrm{NaOH}$ is regenerated, and the liquid is called white liquor, which is again suitable to be added to a fresh batch of wood chips. In this manner, the process is able to operate continuously with only minor addition of make-up chemicals to replace losses.

Efficient utilization of the heat of combustion is critical to the efficiency of the overall operation. Part A of Fig. 20 provides a schematic illustration of how the hot gases generated by combustion of concentrated (or "strong") black liquor provide the energy to convert the water into high-pressure steam within the tubes of a conventional power boiler or kraft recovery boiler. Part B indicates how economizer systems can be utilized to extract additional heat from the partly cooled flue gas and thereby heat up incoming streams of air (for combustion) and water (to be later converted to steam). The optimization of electrical energy from the steam within a pulp and paper mill was considered by Sarimveis et al. (2008).
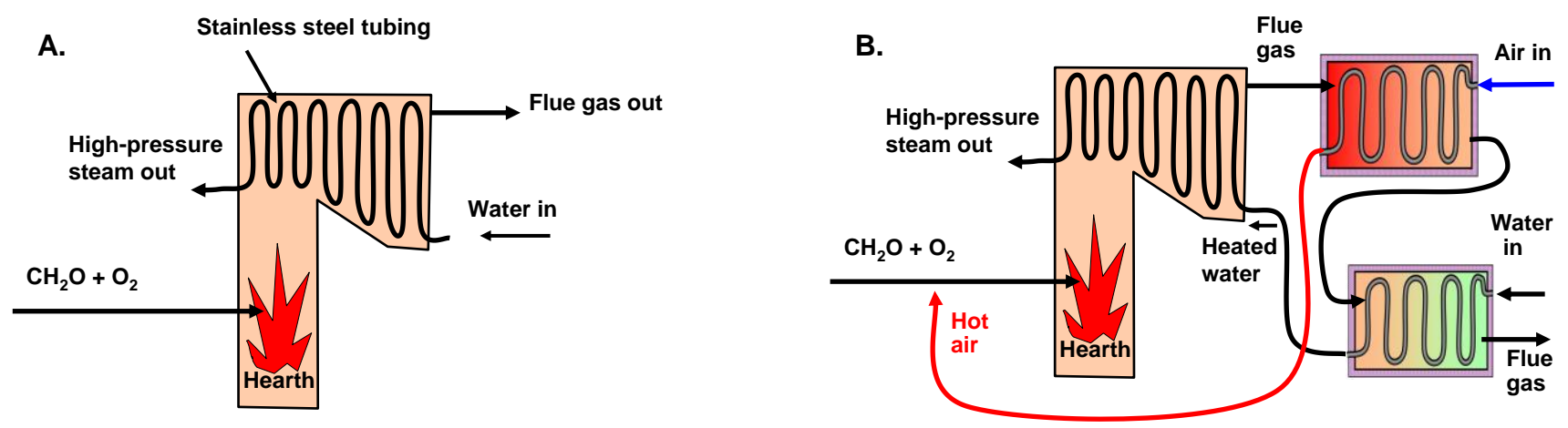

Fig. 20. A: Schematic of power boiler in which the heat of combustion is converted to steam; B: Representation of a boiler that has been fitted with economizer systems to heat up incoming air and/or water with use of partly cooled flue gas

\section{Gasification}

Calculations and demonstrations have shown that much higher efficiencies could be achieved if it were practical to replace a kraft recovery boiler with a gasifier (Joelsson and Gustavsson 2008; Naqvi et al. 2010; Moshkelani et al. 2013; Kong et al. 2016; Molino et al. 2016). For instance, Fleiter et al. (2012) estimated that the electrical energy efficiency of a kraft recovery boiler might be approximately doubled by converting to a gasification system. In such a process, rather than incinerating the organic fraction contained within the black liquor, it is instead pyrolyzed under conditions that mainly yield a mixture of pyrolysis gases, which together are called syngas. Other products of gasification are inorganic compounds, mainly sodium and sulfur salts. The syngas contains $\mathrm{CO}, \mathrm{H}_{2}, \mathrm{CH}_{4}, \mathrm{H}_{2} \mathrm{O}$, and $\mathrm{CO}_{2}$, the first three of which can be later burned to produce energy. The reactions, plus their enthalpies are as follows:

$$
\begin{array}{ll}
2 \mathrm{H}_{2}+\mathrm{O}_{2} \rightarrow 2 \mathrm{H}_{2} \mathrm{O} & \Delta H=-242 \mathrm{~kJ} / \mathrm{mole} \\
2 \mathrm{CO}+\mathrm{O}_{2} \rightarrow 2 \mathrm{CO}_{2} & \Delta H=-566 \mathrm{~kJ} / \mathrm{mole} \\
\left.\mathrm{CH}_{4}+2 \mathrm{O}_{2} \rightarrow \mathrm{CO}_{2}+2 \mathrm{H}_{2} \mathrm{O}\right) & \Delta H=-890 \mathrm{~kJ} / \mathrm{mole}
\end{array}
$$


As shown in Fig. 21, the process can be carried out with various configurations of equipment, based on the positions associated with air intake and syngas output. The gasification process consumes only about 20 to $30 \%$ of the amount of oxygen that would be used in an ordinary incineration process in a boiler (Kong et al. 2016). The hydrogen, methane, and carbon monoxide components of the syngas then can be combusted to generate electricity in a highly efficient gas turbine system. The exhaust from the turbines then could be used to heat incoming air and water streams, as mentioned earlier when referring to exhaust air from a conventional boiler system. Gasification, as an alternative to using biomass as fuel for a boiler, has been understood for many years as a feasible process (Bridgwater 1995; Raskin et al. 2001). More recently, gasification has been considered also as a way to capture the energy value of pulp and paper mill wastes, including sludge from treatment of the wastewater (Chiang et al. 2016). However, in the cited case, the amount of energy obtained from the processing of sludge from the mill operations was of a similar magnitude to the energy needed to run the gasification process itself.
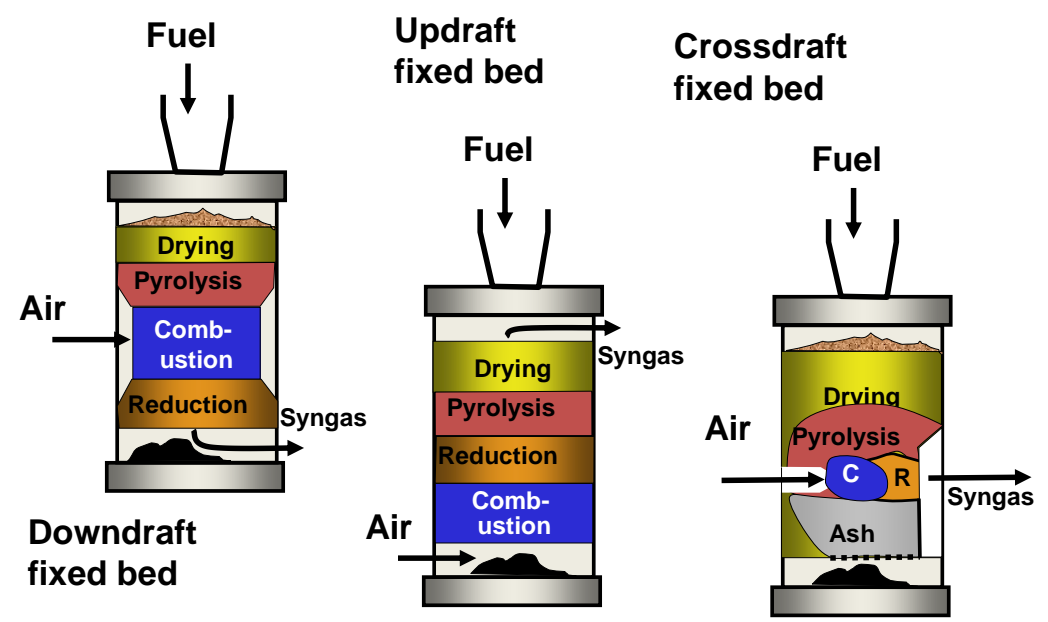

Fig. 21. Different configurations of gasifier equipment, based on the positions of air input and syngas output. The figure has been redrawn based on versions shown in Nelson et al. (2018).

Projects related to black liquor gasification have faced a variety of challenges. For instance, before it can be effectively used, the syngas prepared by pyrolysis of any biomass source needs to be cleaned of impurities, which can include both organic and inorganic compounds (Bridgwater 1995; Abdoulmoumine et al. 2015; Nelson et al. 2018). Depending on the details, the pyrolysis process simultaneously can produce bio-oil, tar, and salt-rich char (Sricharoenchaikul et al. 2002, 2003), some of which can form deposits on the processing equipment (Kong et al. 2016; De Blasio et al. 2019). Such problems have not yet been overcome on a commercial scale when processing black liquor.

\section{Multiple-effect evaporation}

Another part of the inherent inefficiency of a typical kraft recovery boiler operation can be attributed to the fact that the fuel to be consumed in the boiler starts out as a relatively dilute solution in water. To minimize the amount of energy needed to evaporate so much water, the process is conducted in about six or seven stages within units that are called effects (Khanam and Mohanty 2010). Such a system is illustrated in Fig. 22. Part A of the figure depicts a batch digester, which is followed by three washers set up in 
counter-current order, followed by a set of six evaporator effects. Part B of the figure gives a more detailed look at an individual evaporator effect of the rising film type. Note that bubbles of steam within each tube provide mixing and upward motion of the material. After each successive effect, the pressure is lowered sufficiently to allow re-evaporation of the condensate so that it can be used again at a lower pressure in the subsequent effect.
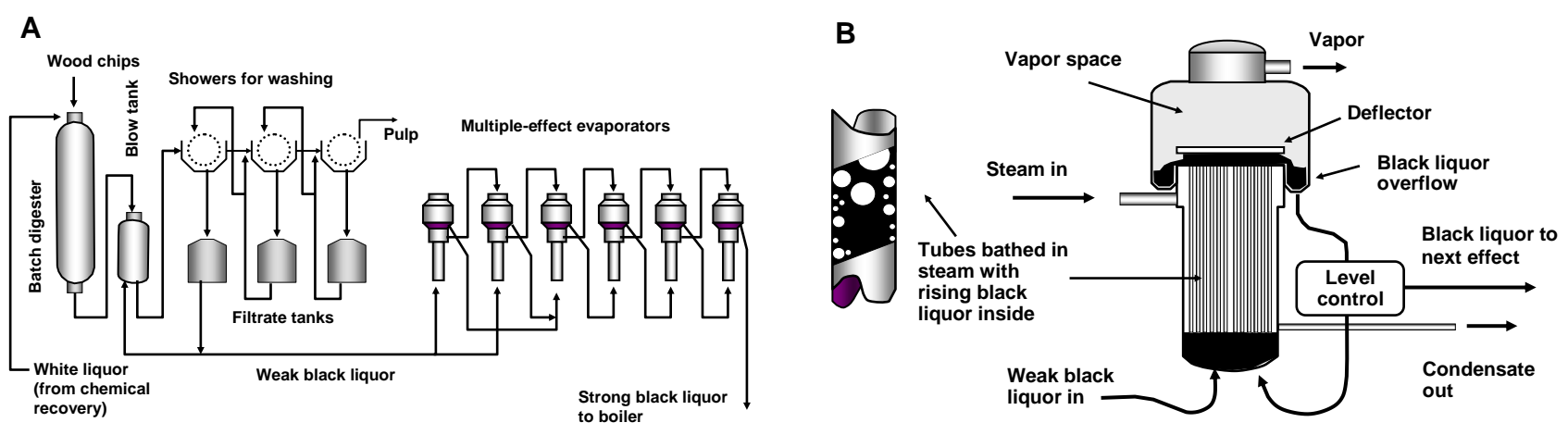

Fig. 22. Equipment for collecting and increasing the solids of black liquor so that it can be added to a recovery boiler. A: Diagram showing a batch digester, after which the cooked pulp is sent to a blow tank and the pulp is then washed, using a counter-current procedure, followed by progressive evaporation, using six effects at decreasing pressure levels; B: Closer detail for the rising film type of evaporator effect

Though the usage of multiple effects can decrease the overall heating requirement of evaporation by about a factor of about 4.5 to 5 (Tikka 2008; Empie 2009), it becomes increasingly difficult to achieve further efficiencies beyond that point. Though it is theoretically possible to employ other technologies such as eutectic freeze crystallization to be able to recover the spent inorganic chemicals in highly concentrated form (Hubbe et al. 2018a), such technologies are a long way away from any demonstration of feasibility in the case of black liquor.

The amount of dilute black liquor, and thus the extent to which water has to be removed before its introduction to a recovery boiler, can be affected by the cost of energy (Hart 2011). By using more fresh water, it is possible to remove more of the spent pulping chemicals from the fibers, but the amount of water that needs to be evaporated is thereby increased (Chew et al. 2011). This relationship became more evident during a recent decline in natural gas prices. When energy is less expensive, companies have an incentive to emphasize savings of chemicals, rather than energy. Thus, the operators change the dilution factors based on the relative costs of energy and pulping chemicals.

\section{Fuel value or higher value from tall oil}

In the kraft pulping of softwood, part way through the process of concentrating the black liquor, long before the mixture is ready to be injected into the recovery boiler, it is standard practice to place the mixture into a tank so that a hydrophobic liquid phase can rise to the top and be skimmed off (Aro and Fatehi 2017). Based on the Swedish word for pine, this mixture has come to be called "tall oil". Components of tall oil include fatty acids, resin acids, and terpenes, each of which has a variety of industrial uses (Johansson 1982; McCoy 2000). In addition, the tall oil can be considered as a fuel source. For instance, the fatty acid component can be converted to biodiesel fuel (Lee et al. 2006; Brännström et al. 2018). The main chemical transformation is shown in Fig. 23. The 
practical value of these concepts recently was confirmed; use of the tall-oil-derived biodiesel yielded lower levels of $\mathrm{CO}$, hydrocarbons, and particulates than ordinary diesel fuel from petroleum, though the nitrogen oxide emissions were higher (Roy et al. 2021).

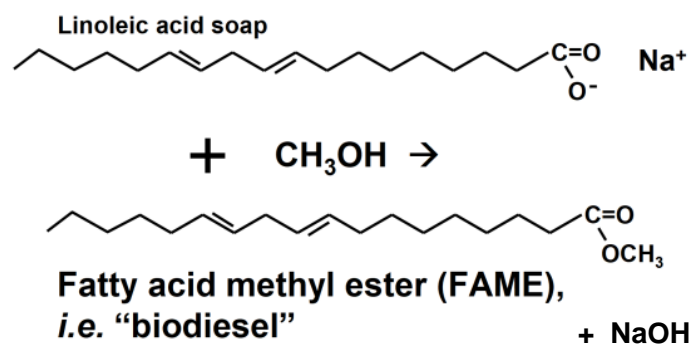

Fig. 23. Conversion of fatty acid (as can be obtained by fractionation of tall oil) to prepare biodiesel

\section{Separation of lignin from black liquor}

In many kraft pulp and paper mills, the overall production rate is constrained by the capacity of a recovery boiler. It follows that the overall production rate at a pulp mill might be increased if a way can be found to decrease the amount of input combustible material. This issue was already mentioned while considering the pre-extraction of hemicellulose. Such considerations have led to the successful development of technology to isolate some of the lignin component, such that the isolated lignin's fuel value is no longer being supplied to the recovery boiler (Wallmo et al. 2009; Kouisni et al. 2012; Zhu et al. 2014; Hubbe et al. 2019). As indicated in part A of Fig. 24, the load on such a boiler system can be reduced by removing some of the lignin during the course of the evaporation of black liquor. Thus, the amount of material to be incinerated, per amount of pulp production, is reduced and the overall capacity of the mill can be raised. The separation of lignin from the black liquor is brought about by acidification. As shown in part B of Fig. 24, the relative amount of lignin separated from black liquor increases with decreasing $\mathrm{pH}$. Carbon dioxide can be employed at the start to protonate the phenolate functional groups, thereby causing the insolubilization of a large proportion of the lignin; subsequent acidification with sulfuric acid can be used when the goal is to precipitate out a high proportion of the lignin and also to displace metal ions from the solids (Hubbe et al. 2019).
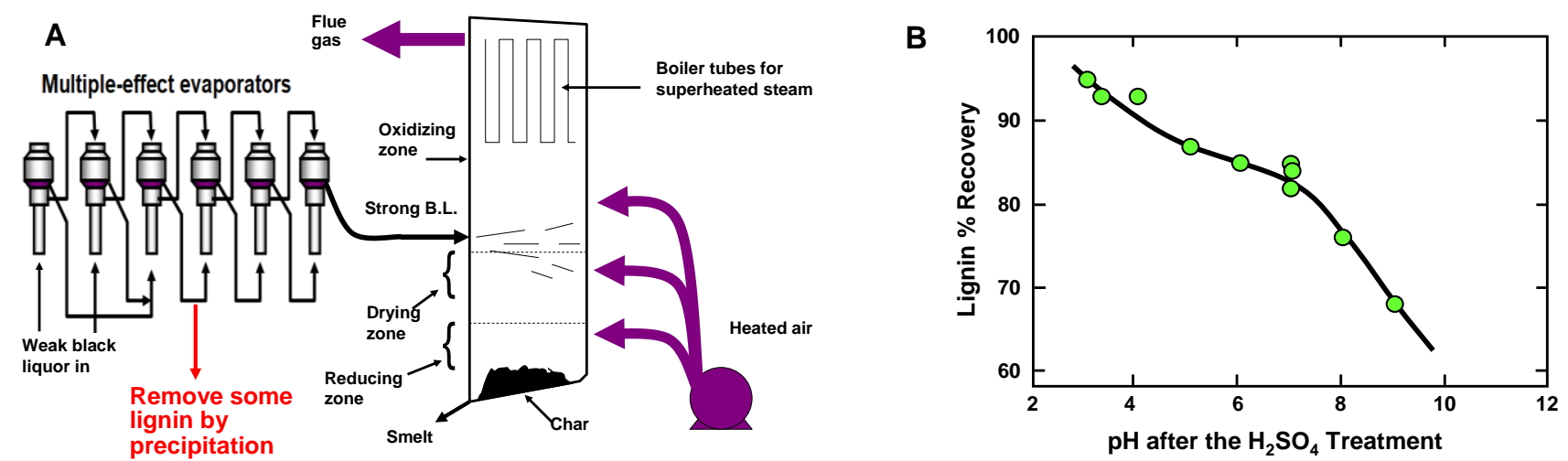

Fig. 24. Concept of debottlenecking of a pulp mill system by precipitation of some of the lignin from the black liquor. Part A: Black liquor acidification with $\mathrm{CO}_{2}$ to bring about precipitation; Part B: Relationship between $\mathrm{pH}$ of the treated black liquor at the proportion of precipitated lignin (figure previously used in Hubbe et al. 2019) 
Membranes represent another potential way to separate lignin from black liquor with a relatively low input of energy (Jin et al. 2013; Arkell et al. 2014; Humpert et al. 2016; Servaes et al. 2017; Esteves Costa et al. 2018; Hubbe et al. 2019; Manorma et al. 2021). For example, good separation with a suitably high flux was achieved with a combination of ultrafiltration and nanofiltration (Arkell et al. 2014). Jin et al. (2013) employed an electrochemical approach, along membrane filtration; such treatment resulted in a drop in $\mathrm{pH}$, which brought about precipitation of the lignin, as discussed in the previous paragraph. In typical cases, the fouling of membranes tends to be minimized under high$\mathrm{pH}$ conditions, such that the lignin remains in the solution phase during membrane separation (Hubbe et al. 2019).

In order to still be able to meet the mill's needs for steam and electricity, after having removed some of the lignin from the black liquor, it is understood that a pinch analysis, leading to process integration, will be required (Axelsson et al. 2006). Another approach, to make up for the deficit in power generation caused by removing some of the lignin, consists of the extraction of hemicellulose prior to pulping, as discussed earlier (Marinova et al. 2009; Moshkelani et al. 2013). The removal of the hemicellulose then makes it possible to further increase the input of wood chips, leading to an excess of steam energy, which ideally will match the amount lost due to the isolation of the lignin (Hamaguchi et al. 2013). Such a combined system can be regarded as an example of a biorefinery (Carvalheiro et al. 2008).

Once the lignin has been separated, there are several potential uses for it, though many of the higher-value potential uses face large obstacles that inhibit their industrial implementation. As a low-value use, the lignin can be co-fired with bark and other biomass in a power boiler (Berglin et al. 2010). Since such a boiler does not have to be engineered for combustion of black liquor, it can be cheaper to construct and more efficient to run (Demirbas 2005; Khan et al. 2009; Saidur et al. 2011). In addition, the precipitated lignin is a damp solid, rather than an aqueous solution, which implies a more favorable effective heating value. Lignin also has potential uses in production of biochar, activated carbon, and various products having a high aromatic carbon content (Rinaldi et al. 2016).

\section{Lime kiln heating with biomass}

Another large demand for heating energy in many kraft pulp and paper mills, after the evaporative drying of the paper, is the heating of the lime kiln, which is part of the kraft liquor recovery process (Peng et al. 2015). Here the goal is to convert calcium carbonate, present in the green liquor coming from the dissolution of smelt from the base of the recovery boiler, back into calcium oxide (lime). The calcium oxide can then be used to form $\mathrm{Ca}(\mathrm{OH})_{2}$, which then can be used to regenerate sodium hydroxide, which is an essential component of the white liquor that is used for kraft pulping. The main chemical reactions associated with the lime kiln and the calcium cycle are as follows,

$$
\begin{array}{ll}
\mathrm{CaCO}_{3} \rightarrow \mathrm{CaO}+\mathrm{CO}_{2}\left(\sim 800^{\circ} \mathrm{C}\right) & \Delta H=+178.4 \mathrm{~kJ} / \mathrm{mole} \\
\mathrm{CaO}+\mathrm{H}_{2} \mathrm{O} \rightarrow \mathrm{Ca}(\mathrm{OH})_{2} & \Delta H=-64.0 \mathrm{~kJ} / \mathrm{mole} \\
\mathrm{Ca}(\mathrm{OH})_{2}+\mathrm{Na}_{2} \mathrm{CO}_{3} \rightarrow \mathrm{CaCO}_{3}+\mathrm{NaOH} & \Delta H=-113 \mathrm{~kJ} / \mathrm{mole}
\end{array}
$$

As shown, a positive $\Delta H$ value needs to be supplied by the kiln operation to drive the first reaction, the calcination (which is endothermic). The other two reactions are exothermic. 
Because of the relative simplicity of the lime kiln, when compared to various other unit operations at a pulp and paper mill, it is reasonable to expect that the heating could be provided, at least in part, by the burning of wood residues. Philp and Azarniouch (1984) reported a savings of $38 \%$ in fossil fuel usage when wet hog fuel was fed to a lime kiln along with the lime mud. In follow-up work, Azarniouch (1986) found that as much as half of the fuel oil being used for a certain lime kiln could be saved by the feeding of wood chips or screened hog fuel with the lime mud entering the kiln. Furthermore, by implementation of process control strategies, efficiency improvements of about $7 \%$ were achieved in one study (Jarvensivu et al. 2001). The improvements were attributed to more stable operations under near-optimized conditions. In particular, there was a consistent decrease in the excess air employed for burning. A more recent survey of mills running lime kilns revealed that the efficiency has been improved in many cases by increasing the solids of lime mud entering the kiln, thus decreasing the evaporative load (Francey et al. 2011). Net improvements in energy-efficiency can be achieved if excess heat energy is used to pre-dry the lime mud before the kiln. Recent progress has been reported in the use of pulping byproducts, biomass, and other options to supply the heat needed in lime kilns (Hart 2020a,b).

\section{Papermaking}

The papermaking operation receives pulp from the pulp mill, prepares the stock by mechanical refining, employs additives to impart desired properties (functional additives), uses the additive to promote process efficiency (process additives), forms the material into a wet sheet, and then removes water from the sheet by mechanical means, including vacuum and pressing, and then by evaporative drying. Alternatively, if the paper mill purchases dry-baled pulp sheets as their starting material, then the first step will be to slush that pulp in a hydropulper. The papermaking operation is a major consumer of energy. Evaporative drying makes up a large share of the energy requirement. However, there are many other energy demands for which there are opportunities for improvements in energyefficiency.

\section{Refining of chemical pulp fibers}

After chemical pulping, including the dominant kraft pulping process, the fibers are typically still too stiff and bulky in the wet state to be able to achieve the degree of interfiber bonding that will be required for most grades of paper, with the possible exception of some tissue grades. Thus, kraft and other chemical pulp fibers are typically passed through double-disk refiners, within which they are subjected to multiple compression and shearing events (Martinez and Kerekes 1994; Paulapuro 2000; Kerekes 2010). Results of this refining include internal delamination and swelling of the fibers, which makes them more flexible and conformable while in the wet state (Laine et al. 2004; Kerekes 2005). The refined fibers also are more readily collapsed into a ribbon-like shape that enhances the development of relative bonded area within the resulting paper product (Mohlin 1997; Batchelor et al. 1999). Refining also affects the fiber surface as a result of breakup of the primary layer and fibrillation of the underlying S1 or S2 layers of a kraft fiber (Fardim and Duran 2003). The resulting increase in accessible surface area can be detected by measurements of cationic demand, using cationic polymers as titrants of surface charge (Carrasco et al. 1996; Bhardwaj et al. 2004). The refined fibers typically achieve much higher tensile, burst, and Z-directional strength, though the tear strength can be expected 
to decrease beyond an optimum level of refining (Lecourt et al. 2010; Gharehkhani et al. 2015).

The amount of energy expended in refining of chemical pulps, though not as great as in the case of mechanical pulps, represents an important area of possible savings in energy usage. Some savings can be achieved by using state-of-the-art refiners and running them under optimum conditions (TAPPI TIP 0404-63 2021; Paulapuro 2000). Cautious treatment with cellulase enzymes can be applied, prior to refining, as a means to decrease the required amount of energy needed to reach target goals in terms of pulp development, as measured by dewatering characteristics and paper strength (Bajpai et al. 2006; Kim et al. 2006; Lecourt et al. 2010; Torres et al. 2012). Bajpai reported energy savings in the range 18 to $45 \%$, especially in the case of softwood pulps and unbleached pulps. Lecourt et al. (2010) reported a $20 \%$ savings in the amount of electrical energy needed to reach specified targets of paper's tensile strength after treatment with cellobiohydrolase. Excessive cellulase treatment, in terms of dosage, time, and other factors, is avoided because it can degrade the inherent strength of the fibers.

\section{Vacuum pumping and frictional losses}

Substantial amounts of electrical energy are required to run the vacuum pumps that enable operation of the high-vacuum flatboxes on the paper machine (Hubbe et al. 2020). However, a large part of the electrical energy needed to run a paper machine is related to frictional losses, and it turns out that there is a strong relationship between vacuum pumping and frictional consumption of energy. That is because the strong suction results in increased friction between the forming fabric and the covers of the high-vacuum flatboxes. The physical situation is well described by the schematic diagram shown earlier in Fig. 4. It has been estimated that about $80 \%$ of the frictional load to run the paper machine can be attributed to the high-vacuum suction boxes (Holmberg et al. 2013).

As discussed elsewhere, the energy consumption due to the combination of vacuum pumping and friction can be reduced by optimizing the applied vacuum (generally increasing from one vacuum unit to the next, following the path of manufacture). In addition, it is important to cease each application of vacuum when approaching a point of diminishing returns (Baldwin 1997; Hubbe et al. 2020). Such practices aim to eliminate non-productive application of vacuum. In addition, utilization of energy-efficient and properly sized drives for the vacuum pumping can save substantial amounts of energy (Uimonen 2017). Further gains can be achieved by attention to the composition and maintenance of vacuum box covers to minimize friction (Baldwin 1997; Holmberg et al. 2013).

\section{Additives for enhanced water removal in the wet end}

The forming section of a paper machine removes roughly $95 \%$ to $98 \%$ of the water present in the stock emerging from the headbox, and it does so with a relatively low expenditure of energy, compared to the amount of water removed. When fibers are refined, usually in an effort to increase their inter-fiber bonding ability, the rate of release of water during papermaking is strongly decreased. In light of that situation, one can understand why a lot of attention has been paid to increasing the rate and extent of wet-end removal of water by the use of chemical additives. The nature of these additives, as well as their mechanisms of action, have been covered in earlier reviews (Lindström 1989; Hubbe 2005; Hubbe and Heitmann 2007; Hubbe and Dölle 2018). Briefly stated, the additives work by combinations of coagulation (related to charge interactions), polymer bridging, and 
polyelectrolyte complexation. Faster dewatering is achieved partly by avoiding the plugging up of drainage channels in the wet web of paper, and partly by achieving a bulky structure of the wet web, such that the drainage channels remain larger than in the absence of treatment (Lindström 1989). The latter effect can be achieved if there are attractive forces between the cellulosic surfaces, such that they tend to stick together upon contact rather than sliding. Mechanisms that can contribute to such effects include the charged patch mechanism (Gregory 1976; Gruber et al. 1997) and interactions involving micro- or nanoparticles and cationic polymers such as cationic acrylamide copolymer retention aids (Hubbe 2005).

A lesser-known way to facilitate dewatering from the paper web consists of increasing the content of mineral fillers (Dong et al. 2008). Compared to an equivalent amount of cellulosic material, the mineral content tends to be associated with less water. A sheetforming test with applied vacuum showed that the rate of water release generally increases with increasing filler content (Dong et al. 2008). In addition, the lower water retention by the minerals can be expected to lead to lower moisture after wet-pressing. Accordingly, Joelsson and Gustavsson (2008) predicted an overall reduction of greenhouse gas emissions from a papermaking process when increasing the filler content. However, there are constraints on how much mineral content can be added to paper. In general, increasing fiber can be expected to lead to decreasing strength and increasing apparent density of the paper (Hubbe and Gill 2016).

Rates of water release from refined cellulosic fibers can be increased by treatment with cellulase enzymes (Bajpai 1999; Wong and Mansfield 1999). The idea is to treat the furnish under conditions that are sufficient to digest some of the very fine fibrillar cellulosic material, which may have been produced by fibrillation of the outer cell wall material during refining. The combination of treatment dosage and time needs to be constrained to avoid substantial loss of fiber strength or yield. Energy savings on the paper machine have been projected based on enzymatic enhancement of dewatering rates (Kim et al. 2006). In such cases, there appears to be an implicit assumption that a higher solids content of the wet-web entering the wet-press section is likely to translate into a higher solids content of the paper coming out of those operations, which will be considered next.

\section{Water removal in the press section}

After vacuum dewatering at the flatboxes and at a vacuum couch roll in the forming section of a typical paper machine, the solids content may be in the neighborhood of 18 to $20 \%$ (Bajpai 2016). Moreover, the apparent density of the wet web at that point is much lower (based on the solids content) in comparison to the final forms of most paper grades, with the exception of tissue and towel products. Thus, the web pressing operation can be viewed as having a dual role. In addition to removal of water, it also has the job of consolidating the paper or paperboard into a denser sheet having more intimate contact among the fibers (McDonald 2020). The wet-press section plays a critical role because so much of the energy usage in papermaking is devoted to evaporation of water from paper, and because the wet-press section is the last chance to remove water before evaporative drying (Sherlaw 1980; TAPPI TIP 0404-63 2021). It has been estimated that five times as much energy is consumed in removal of a unit of water in the press section in comparison to the forming section; however, up to 25 times more energy is needed in the dryer section to remove a unit of water, compared to the forming section (Dong et al. 2008; Bajpai 2016). In terms of electrical energy, it has been estimated that a typical wet-pressing operation consumes about one-third of the energy to run the whole paper machine (Holmberg et al. 
2013). These approximate relationships were depicted by McGregor and Knight (1996), whose main findings are shown in Fig. 25. When considering removal of the same mass of water at three different main sections of the paper machine, it becomes clear that papermakers have a large incentive to attempt to push for more complete water removal earlier in the process. In particular, there is a large incentive to attempt to increase the solids content of the wet web as it leaves the final wet-press nip.

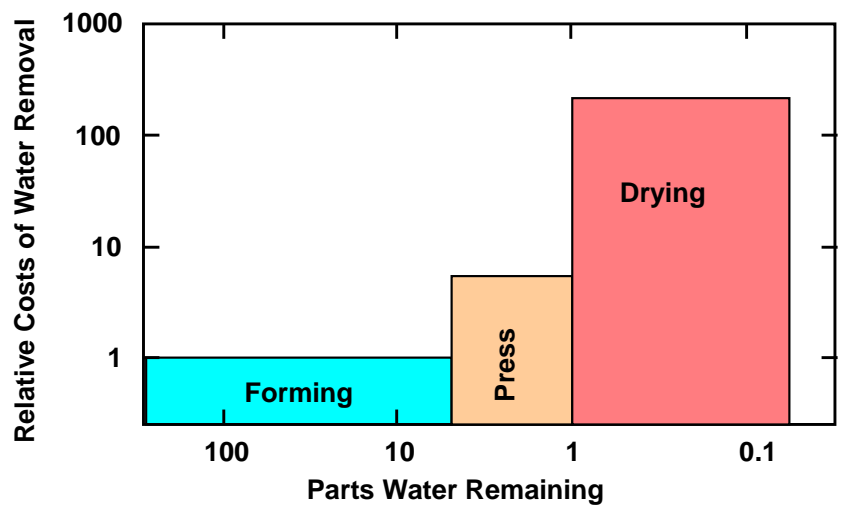

Fig. 25. Plot of relative costs of removing a unit mass of water in the forming, pressing, and drying sections of a typical paper machine. Note the logarithmic scales in both axes of the plot.

The basic action within a wet-pressing operation involves squeezing the wet web against one felt or between a pair of felts during passage through a nip between two massive steel rolls (Hubbe et al. 2020; McDonald 2020). Because the bat-on-mesh structure of a modern press felt has a lot of void volume and high permeability, much of the water squeezed from between the fibers in the wet web ends up in the felt, from which it is removed by vacuum at another point in its path of travel. However, some of the water remains as a film between the felt and the wet web of paper at the point of their detachment, and some of that water is drawn back into the paper (McDonald and Kerekes 2017, 2018; Hubbe et al. 2020). In addition, the typical sizes of capillary spaces within the paper web are much smaller than those of the press felt, and the resulting net capillary suction will result in net flow from the felt back into the paper in the expanding part the sheet's passage the nip (Szikla 1991; McDonald and Kerekes 2018).

Because the viscosity of water decreases with increasing temperature, higher solids levels after wet-pressing are routinely achieved by heating up the ingoing damp sheet. This is accomplished by means of a steam box, which is placed adjacent to the paper just before the press nip (Laurijssen et al. 2010a; Bajpai 2016; TAPPI TIP 0404-63 2021). Figure 26 shows the effect of temperature on water's viscosity (part A) and also the optional placement of steam boxes in a typical press section (part B). It has been estimated that such heating can increase the outgoing solids content by $1 \%$ for each $10{ }^{\circ} \mathrm{C}$ of temperature increase (TAPPI TIP 0404-63 2021). Steam box technology has a long history of successful use on paper machines.

Figure 27 shows some results that have been published, comparing the dryness after a wet-press operation that were achieved without and with application of a steam box (Talja et al. 1998). As shown, the steam box application caused the sheets exiting the press nip to be dryer, and the press rolls were hotter. 
A

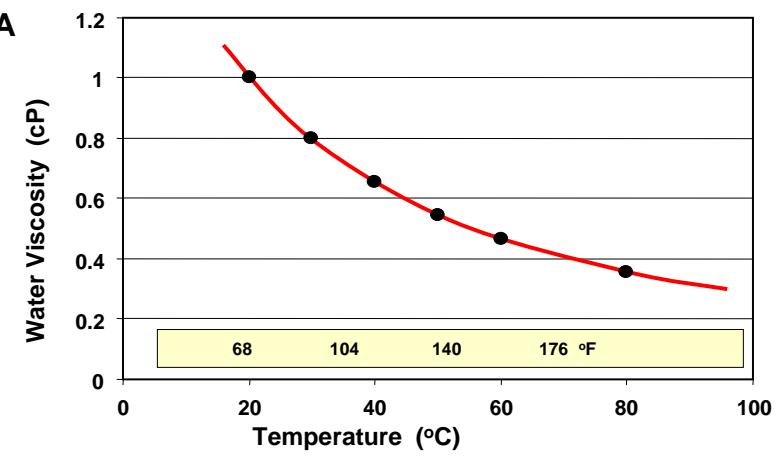

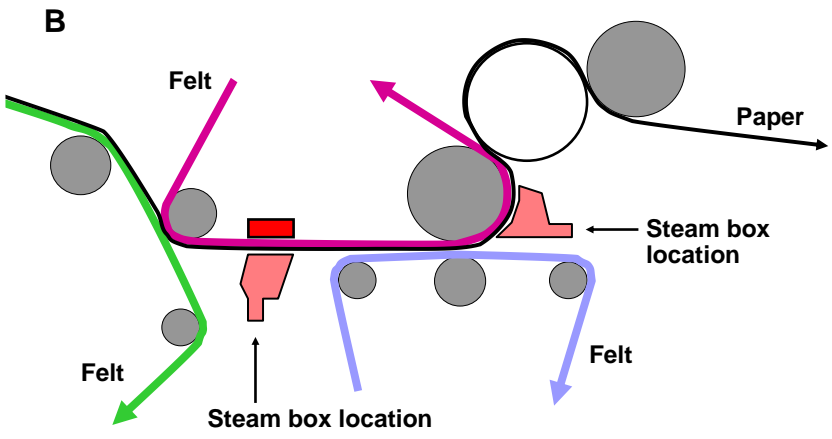

Fig. 26. Steam box issues. A: Effect of temperature on water's viscosity; B: Optional placement of steam boxes in a typical wet-press section

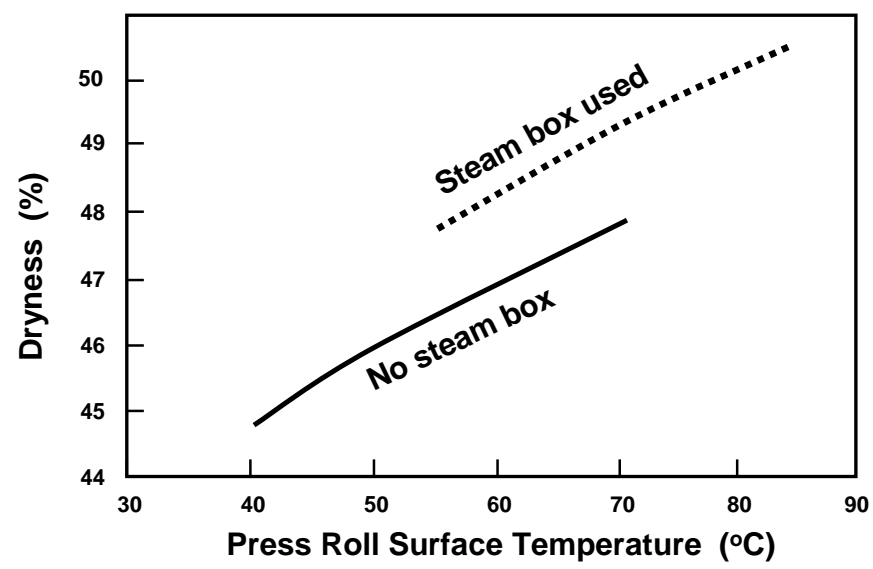

Fig. 27. Effect of steam box usage on the dryness of wet-pressed paper and the temperature of the press roll surfaces. Figure replotted based on an original by Talja (1998)

\section{Press drying attempts}

In an effort to go beyond what can be achieved with a steam box, a further logical step involves heating of the paper web within the press nip. A potential advantage is that the fibers are subjected to plasticization, thereby achieving a higher degree of inter-fiber contact and bondedness (Walker 1990; Bajpai 2016). Laboratory tests, carried out under quasi-static conditions, have shown the possibility of large gains in tensile strength properties (Krook et al. 1996). Related work showed a potential energy savings, as well as potential to achieve high smoothness on one side of the paper (Langdon 1991). By combining hot-pressing with recovery of the latent heat in the evolved steam, there is opportunity for energy savings, compared to conventional technology (De Beer et al. 1998). In principle, it would be an advantage to displace liquid water by steam, thereby decreasing the needed amount of evaporation. However, there is an inherent problem when such ideas are attempted on an ordinary paper machine. The development of steam pressure within the compressed paper in the nip can easily result in an explosive expansion and delamination as the sheet exits the nip (De Beer et al. 1998). It appears that the sheet does not spend a sufficient amount of time in a typical press nip to allow the needed mass transfer to finish taking place (Michell 1984). There have been four attempts to commercialize hot-press technology, and all of them have failed (Laurijssen et al. 2010a). 


\section{Extended nip presses}

A highly recommended strategy to increase the amount of water removed from a wet web of paper within a wet-press nip involves increasing the length of the nip (Laurijssen et al. 2010a; TAPPI TIP 0404-63 2021). An example of this type of equipment is shown schematically in Fig. 28. In the version of equipment depicted, rather than passing between two rolls, the sheet and associated felts pass between a roll and a rubber blanket, which is lubricated on its back side. The pressure is maintained by use of a shoe, having the inverse shape of the roll in the zone of contact. Though the construction of a so-called extended nip press or "shoe press" involves engineering challenges, the results have been highly successful and widely implemented, especially on large paperboard machines (Paulapuro and Nordman 1991; McDonald and Kerekes 2017a). Not only does the longer nip help to overcome the constraints of flow (Hubbe et al. 2020), but it also can permit optimization of the pressure profile. Thus, the pressure can be "ramped up" even within a single nip (Hii et al. 2012). This is in keeping with a time-testing strategy of gradually increasing the intensity of water-removal measures throughout the paper machine system.

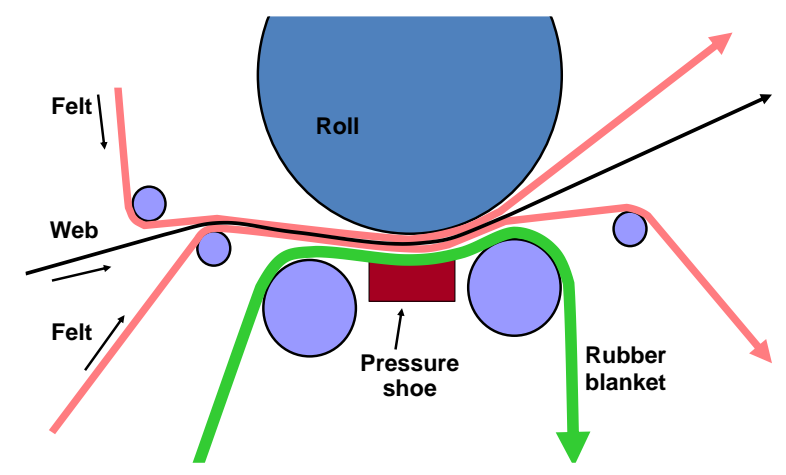

Fig. 28. Schematic diagram of an extended nip wet-press

\section{Drying efficiency}

If one looks at essentially any commercial paper machine, the longest part of the equipment, by far, is devoted to the drying process. It has been estimated that about $50 \%$ to $60 \%$ of all of the energy and about $80 \%$ of all of the steam is consumed in the dryers (Dong et al. 2008; Laurijssen et al. 2010a). The technology of drying the paper web by passing it around steam-heated dryer cans has demonstrated a remarkable staying power and remains the dominant form of drying for most paper grades (Stenström 2020). Because the dryer section is typically enclosed in a hood, and the process seems outwardly simple, it is sometimes easy to overlook the many complicated aspects of the process. But details matter; for instance the handling of the condensate within the dryer cans and the handling of the air outside of the cans affect not only the energy usage, but also the quality of the resulting paper (Keller 2018).

It has long been believed that the mechanism of drying of paper involves three principal periods, namely heat-up, constant rate drying, and declining rate drying (Sain et al. 1995; Karlsson 2000; McCabe et al. 2001). Initially the temperature of the wet web will be far below the boiling point of water. It follows that relatively little evaporation occurs as the sheet warms up. Once the boiling point has been reached at the paper web's surface, the constant rate drying period begins. In principle, as long as the surface of the paper remains wet, capillary forces can assist in bringing water continually to the surface, allowing effective contact with the source of heat. Thereafter, the rate of heat transfer will 
also depend on the rate of diffusion of water vapor to the outer surfaces. Thus, limitations in the rate of diffusion may be responsible for the declining rate of drying. The generalized trend is illustrated in Fig. 29. While the concept of a constant rate period and a declining rate period are useful as an approximation, deviations can be expected. For instance, measurements with magnetic resonance imaging have shown that such a model is not strictly true. It has been found that the capillary flow fails to fully compensate for the loss of water at the surface (Bernada et al. 1998).

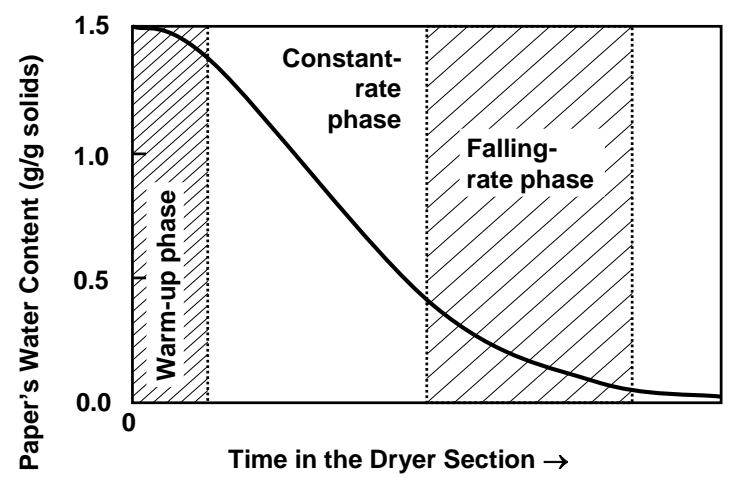

Fig. 29. The three phases of a typical drying process

Factors that tend to slow down the transfer of heat from the condensing steam (within a dryer can) outward to the paper web were considered in an earlier review (Hubbe et al. 2020). Figure 30 illustrates the many successive layers of resistance through which heat must pass in order to bring about the conventional drying of paper. As shown in part A of the figure, heat transfer is impeded by the presence of a condensate layer within the drier can (Wilhelmsson et al. 1995), by stagnant conditions within that layer, by a layer of scale or rust (Sherlaw 1980), by the metal shell itself, by any deposits on the dryer can outer surface, by any layer of air, by the properties of the paper sheet, by the humidity of the adjacent air, and by the stagnant nature of the adjacent air.

A

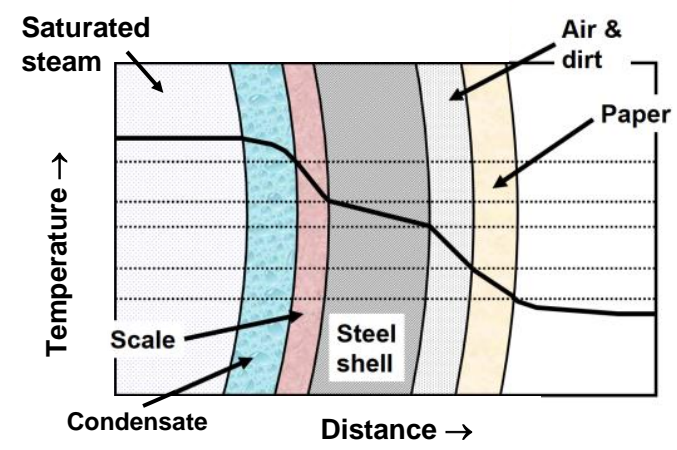

B

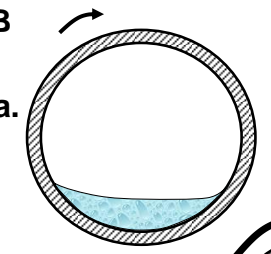

c. b.

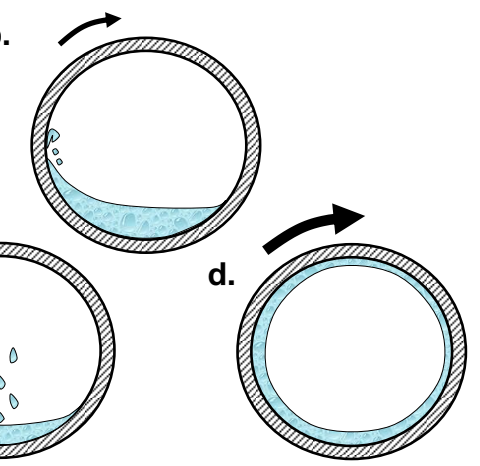

Fig. 30. Part A: Layers of resistance through which heat needs to pass during paper drying with steam-heated dryer cans; Part B: Effects of different paper machine running speeds on status of condensate within a dryer can

Some of these issues can be addressed by careful measurements, leading to diagnosis and correction of problems (Garvin and Pantaleo 1970). For example, the temperature sensed on a dryer can surface can indicate a need to fix a siphon system for 
condensate removal or to invest in equipment to induce turbulent flow in a condensate layer. Infrared methods can be used to sense the temperatures at the surfaces of dryer cans, making it possible to detect hidden problems related to condensate handling and other issues (Bhatani et al. 2012). Further savings can be achieved by managing the discharge of condensate, using closed tanks (Bujak 2008).

The efficiency of a typical dryer section can be improved by implementing a variety of best-practice guidelines (Sherlaw 1980; Reese 2005; TAPPI TIP 0404-63 2021). These include usage of permeable and well-fitted dryer fabrics (Taylor 2011) and implementation of pocket ventilation at a temperature near to that of the system (Walker 1977; Sherlaw 1980). Figure 31 illustrates a typical pocket ventilation system and some of its effects. As shown in part A of the figure, a blowbox can be positioned so as to blow warm, relatively dry air through the uncovered forming fabric into the pocket area, allowing a return flow of air at another point where the forming fabric is not covered with the paper sheet. Part B of the figure shows the expected effect on the distribution of vapor pressure of water across the width of the paper machine.
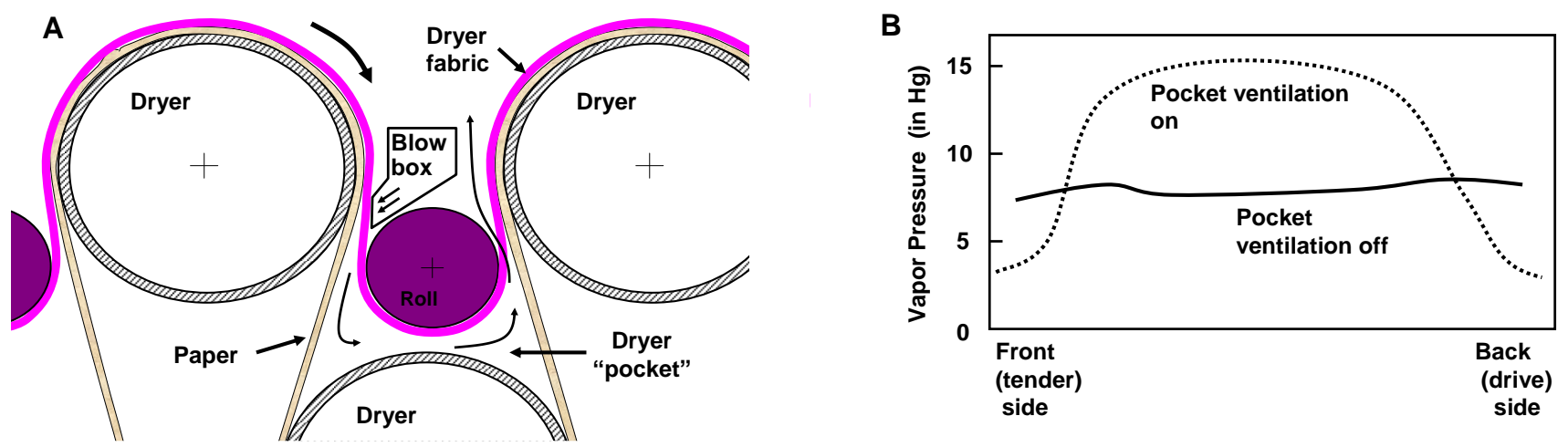

Fig. 31. A: Typical pocket ventilation system; B: Its effects on water vapor pressure across the width of a paper machine

Fabric tension needs to be high enough, as well as uniform, to achieve good thermal transfer to the paper (Garvin and Pantaleo 1970; Sherlaw 1980; Stenström 2020). Substantial savings can be achieved by enclosing the dryer section in a hood or hoods, thus minimizing the amount of air that enters (Sherlaw 1980). This is illustrated schematically in Fig. 32.

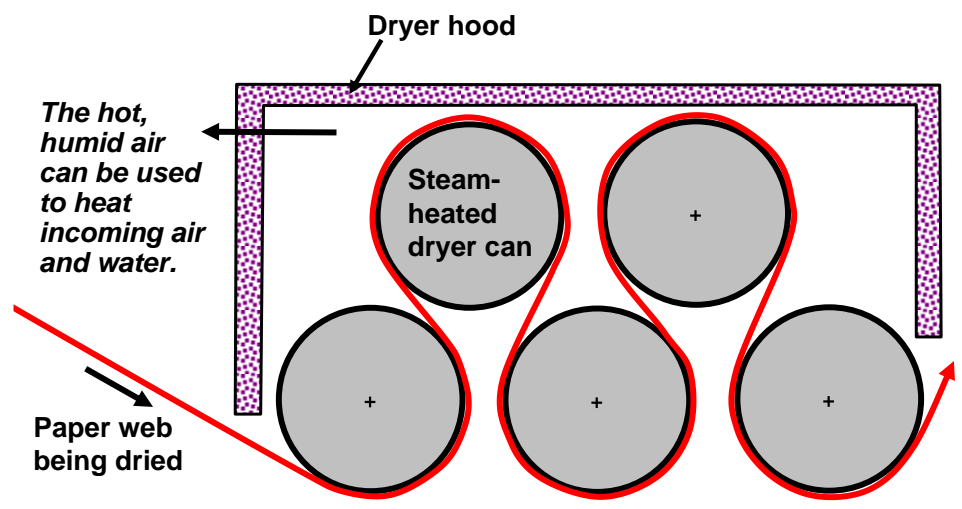

Fig. 32. Schematic illustration of dryer cans enclosed within a hood in a paper machine system, which enables recovery of the latent heat within the vapor 
Air can be regarded as a wasteful load on the dryer system, since it cannot be condensed to recover its heat. In similar fashion, it is generally recommended to allow a small excess of steam to "blow through" the dryer can system as a means to continually purge non-condensable gases from within the cans (Garvin and Pantaleo 1970; Walker 1977; Sherlaw 1980; Smook 1992).

Over-drying of paper sheets is a common practice that has its roots in the frequent need to overcome moisture uniformity problems, i.e. machine-directional moisture streaks. Such defects can have a variety of causes, including uneven filling of press felts with debris, crown issues in press rolls, and condensate handling problems within drying cylinders, among others. Such issues merit priority attention to solve each problem at its roots. Over-drying is inefficient, not only because most of the sheet does not need to be dried further at that point, but also because the material is in its "falling rate" period of drying (TAPPI TIP 0404-63 2021). In addition, excessive drying tends to embrittle the paper and decrease the potential performance of fibers later obtained by recovery and recycling of that paper (Welf et al. 2005). Thus, when other problems affecting the uniformity of paper have been solved, additional savings and overall positive results can be achieved by keeping the final moisture content at the reel near to its maximum specified level (TAPPI TIP 0404-63 2021).

\section{Size-press starch solids}

The size press is a widely utilized operation on paper machines making a variety of printing papers and board grades. At the size press an aqueous solution of starch, or other selected mixtures, is applied to the paper surface. The main objectives of size press application are related to paper strength, including the stiffness of the sheet, surface strength, and the mitigation of dusting tendencies. In addition, papermakers sometimes supplement the size-press starch with hydrophobic copolymers, which can help impede penetration of liquids into the finished paper (Bildik Dal and Hubbe 2021). But from an energy standpoint, the size press can be viewed as taking a step backwards - adding water back to a product from which the water had just been removed. The problem is illustrated in part A of Fig. 33, which considers a typical trend of the temperature of paper as it passes through a typical dryer section with a size press. As shown, at the size press location, the temperature drops abruptly, and some of the drying process essentially has to be repeated. In fact, the overall rate of production can be increased and the steam demand can be decreased in a typical paper machine system if a way can be found to increase the solids content of the starch (or other) solution used at the size press (Laurijssen et al. 2010a). A typical solids content of starch solution for use at the size press is in the range $3 \%$ to $9 \%$ (Laurijssen et al. 2010a; Klass 1990). The solids content of starch can be higher when using film-press devices in which a film of starch is metered onto a roll and then fed into a nip, where it comes into contact with the paper (Klass 1990; Kohl et al. 1999). Such a system is shown schematically in part B of Fig. 33. In general, the goal is to prepare a starch layer that will remain near to the surface of the paper, thus having its best effect in increasing sheet stiffness and surface strength. Starch penetration depends not only on the solids content of the solution, but also the extent of hydrophobic sizing and porosity of the paper web (Cho and Garnier 2000). Though higher solids content of starch solutions can save on drying requirements after the size press, there are practical limitations that may involve rheology (Klass 1990; Voss et al. 2002). There is a need for research to determine where the practical limitations of starch solids may lie, and how to reach those limits. 

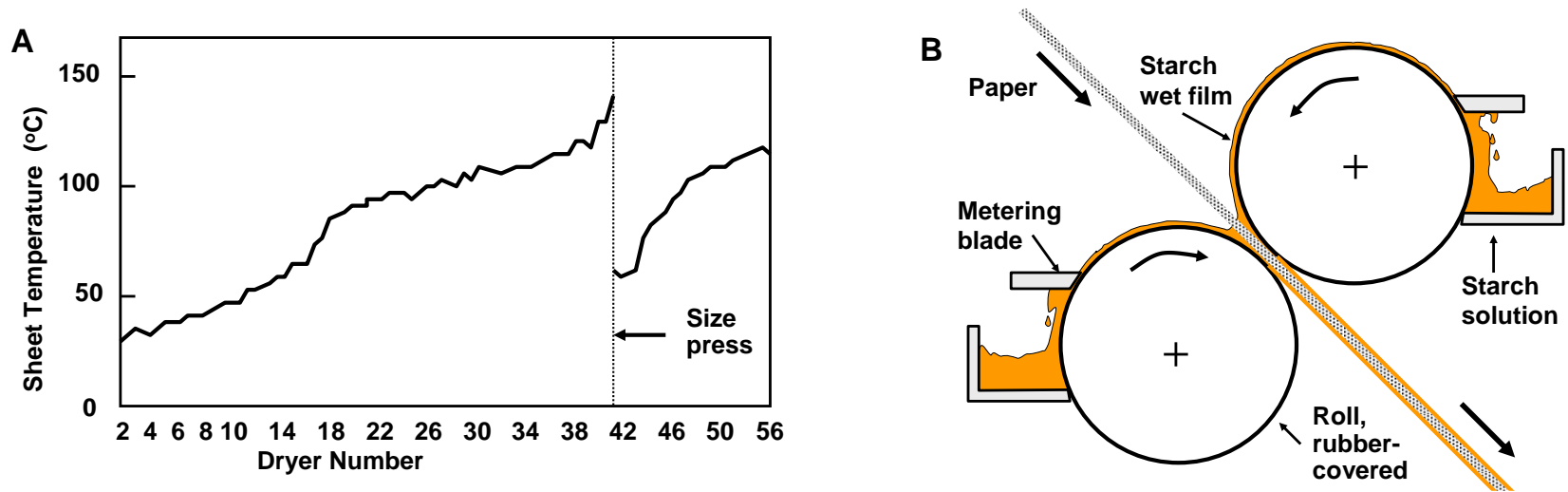

Fig. 33. The size press and drying issues: A: Typical development of sheet temperature during passage through a dryer section that includes a size press; $\mathbf{B}$ : Schematic diagram of a metering blade size press, which enables usage of a higher solids content of the starch solution

\section{Heat exchange for the paper machine}

The handling of vapor and air coming from the evaporation process on the paper machine represents a major area of potential savings in useful energy (Fleiter et al. 2012). The reasons follow from the earlier discussion of the principles of exergy analysis and process integration. Evaporation of water from a paper web produces a large volume of hot and wet exhaust air, and the only way to minimize exergy losses is to use as much as possible of the potentially wasted energy as a means to heat up various incoming streams of air and water (Laurijssen et al. 2010a). This is best achieved by using closed hoods over the groups of dryer cans. The leakage of air into these spaces is kept to a minimum (Walker 1977; Chow 1982; Reese 1988). One indicator of an energy-efficient system is that the dew-point temperature should be high (Laurijssen et al. 2010a). Expressed differently, the humidity within the hood needs to be high in order to maximize energy-efficiency of drying (Sivill et al. 2005).

Ideally, in a heat exchange process, the differences in temperature between the stream being cooled down and the stream being heated up ought to be relatively near together, throughout the system (Browne et al. 2001; Koufos and Retsina 2001; Savulescu and Alva-Argaez 2008; Atkins et al. 2012; Bonhivers et al. 2016). This is done by modifying or replacing parts of the heat-exchange network structure and reconnecting it so that it more closely approaches an ideal system, while at the same time avoiding too many heat exchange units or excessively long distances between interacting streams. The hottest vapors, which also contain the most latent heat, can be used to heat incoming air for pocket ventilation, for example. Intermediate-temperature streams, such as condensate, can be used for the initial heating up of boiler water and incoming air for such uses as the drying of hog fuel, lime mud, or air for pocket ventilation, etc. Yet lower categories of warm moist air, farther down the chain of heat exchangers, can be used to heat up white water on the paper machine, which can help to achieve more rapid dewatering.

\section{Infrared drying}

Some types of paper require specialized drying operations, and those operations often come with an energy penalty. For example, the sticky nature of various latex binders in aqueous coating formulations precludes the use of conventional steam-heated dryer cans (Aust 2009; Lehtinen 2000). Instead, the sheet is conveyed with a series of air-turns though a sequence of non-contact drying units, including infra-red heating, which is not highly 
energy-efficient (Aghbashlo 2015; Obando et al. 2015). A further disadvantage is that IR drying requires the usage of electricity, rather than the readily available, bio-based steam that is present in a typical pulp and paper facility. Fortunately, due to the relatively highsolids nature of typical coating formulations, there is typically less water that needs to be evaporated in comparison to either the paper machine in general or the size press. A potential advantage of an IR drying system is that it may be able to extend the constantrate drying phase to lower levels of moisture (Sain et al. 1995). Thus, there is potential to boost the rate of drying in comparison to reliance on the use of dryer cans.

\section{Air impingement drying}

Air-impingement drying means that hot air is directed to the paper surface to bring about evaporation. The energy-efficiency of air-impingement drying is in a similar range to conventional paper drying with steam-heated cans (Luarijssen et al. 2010). The potential downside, for most grades of paper or paperboard, is that there is a greater degree of contraction of the sheet, due to a lack of tension in either direction. This lack of tension on the sheet during the drying process means that the resulting pulp sheet cannot be expected to achieve the levels of dimensional stability and tensile properties that are achieved on typical paper and paperboard machines. For this reason, contactless airimpingement drying is mainly confined to such products as market pulp (MacLeod et al. 2010) and tissue products. It is also used after application of aqueous coatings to the paper surface, as already noted. When drying market pulp in a Flakt dryer, the sheet is both conveyed and dried by currents of heated air (Lindqvist 1980). The high permeability of unrefined fibers, which are mainly subjected to such pulp drying operations, appears to be well suited to the air-impingement system. The system is reputed to achieve a high efficiency of energy use in drying, which may be attributed to an efficient hood system, with energy recovery.

Through-air drying (TAD)

A technology called "through-air drying" (TAD) has become widely used for preparation of high-end tissue and towel paper products. Part A of Fig. 34 shows the hood setup for such a system.

A

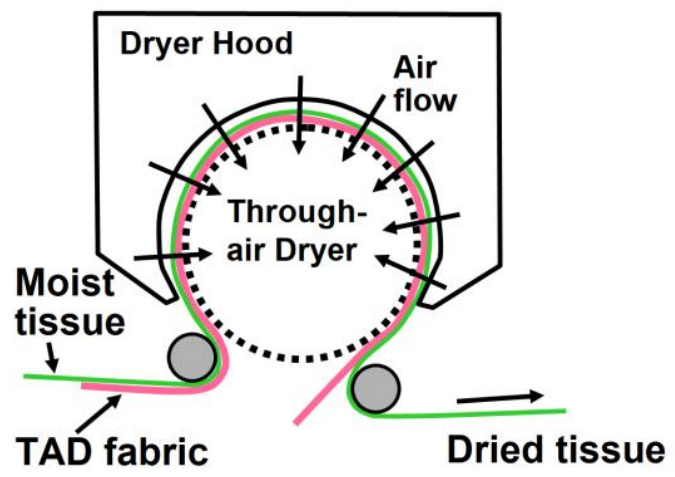

B

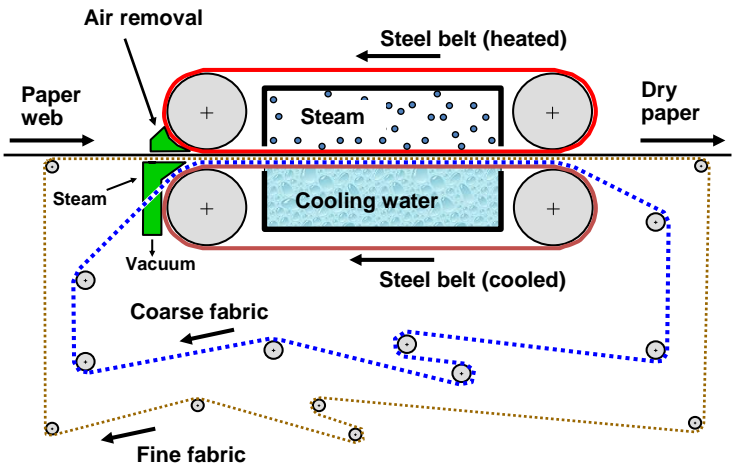

Fig. 34. Production-scale innovations in paper drying. A: Set-up of a through-air drying (TAD) system for tissue and towel production; B: Schematic of a Condebelt system, which has been used for the production of linerboard (redrawn based on an original by Lindberg, 1997) 
Unlike a typical dryer hood, the TAD system is set up to pass dry heated air from a pressurized hood through the paper and then through the cylinder screen upon which the sheet is resting (Lee et al. 2002; Ryan et al. 2003). The technology can yield highly bulky paper with a soft feel and a high ability to absorb water; however the energy consumption is high (Cui et al. 1999). Though TAD has the potential to achieve high efficiency, due to the efficient contact of the hot air with fibers during passage through the sheet, this is offset by the fact that the paper entering the TAD dryer section generally has a high moisture content (Laurijssen et al. 2010a). In an effort to maximize bulk and softness, only a minimum of pressing is applied to the pulp, and this leaves a lot of water to be removed by evaporation.

\section{Condebelt drying}

Condebelt drying has been implemented on three commercial paper machines that make paperboard products (Stenström 2020). A schematic is provided in part B of Fig. 34 . As it passes through the dryer, the paper web is carried between a pair of flexible steel belts. The assembly is continuously heated from one side and cooled on the other (Bajpai 2016). A pair of fabrics, on the cooled side, provides a place for condensate to collect. Continuous enclosure of the paper, together the fabrics, between the steel belts during the entire process of drying ensures that there is essentially no dimensional change to the sheet. Because of the fibers' natural tendency to shrink as they dry, a high tension is maintained, which leads to fiber straightening and development of high values of elastic modulus within the plane of the sheet. In addition, the combination of time, temperature, and relatively high moisture at the beginning and middle phases of the process promote plastic flow of lignin and hemicellulose within the fibers. This leads to exceptionally intimate contact at fiber junctions, especially in high-yield pulp grades. In terms of energy, a savings in the range of about 10 to $20 \%$ has been estimated (De Beer et al. 1998; Laurijssen et al. 2010a), some of which has been attributed to less leakage of steam energy. A limitation of the Condebelt process is that the side of the sheet that is being cooled during drying becomes highly roughened with an imprint of the plastic fabric. Such roughness is not regarded as a critical problem in the case of linerboard, since only one side of the sheet is exposed during its end-use.

\section{After Pulping and Papermaking}

Recovery of materials from primary effluent

Liquid effluent that leaves from a pulp and papermaking facility, on its way to wastewater treatment, will carry energy in two forms. One of these is heat. Some pulp and paper mills, especially in the Nordic countries, have made arrangements to supply heat in the winter to heat buildings both within the mill and in the surrounding area. Such beneficial usage of relatively low-temperature heat resources is often planned by the application of pinch analysis and process integration.

The other form of heat loss associated with effluent discharges involves the loss of materials that really ought to have been incorporated into paper. Losses in yield due to discharge in the wastewater need to be compensated by corresponding increases in inputs to the process as a whole, and one can calculate the amount of energy that it would require to increase overall production by a given amount. Such reasoning has led many papermakers to wonder whether it is feasible to recover solids from a primary wastewater clarifier and return it to the paper machine system. Issues of contamination, low brightness, and unintended inoculation of slime bacteria often stand in the way of such practices. In 
some cases it has been feasible to upgrade the mineral content obtained from primary sludge at a papermaking facility and employ it is low-brightness grades of paper after hydrothermal treatment or oxidation (Hamm and Gottsching 1998; Johnston et al. 2000; Tofani et al. 2021). The European Union has disallowed the disposal of sludge from pulp and paper facilities (An et al. 2020), and this places additional incentive for mills to find alternative uses.

In light of the issues just discussed, papermakers have an increasingly strong incentive to prevent solids from passing into the wastewater. To achieve this goal, papermakers generally use a multi-part strategy, as follows: (1) Paper machines are designed in such a way that most of the water removed from the sheet during the paper forming process becomes immediately sent back to dilute incoming thick-stock; (2) retention aids, including very-high-mass cationic copolymers of acrylamide, are routinely used to achieve a high efficiency of attachment of fine particles onto the fibers during the forming process; (3) excess water from the process is sent to a saveall device in which fine particles are filtered from the water onto a fiber mat, which is sent back to the paper machine; and (4) increasing amounts of the filtered process water from the saveall are being used for such purposes as showers on the paper machine. Part A of Fig. 35 illustrates the water balance in a typical paper machine, showing why it is reasonable to expect that there will always be ample flow to the saveall. Part B of the figure shows the operation of a typical disc filter saveall device.
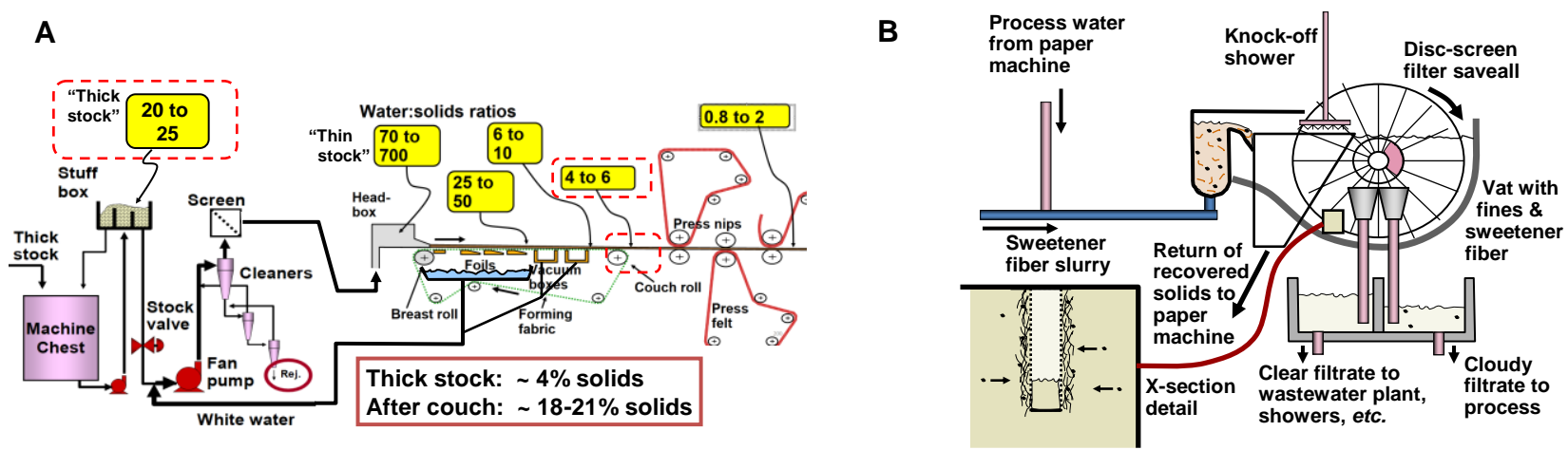

Fig. 35. A: Excess water in a typical paper machine system is shown by comparing the incoming solids content of thick stock (dashed red rounded square at upper left) relative to the solids content after the forming section (dashed red rounded square in the center right). Labels highlighted in yellow indicate the ratio of water to solids at key points. B: Operation of a typical disc-type saveall device

\section{Energy issues related to aerated biological treatment}

Aerated systems, with the return of some of the sludge back to the intake (i.e. activated sludge) have been the most widely used systems in the US to reduce the biological oxygen demand of wastewater (Diez et al. 2002; Hubbe et al. 2016). Because this process step normally comes after the primary clarification of the wastewater, the stage is called secondary treatment. Logic would suggest that in order to decrease oxygen demand levels, the best approach is to pump air into the system, or to employ a fountain system, etc., to entrain bubbles. Such systems can work well, but the electrical energy required for aeration has been stated to be a prime candidate for economization (Stoica et al. 2009). The cited study faults some operators of activated sludge wastewater treatment plants for sometimes attempting to minimize sludge volumes, when they ought to be adding just enough air to 
meet the targets for water quality. In principle, it should be possible to optimize the amount of aeration by sensing the dissolved oxygen level and utilizing a suitable control system (Man et al. 2018). Another study showed that air-pumping energy can be saved, with equivalent aeration effects, by use of intermittent air injection into a secondary wastewater treatment system (Herrmann-Heber et al. 2020).

\section{Incineration of secondary wastewater sludge}

Incineration is a plausible way to gain energy from organic wastes. However, sludge from biological treatment of paper industry wastewater typically contains large amounts of water. As was shown earlier in Fig. 10, the need to evaporate such water greatly decreases the effective heating value of the sludge (Saidur et al. 2011). Principal means to decrease the water content of biological sludge include belt presses (Vaxelaire and Olivier 2006) and screw presses (Badar 1987). Belt presses can achieve solids levels in the range of 18 to 35\% (Russell 2019). Dewatering of biological sludge is inherently difficult (Xu and Lancaster 2009). This may be because each bacterial cell functions much like a water balloon. Although the solids of the sludge could be increased by application of very high applied pressures, the water released from the cells would be rich in organic substances, contributing to a high biological oxygen demand.

By using waste heat from an integrated pulp and paper mill as a means to pre-dry the sludge, incineration technology comes closer to being a viable option. An equivalent system was tested in which wet sludge was treated with steam from a boiler, which was fired with the same sludge after it has been dried (Chiang et al. 2016). Based on trial results, considering a mixture of paper mill sludge and municipal sludge, along with gasification technology, the system was judged to be "thermally self-sufficient". Xu and Lancaster (2009) used the words "can be energy deficient" when describing the application of incineration processes to various sludges from secondary wastewater treatment. In other words, there was no net energy produced by the gasification plant. An analysis by Mohammadi et al. (2019) judged the incineration of pulp and paper mill sludge from aerobic biological treatment to be environmentally unfavorable, even when employing effective thickening measures.

\section{Anaerobic digestion of sludge}

From an energy perspective, a more favorable way to handle the biological sludge from secondary treatment of wastewater from pulp and paper facilities is to employ anaerobic conditions ( $\mathrm{Xu}$ and Lancaster 2009; Yerushalmi et al. 2013; Yang et al. 2019). Some of the benefits of using anaerobic treatment are immediate, such as not having to run aeration pumps and thereby saving that amount of electrical energy. In addition, the amount of sludge left over after anaerobic treatment typically is less than for a corresponding activated sludge system (Mahmood and Elliott 2006; Chong et al. 2012). A third benefit is that energy-rich methane gas, and sometimes hydrogen as well, can be collected, while using a process that does not require evaporation of water (Gherghel et al. 2019). The results are expected to be more eco-friendly compared to either landfilling or incineration (Mohammadi et al. 2019).

Basic anaerobic processes are understood to involve synergistic work of two populations of microbes, together with the enzymes that they release (Rao et al. 2010; Silva Rabelo et al. 2018). These include the saprophytic bacteria, which form acids, and the methane-forming bacteria. In particular, acetic acid is converted to methane and carbon dioxide. By carrying out two stages of processing, it is possible to capture relative large 
amounts of both methane and hydrogen, with an overall gain in the amount of recovered fuel value (An et al. 2020). According to the cited work, a different microbial community becomes dominant after centrifugation to remove solids produced in the first cycle.

The basic methanogenesis reactions occurring in the course of anaerobic digestion can be approximately represented as Eqs. 10 and 11 .

$$
\begin{array}{ll}
2 \mathrm{CH}_{2} \mathrm{O} \rightarrow \mathrm{CH}_{4}+\mathrm{CO}_{2} & \Delta H=-151.6 \mathrm{~kJ} / \mathrm{mole} \\
\mathrm{CH}_{3} \mathrm{OOH} \rightarrow \mathrm{CH}_{4}+\mathrm{CO}_{2} & \Delta H=-15.8 \mathrm{~kJ} / \mathrm{mole}
\end{array}
$$

Based on the heats of formation of cellulose $\left(-950 \mathrm{~kJ} / \mathrm{mole}\right.$ of $\left.\left(\mathrm{CH}_{2} \mathrm{O}\right) 6\right)$, methane $(-74.8$ $\mathrm{kJ} / \mathrm{mole})$, and carbon dioxide $(-393.5 \mathrm{~kJ} / \mathrm{mole})$, the reaction expressed by Eq. 10 will be favorable, as shown. Keeping in mind that methane is a potent green-house gas, carrying out these reactions makes sense only when using a well-sealed reactor, allowing for full recovery of methane to be used as a fuel for energy generation.

A key challenge to the successful implementation of anaerobic wastewater treatment in pulp and paper facilities involves the fact that different substances generated in the pulping of wood fibers have quite different susceptibilities to anaerobic biodegradation. Even when comparing different plant materials, very large differences in methane yield have been found (Martinez-Gutierrez 2018). Ekstrand et al. (2013) observed high conversion of organic substances present in condensate streams from kraft pulping and in neutral sulfite semichemical pulping effluent. However, the biodegradation was inhibited by the presence of tannins, resins acids, and decomposition products of lignin. Consequently, many other contaminated aqueous streams of wastewater from kraft pulping were not effectively degraded by the treatment. Similarly, Hinds et al. (2016) reported that when lignocellulosic matter, such as yard waste, was added to a municipal wastewater treatment system using an anaerobic process, the decomposition was limited. Notably, the results were much improved by inoculating the system with sludge from a pulp and paper mill operation. Essentially the opposite approach also has been shown to be effective utilizing the biota from the rumens of cattle to pretreat paper mill sludge to enhance its anaerobic digestion (Takizawa et al. 2018). It follows that the successful degradation is dependent on developing and maintaining a favorable microbial community. In related work, it has been found the co-digestion of pulp and paper mill wastewater or other lignocellulosic substances with animal wastes can enhance anaerobic digestion, with the production of methane (Mussoline et al. 2013; Neshat et al. 2017; Li et al. 2018; Liew et al. 2020). Here, part of the explanation may be that the combination yields a favorable ratio of carbon to available nitrogen, thus favoring the biological processes associated with microbial growth (Hubbe et al. 2010; Mao et al. 2015; Neshat et al. 2017).

It is reasonable to expect that the rate of biodegradation can be accelerated by breaking down cellulosic materials to small dimensions, thereby allowing greater access of enzymes to the material. This principle has been demonstrated, for instance, by Rodriguez et al. (2017), who showed that ordinary mechanical refining of waste paper, using a Hollander beater, increased the methane yield from subsequent anaerobic digestion. In addition, an electrohydrolysis treatment has been shown to promote greater methane production during subsequent anaerobic digestion of pulp and paper mill waste sludge (Veluchamy et al. 2018).

Because anaerobic digestion is routinely carried out in an enclosed reactor vessel, high-temperature treatment can be considered. Thus, Precci Lopes et al. (2018) found that heating of an anaerobic bioreactor system yielded favorable results for the digestion of 
sludge from a kraft pulping operation. A thermophilic population of microbes was favored by the $55^{\circ} \mathrm{C}$ temperature employed in the study. The authors judged their system to have been somewhat unsuccessful, since the energy content of the produced methane was smaller than the energy required for heating. However, in the context of a well-integrated pulp and paper making operation, heating of the wastewater to $55{ }^{\circ} \mathrm{C}$ could readily be achieved by transferring heat from other process streams, such as condensates.

\section{Waste Paper as Fuel or for Recycling}

To give a complete consideration of energy usage in the papermaking process, the energy value of the paper product also needs to be discussed. After the paper product has served its main intended function, it can be regarded as a candidate for energy recovery, through incineration. The effective heating value of wastepaper can be estimated based on Fig. 10, which appeared earlier in this article. It is technically feasible to feed used paper to boilers or gasifiers as a means to obtain steam or electricity. When such practices reduce the usage of fossil fuels, there can be a net decrease in production of greenhouse gases (Finnveden et al. 2005). Depending on the boundary conditions for life cycle assessment, there are some situations in which the incineration of paper, with recovery of energy, has been judged to be environmentally favorable (Merrild et al. 2008). However, it is more generally concluded, when using a broader context for life cycle analysis, that the recycling of paper is more advantageous than incineration, and that both are more favorable than landfilling (Villanueva and Wenzel 2007; Merrild et al. 2008).

The recycling of paper requires the input of energy, but generally not so much energy as making the paper from scratch (Laurijssen et al. 2010b). This trend was found to be true for all grades that were considered, though the savings were dependent on the kind of paper. Detailed quantification is made difficult by the need to remove inks, depending on the type of recovered paper and the intended recycled paper product (Vukoje and Rozic 2018).

\section{Integrative Approaches}

Steps to increase bioenergy usage

Earlier in this article it was mentioned that pulp and paper mills are often well situated to be able to generate energy from underutilized biomass (Blackwell and MacCallum 1983). Bark that has been removed from logs is already present at the mill yard in many cases, so the bark is routinely used to fuel hog-fuel boilers. There are often opportunities to push such practices to higher levels by increasing the amounts of underutilized biomass that are collected and incinerated (Browne et al. 2001; Gong 2005; Gavrileseu 2008; Szabó et al. 2009). For example, in Sweden there has been a consistent effort to replace fossil fuels with biofuels, wherever possible in the pulp and paper industry (Bergquist and Söderholm 2015). Such practices have helped the country to become less dependent on foreign sources of energy, with a favorable effect on the economy. Holmberg and Gustavsson (2007) calculated the amount of biomass that would need to be incinerated to generate enough electricity to run a mechanical pulping operation. As illustrated in Fig. 36 , they discovered that the amount of wood material that would be needed to generate the needed electrical energy was approximately equal to the loss in yield when preparing kraft pulp. In other words, kraft pulps and mechanical pulps can be regarded as requiring about the same amount of net resources, even though the yield of the mechanical pulps is much higher. Mechanical pulps usually are produced with usage of a large amount of nonrenewable electrical energy. However, if that energy were generated from biomass, the 
results would look like Fig. 36. Likewise, when using the kraft pulping process, Laurijssen et al. (2010b) estimated that the paper industry was generating about $50 \%$ of the energy needed to run all of its processes, and one of the challenges of the coming decades will be to come closer to energy self-sufficiency.

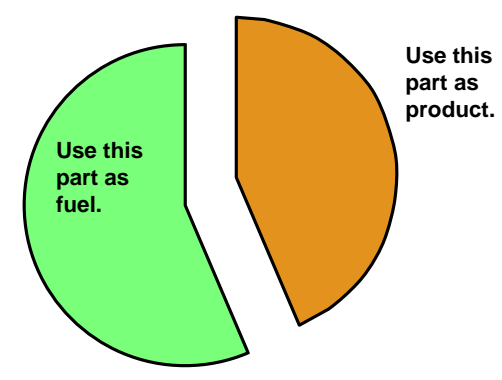

Fig. 36. Representation of the amount of wood that would be required to fully power a mechanical pulping process by use of power boilers

\section{Pinch analysis with placement of bridges}

After having considered issues related to hog-fuel boilers, pulping, chemical recovery, papermaking, and wastewater sludge processing, it is appropriate to return to the topic of process integration. Specifically, the operating team of a pulp and paper mill may need to decide on the most prudent ways to upgrade an existing heat exchanger network. As was noted earlier, the form of the graphical analysis that has been used in earlier studies does not lend itself well to addressing some of the detailed needs of engineers (Bonhivers et al. 2014). The cited authors introduced a new practice of showing the cumulative energy of the source and sink streams on the vertical axis and the temperature on the horizontal axis.

Bonhivers et al. (2014) demonstrated their approach by first considering an industrial system. As a way to keep things simple, only sensible heat was involved in the example. Figure 37 summarizes the system as a set of three sink streams, a cold utility (e.g. a refrigeration unit), a hot utility (e.g. an electric heater), and three source streams. Note that the initial heat exchanger network (HEN) involves seven different exchanges of heat (shown by the vertical dotted green arrow). Four of these heat transfers are emphasized with highlighting, as they involve transfers of heat to or from one of the utilities. In principle, there may be opportunities to save exergy if some of the heat transferred to or from one of the utilities can be rerouted so that the energy is supplied by a heat exchanger. The two purple arrows (horizontal to the right) show the two new heat exchanger connections that were proposed in this example.

Figure 38 depicts the same example according to a modified format of a pinch analysis. To be compatible with the previous figures, the format has been modified from the traditional form such that the enthalpy on the vertical axis and temperature is on the horizontal axis. In this diagram, the two cold utilities are given the labels $\mathrm{C} 1$ and $\mathrm{C} 2$, and the two hot utilities are $\mathrm{H} 1$ and $\mathrm{H} 2$. The three heat exchangers are E1, E2, and E3. The cumulative "cold balanced composite curve" (in dark blue) represents all of the streams that are in the process of being cooled (source streams). Likewise, the "hot balanced composite curve" is a summation of all of the streaming being heated (sink streams). The two upward arrows in Fig. 38 represent the two new proposed connections within the HEN. 


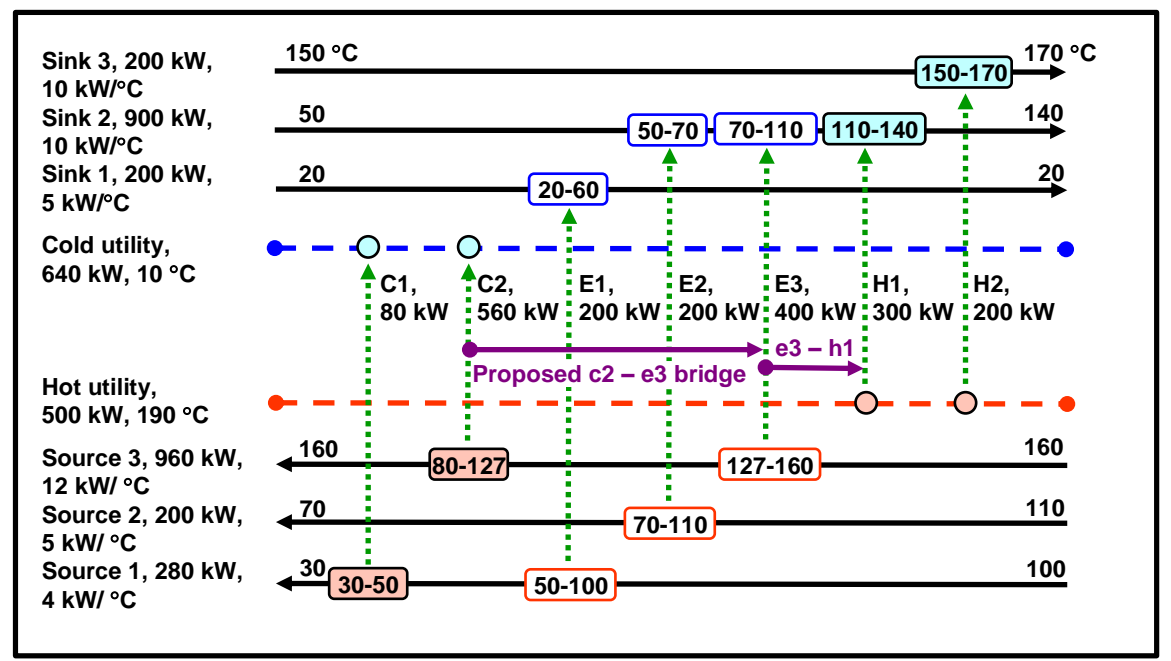

Fig. 37. Heat exchanger network "grid" diagram showing the initial heat exchange connections (green dotted vertical arrows) and two proposed bridges (purple horizontal arrows). Numbers in the plot show temperatures in ${ }^{\circ} \mathrm{C}$. Highlighting indicates each exchange of heat with a utility, generally requiring the usage of non-renewable electricity. Figure redrawn.

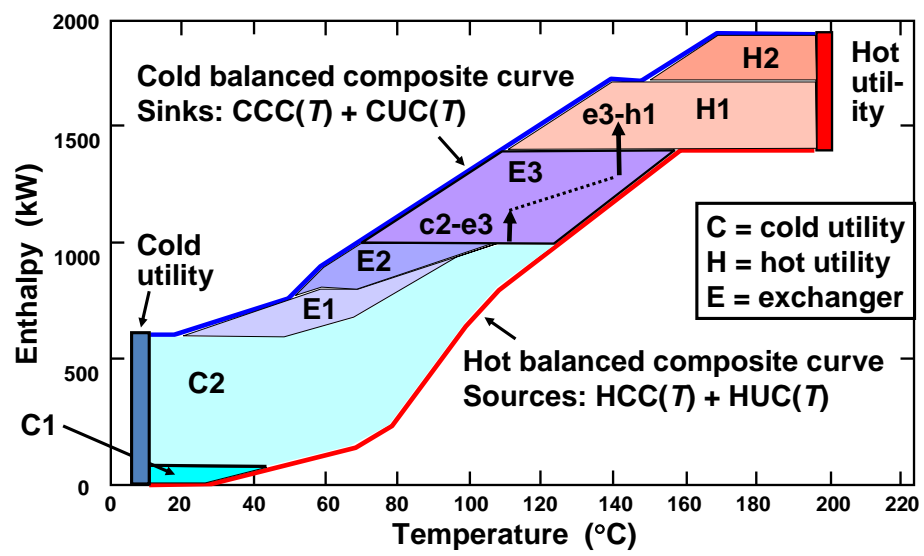

Fig. 38. Modified form of pinch analysis, showing the same initial condition and proposed bridge retrofits as in the previous figure. Figure redrawn

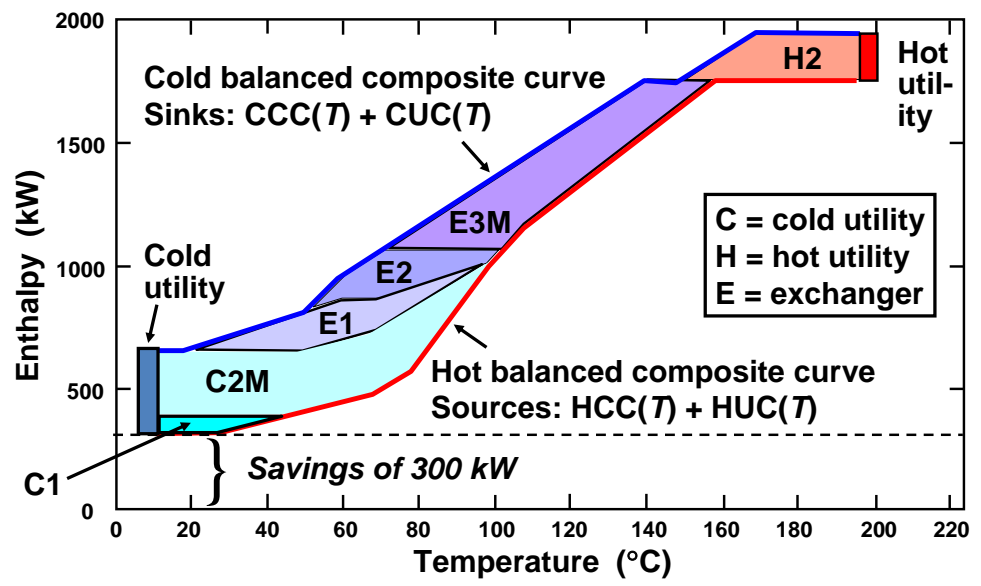

Fig. 39. Modified form of pinch analysis, showing final condition after implementation of the proposed bridge retrofits. Figure redrawn 
Figure 39 shows the final situation, using the same pinch analysis form, after implementation of the proposed changes. What should be immediately apparent is that, by making the changes, the two composite curves have been brought much closer together. Note that one of the hot utilities (H1) is no longer needed in the reconfigured system, and one of the cold utilities (C2) has been modified in a way that much less heat has to be transferred. The resulting savings in exergy $(300 \mathrm{~kW})$ is indicated at the base of the diagram.

\section{Heat from a pulping process for drying of biomass}

Another situation worth reconsidering, after having discussed aspects from different parts of a pulp and paper mill system, involves potential improvements in the efficiency of using biomass residues. Andersson et al. (2006) compared various options for the drying of biomass, as part of a pellet production system. The idea was to take advantage of the presence of a pulp and paper mill, and in particular, the chance to use various heat sources related to a kraft recovery boiler. Four of those options are represented in Fig. 40. As shown, those options included (a) partly cooled flue gas, (b) high-medium pressure steam (26 bar), (c) low-medium pressure steam (10 bar), and (d) waste heat (ca. $95^{\circ} \mathrm{C}$ ) in combination with a new design of vacuum dryer.

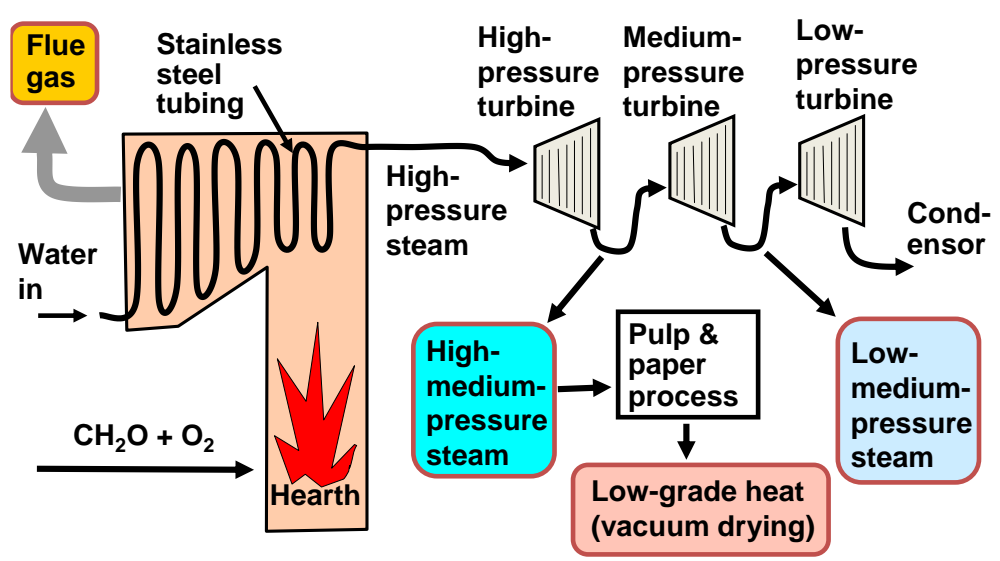

Fig. 40. Heat sources considered by Andersson et al. (2006)

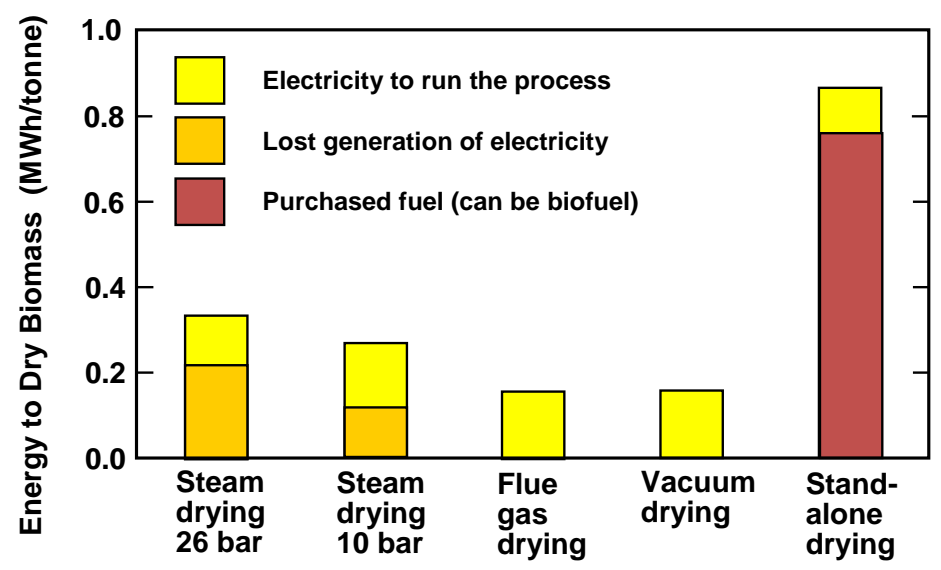

Fig. 41. Calculated net energy usage for the five biomass-drying systems compared by Andersson et al. (2006). Figure redrawn 
In addition to the heat source options depicted in Fig. 40, the authors also considered a stand-alone drying facility in which the drying energy was supplied by the burning of purchased fuel (which can be biofuel) (Andersson et al. 2006). Figure 41 shows the calculated results when considering the impact on the energy usage of the whole mill. As indicated, the least amount of required energy input was predicted for implementation of the flue gas drying system or the vacuum drying (low-level waste heat) systems. The two steam-drying scenarios (with two intermediate steam pressures) gave promising results, but they both decreased the amount of electricity generation in the facility. The stand-alone system required about five times as much energy input compared to the two most favorable systems. The main take-away message was a strong demonstration of the value of process integration. Notably, the most favorable results were obtained when using relatively low-grade heat sources that were unsuitable for steam production.

\section{STRATEGIES FOR IMPLEMENTATION}

Having considered energy issues affecting unit operations throughout pulping, papermaking, and waste handling, it is clear that there are many known measures that can be taken to make the facilities more energy-effective, i.e. to decrease the needless losses of exergy. But such measures often are not put into practice. This section will consider issues that can hinder such implementation, including issues of priorities and the influence of risks. Also, to round out the discussion, some issues related to application of life-cycle assessment will be considered.

\section{Fixing What is Broken}

When a pulp mill or a paper mill is first constructed, it is reasonable to expect that a full range of energy-saving strategies, as have been outlined in this review, will already have been incorporated into the design. Though improvements relative to the initial design are possible, it is likely that greater and more immediate savings can be achieved by fixing broken valves, non-functioning or uncalibrated sensors, leaks, and other things that are broken. Some of these items may fall into the category of "simple losses," but all of them together can result in an underperforming process. Thus, periodic audits of the system, using checklists and portable flow meters, etc., should have high priority (Reese 2018; Reese and Deodar 2018; Gilbreath 2019; Reese et al. 2020). Design improvements, based on principles outlined in this review, can be considered for well-maintained facilities and especially when planning for new mills.

\section{Coordinating Process Innovations with New Construction}

Pulp and paper companies, as well as individual manufacturing facilities within those companies, face many changes in their operations. Major changes in product lines, types of raw materials, and levels of production may require capital investments. Some mills will need to be changed completely. Others may require debottlenecking, meaning that some unit operations need to be extensively upgraded or replaced so that future processing demands can be met. There can be advantages of coordinating energy-saving innovations during the planning such projects. 


\section{Prioritizing Process Efficiency}

Within a manufacturing company, efficiency-related and energy-saving projects are continually in competition with other projects, some of which involve new product initiatives, production expansions, or quality improvements. Implementation of a project that appears favorable economically may be slowed or blocked by a lack of time of already burdened staff members (Lawrence et al. 2018). In addition, it has been proposed that bureaucracies and organizational structures might stand in the way of energy-saving projects (DeCanio 1998). A case is made in the cited work that even though certain energysaving initiatives may be excellent investments, they might not be good fits to corporate priorities. Even in industries that are energy-intensive, such as the foundry industry and the pulp and paper industry, it has been reported that energy issues often do not play a big role in upper management decisions (Thollander and Ottosson 2010). Rogers et al. (2018) suggest that a way to make sure that energy-savings initiatives don't get overlooked is to set up benchmarks - essentially showcasing the company's situation relative to perceived industrial leaders with respect to various energy criteria. This gives a company a way continually to self-justify and prioritize various efforts and expenses aimed at making their processes more energy-efficient.

Another likely barrier to investments in energy-related improvement may be due to complexity itself (Walker 1977; Lawrence et al. 2018). For instance, it has been suggested that management teams often opt for installation of direct heat transfer (DHT) systems, such as seam injection, because they have simpler designs compared to systems that are optimized in terms of energy usage and maximizing the project returns (Savulescu and Alva-Argaez 2008). The pinch analysis, as discussed earlier, appears to be a useful way to cut through some of the complexity by portraying the main issues in a clear graphical form (Atkins et al. 2012; Bonhivers et al. 2016). Improvements in available software, coupled with ever-increasing computing power and the integration of process instrumentation, also can be expected to help corporations to reduce the expense of energy-related planning.

Governmental policies, which can include taxes, incentives, and prohibitions, can influence rates of adoption of energy-saving technologies. It is well known that allowing corporations to depreciate the value of assets at accelerated rates can promote capital expenditures, which in the long run are beneficial to both the corporation and the general economy. Initiatives such as using the excess low-grade heat from a pulp and paper mill to heat buildings within an adjacent district of the city, were mentioned earlier in this article (Andersson et al. 2006). Such initiatives are often motivated by tax incentives and government-led planning.

\section{Risks}

In addition to their projected returns, alternative potential projects are also judged in terms of risk. In addition to being an energy-intensive industry, pulp and paper is also a capital-intensive industry, and this can lead to a cautious approach to business. As noted earlier, equipment in pulp and paper mills often is kept in continuous service for multiple decades, and this circumstance can increase the companies' aversion to risk.

Technoeconomic analysis is used as a tool to address some of the technical risks associated with projects. For instance, the costs and benefits related to the use of nanocellulose in papermaking has been considered in terms of its economic viability (de Assis et al. 2018). Energy is a significant component for certain nanocellulose products, and there are also energy implications related to the challenges of removing water from the nanocellulose during the papermaking process. Uncertainty is a key component of risk. 
For instance, there can be doubts about the ability of a promising technology to be scaled up to commercial scale. Such risks can include disruptions in production, inappropriate steps relative to the equipment capabilities, and logistical problems (Thollander and Ottosson 2008). There is often a critical lack of pilot-scale work to help bridge the gap between research laboratories and production lines. In addition, there are market risks; this is a particular challenge for the pulp and paper industry, since the capital equipment needs to be paid for by many years of high-volume production. Kong et al. (2016) assessed a range of energy-related emerging technologies that have the theoretical potential to make a big difference in the pulp and paper industry. Some of the technologies that were considered in that article still have not been shown to work successfully at a commercial scale (e.g. black liquor gasification), so the technical risks need to be regarded as very serious in the cases that were considered.

\section{Life Cycle Assessment Uncertainties}

The goal of life-cycle assessment (LCA) is, by application of an organized set of calculations, to objectively judge and compare the relative environmental impacts of alternative technologies. Depending on how the assessment is organized, especially with respect to setting boundary conditions, it is possible to reach different conclusions. Though the present article has emphasized energy-related issues, it is important to keep in mind that a full life-cycle assessment can consider many other factors, such as toxicity in the form of sulfur gases, nitrogen oxides, and radioactive compounds, for instance (Turconi et al. 2013). A detailed LCA relative to the paper industry was carried out recently (Man et al. 2019). The authors concluded that energy savings represent a major focus of concern for the industry. Consistent with the scope of the present article, they noted a need to consider the entire supply chain, starting from the sourcing of materials and following through to the end fates of main products and byproducts. They saw "big data" and modern simulation methods as offering a path for industry technologists to follow in future LCA work. A related LCA by Sun et al. (2018) found large differences in the production of $\mathrm{CO}_{2}$ equivalents produced by different pulp and paper facilities, with energy usage making a dominant contribution. But once again, they found large differences that were attributable to the usage of different boundary conditions, assumptions, and methods in different individual LCA studies carried out relative to the industry. A so-called "cradle-to-gate" analysis may be fine when comparing the environmental impacts of two processes that have equivalent effects outside of the system boundaries; however, a "cradle-to-grave" analysis can give a more complete assessment of the overall impact (Gaudreault et al. 2010). The latter approach had the potential to encourage collaborations between different businesses or governmental units to find suitable needs for low-level heat that is available at pulp and paper mill sites.

\section{CLOSING COMMENTS}

Based on the various principles that have been considered in this review article, there appear to be many improvements that can be made after comparing the operations of an existing pulp and paper facility with a hypothetical ideal version of that facility within which the best exergy-saving strategies have been implemented. To embark immediately on the construction of an all-new facility that incorporates all of the most advanced hypothetical strategies, all at the same time, would be costly and very risky. It would be 
like placing simultaneous, mutually-dependent bets. There are some highly promising technologies, such as hot-press dewatering of paper and black liquor gasification, which have looked good at the laboratory scale but have not yet shown convincing success at the production scale. Still, it is apparent that great opportunities lie in two areas: the implementation of best proven technologies and continued attention to some "low-hanging fruit" opportunities in existing facilities. With progress in computer analysis of industrial systems, together with pinch analysis and imagination, it becomes easier to identify favorable options. The goal is to take low-cost steps that can make an existing facility perform nearer to what already has been demonstrated to be achievable at a commercial scale in terms of energy-efficiency.

\section{ACKNOWLEDGMENTS}

The work of Martin Hubbe, in the area of papermaking chemistry and related fields, is supported by an endowment from the Buckman Foundation. The following volunteers studied an earlier version of this document and provided important insights, corrections, and clarifications: Michael Lecourt, Institut Technologique FCBA, Grenoble Biosense, France; Bogdan-Marian Tofanica, Gheorghe Asachi Tech. Univ. Iasi, Romania; Qiang Li, Texas A\&M Univ., College Station, TX, USA; Qiang Han, International Paper, Memphis, TN, USA; Richard Reese, Dick Reese \& Associates, Peachtree Corners, GA, USA; and Pramod Kumar Bajpai, Thapar Univ., Patiala, India.

\section{REFERENCES CITED}

Abdelaziz, E. A., Saidur, R., and Mekhilef, S. (2011). “A review on energy saving strategies in industrial sector," Renew. Sustain. Energy Rev. 15(1), 150-168. DOI: 10.1016/j.rser.2010.09.003

Abdoulmoumine, N., Adhikari, S., Kulkarni, A., and Chattanathan, S. (2015). "A review on biomass gasification syngas cleanup," Appl. Energy 155, 294-307. DOI: 10.1016/j.apenergy.2015.05.095

Aghbashlo, M. (2015). "A proposed mathematical model for exergy analysis of an infrared (IR) drying process,” Int. J. Exergy 18(4), 480-500. DOI: 10.1504/IJEX.2015.072912

Ahmetović, E., Kravanja, Z., Ibrić, N., Grossmann, I. E., and Savulescu, L. E. (2021). "State of the art methods for combined water and energy systems optimisation in kraft pulp mills," Optimiz. Eng., Early access. DOI: 10.1007/s11081-021-09612-4

Al-Dajani, W. W., and Tschirner, U. W. (2008). "Pre-extraction of hemicelluloses and subsequent kraft pulping. Part 1: Alkaline extraction," TAPPI J. 7(6), 3-8.

Amiri, R., Yuan, Z., and Beaulieu, S. (2010). "Mechanical pulp quality and fractionation. Part 1: Upgrading newsprint TMP for value-added grades," J. Pulp Paper Sci. 36(34), 71-78.

An, Q., Cheng, J. R., Wang, Y. T., and Zhu, M. J. (2020). "Performance and energy recovery of single and two stage biogas production from paper sludge: Clostridium thermocellum augmentation and microbial community analysis," Renew. Energy 148, 214-222. DOI: 10.1016/j.renene.2019.11.142 
Andersson, E., Harvey, S., and Berntsson, T. (2006). "Energy efficient upgrading of biofuel integrated with a pulp mill," Energy 31(10-11), 1384-1394. DOI: 10.1016/j.energy.2005.05.020

Arkell, A., Olsson, J., and Wallberg, O. (2014). "Process performance in lignin separation from softwood black liquor by membrane filtration," Chem. Eng. Res. Design 92(9), 1792-1800. DOI: 10.1016/j.cherd.2013.12.018

Aro, T., and Fatehi, P. (2017). "Tall oil production from black liquor: Challenges and opportunities," Separ. Purif. Technol. 175, 469-480. DOI: 10.1016/j.seppur.2016.10.027

Atkins, M., Walmsley, M., Morrison, A., and Neale, J. (2012). "Process integration in pulp and paper mills for energy and water reduction - A review," APPITA J. 65(2), $170-177$.

Aust, R. (2009). "Energy savings possibilities in non-contact drying of coated papers," Wochenblatt fur Papeirfabrikation 137(21-22), 1008-1013.

Axelsson, E., Olsson, M. R., and Berntsson, T. (2006). "Heat integration opportunities in average Scandinavian kraft pulp mills: Pinch analyses of model mills," Nordic Pulp Paper Res. J. 21(4), 466-475. DOI: 10.3183/npprj-2006-21-04-p466-475

Azarniouch, M. K. (1986). "Wood residues as fuel source for lime kilns: Phase III - Mill trials," Pulp Paper Canada 87(6), 112-116.

Back, E. L., and Salmén, N. L. (1982). "Glass transition of wood components hold implications for molding and pulping processes," TAPPI 65(7), 107-110.

Badar, T. A. (1987). "Sludge dewatering through screw presses - From pilot scale to plant-operation," TAPPI J. 70(9), 73-78.

Bai, L. K., Hu, H. R., and Xu, J. F. (2012). "Influences of configuration and molecular weight of hemicelluloses on their paper-strengthening effects," Carbohydr. Polym. 88(4), 1258-1263. DOI: 10.1016/j.carbpol.2012.02.002

Bajpai, P. (1999). "Application of enzymes in the pulp and paper industry," Biotech. Prog. 15(2), 147-157. DOI: 10.1021/bp990013k

Bajpai, P. (2016). Pulp and Paper Industry: Energy Conservation, Elsevier, Amsterdam, The Netherlands. ISBN 978012803428601280342899780128034118.

Bajpai, P., Mishra, S. P., Mishra, O. P., Kumar, S., and Bajpai, P. K. (2006). "Use of enzymes for reduction in refining energy - Laboratory studies," TAPPI J. 5(11), 2532.

Balcombe, P., Speirs, J. F., Brandon, N. P., and Hawkes, A. D. (2018). "Methane emissions: Choosing the right climate metric and time horizon," Environ. Sci. - Proc. Impacts 20(10), 1323-1339. DOI: 10.1039/c8em00414e

Baldwin, L. (1997). "High-vacuum dewatering," Paper Technology 38(4), 23-28.

Batchelor, W. J., Kure, K. A., and Ouellet, D. (1999). "Refining and the development of fibre properties," Nordic Pulp Paper Res. J. 14(4), 285-291. DOI: 10.3183/npprj1999-14-04-p285-291

Becker, H., and Marechal, F. (2012). "Energy integration of industrial sites with heat exchange restrictions," Computers Chem. Eng. 37, 104-118. DOI:

10.1016/j.compchemeng.2011.09.014

Berglin, N., Tomani, P., Salman, H., Svard, S. H., and Amand, L. E. (2010). "Pilot-scale combustion studies with kraft lignin in a powder burner and a CFB boiler," TAPPI J. 9(6), 24-30. DOI: 10.32964/TJ9.6.24 
Bergquist, A.-K., and Söderholm, K. (2015). "Sustainable energy transition: The case of the Swedish pulp and paper industry 1973-1990," Energy Effic. 9(5), 1179-1192. DOI: $10.1007 / \mathrm{s} 12053-015-9416-5$

Bernada, P., Stenström, S., and Månsson, S. (1998). "Experimental study of the moisture distribution inside a pulp sheet using MRI. Part II: Principles of the MRI technique," J. Pulp Paper Sci. 24(12), 380-387.

Bhabha, G., Lee, J., Ekiert, D. C., Gam, J., Wilson, I. A., Dyson, H. J., Benkovic, S. J., and Wright, P. E. (2011). "A dynamic knockout reveals that conformational fluctuations influence the chemical step of enzyme catalysis," Science 332(6026), 234-238. DOI: 10.1126/science.1198542

Bhardwaj, N. K., Duong, T. D., and Nguyen, K. L. (2004). "Pulp charge determination by different methods: Effect of beating/refining," Colloids Surf. A - Physicochem. Eng. Aspects 236, 39-44. DOI: 10.1016/j.colsurfa.2004.01.024

Bhutani, N., Lindberg, C. F., Starr, K., and Horton, R. (2012). "Energy assessment of paper machines," in: $20112^{\text {nd }}$ International Conference on Advances in Energy Engineering (ICAEE), Energy Procedia 14, 955-963. DOI: 10.1016/j.egypro.2011.12.1039

Bildik Dal, A. E., and Hubbe, M. A. (2021). "Hydrophobic copolymers added with starch at the size press of a paper machine: A review of findings and likely mechanisms," BioResources 16(1), 2138-2180. DOI: 10.15376/biores.16.1.BildikDal

Black, B. C., and Weisel, G. J. (2010). Global Warming, Greenwood, Santa Barbara, CA, USA.

Blackwell, B. R., and MacCallum, C. (1983). "Hog fuel drying concepts,” Pulp Paper Canada 84(1), 49-55.

Bonhivers, J. C., Moussavi, A., Alva-Argaez, A., and Stuart, P. R. (2016). "Linking pinch analysis and bridge analysis to save energy by heat-exchanger network retrofit," Appl. Thermal Eng. 106, 443-472. DOI: 10.1016/j.applthermaleng.2016.05.174

Brännström, H., Kumar, H., and Alén, R. (2018). "Current and potential biofuel production from plant oils," Bioenergy Res. 11(3), 592-613. DOI: 10.1007/s12155018-9923-2

Bridgwater, A. V. (1995). "The technical and economic feasibility of biomass gasification for power generation," Fuel 74(5), 631-653. DOI: 10.1016/00162361(95)00001-L

Browne, T. C., Francis, D. W., and Towers, M. T. (2001). "Energy cost reduction in the pulp and paper industry: An overview - Increased energy efficiency can lead to improved competitive advantage," Pulp Paper Canada 102(2), 26-30.

Bruce, D., and Hulkkonen, S. (1998). "Steam drying: Benefits, technology and a survey of applications," Pulp Paper Canada 99(12), 114-117.

Bujak, J. (2008). "Energy savings and heat efficiency in the paper industry: A case study of a corrugated board machine," Energy 33, 1597-1608. DOI: 10.1016/j.energy.2008.07.005

Carrasco, F., Mutje, P., and Pelach, M. A. (1996). "Refining of bleached cellulosic pulps: Characterization by application of the colloidal titration technique," Wood Sci. Technol. 30(4), 227-236. DOI: 10.1007/BF00229345

Carvalheiro, F., Duarte, L. C., and Girio, F. M. (2008). "Hemicellulose biorefineries: A review on biomass pretreatments," J. Sci. Indust. Res. 67(11), 849-864. 
Chang, X. F., Olson, J. A., and Beatson, R. P. (2012). "A comparison between the effects of ozone and alkaline peroxide treatments on TMP properties and subsequent low consistency refining," BioResources 7(1), 99-111.

Cheng, F. Z., Li, Y. M., and Chen, D. H. (2013). "Energy consumption and morphological development of eucalyptus alkaline peroxide mechanical pulp by carboxymethyl cellulose-assisted refining," BioResources 8(2), 2173-2185. DOI: 10.15376/biores.8.2.2173-2185

Cherubini, F., and Stromman, A. H. (2011). "Life cycle assessment of bioenergy systems: State of the art and future challenges," Bioresour. Technol. 102(2), 437-451. DOI: 10.1016/j.biortech.2010.08.010

Chew, I. M. L., Foo, D. C. Y., Lam, H. L., Bonhivers, J.-C., Stuart, P., Savulescu, L. E., and Alva-Argaez, A. (2011), "Simultaneous water and energy optimization for a pulp and paper mill," Chem. Eng. Trans. 25, 441-446.

Chiang, K. Y., Lu, C. H., Liao, C. K., and Ger, R. H. R. (2016). "Characteristics of hydrogen energy yield by co-gasified of sewage sludge and paper-mill sludge in a commercial scale plant," Int. J. Hydrogen Energy 41(46), 21641-21648. DOI: 10.1016/j.ijhydene.2016.06.199

Cho, B.-U., and Garnier, G. (2000). "Effect of the paper structure and composition on the surface sizing pick-up," TAPPI J. 83(12), 60 (digital content).

Chong, S. H., Sen, T. K., Kayaalp, A., and Ang, H. M. (2012). "The performance enhancements of upflow anaerobic sludge blanket (UASB) reactors for domestic sludge treatment - A State-of-the-art review," Water Res. 46(11), 3434-3470. DOI: 10.1016/j.watres.2012.03.066

Chow, D. K. (1982). "Conditions for minimizing energy consumption while drying paper," TAPPI J. 65(9), 130-132.

Costa, V. A. F., Tarelho, L. A. C., and Sobrinho, A. (2019). "Mass, energy and exergy analysis of a biomass boiler: A Portuguese representative case of the pulp and paper industry," Appl. Thermal Eng. 152, 350-361. DOI:

10.1016/j.applthermaleng.2019.01.033

Cui, Y. B., Ramaswamy, S., and Tourigny, C. (1999). "Through-air drying of tissue and towel grades," TAPPI J. 82(4), 203-208.

de Assis, C. A., Iglesias, M. C., Bilodeau, M., Johnson, D., Phillips, R., Peresin, M. S., Bilek, E. M., Rojas, O. J., Venditti, R., and Gonzalez, R. (2018). "Cellulose microand nanofibrils (CMNF) manufacturing - financial and risk assessment," Biofuels Bioprod. Bioref. - BIOFPR 12(2), 251-264. DOI: 10.1002/bbb.1835

De Beer, J., Worrell, E., and Blok, K. (1998). "Long-term energy-efficiency improvements in the paper and board industry," Energy 23(1), 21-42. DOI: 10.1016/S0360-5442(97)00065-0

De Blasio, C., De Gisi, S., Molino, A., Simonetti, M., Santarelli, M., and BjorklundSankiaho, M. (2019). "Concerning operational aspects in supercritical water gasification of kraft black liquor," Renew. Energy 130, 891-901. DOI: 10.1016/j.renene.2018.07.004

DeCanio, S. J. (1998). "The efficiency paradox: Bureaucratic and organizational barriers to profitable energy-saving investments," Energy Policy 26(5), article no. 441e54. DOI: 10.1016/S0301-4215(97)00152-3

deGroot, B., vanderKolk, J. C., vanderMeer, P., vanDam, J. E. G., and vantRiet, K. (1997). "Alkaline swelling of hemp woody core chips," J. Wood Chem. Technol. 17(1-2), 187-208. DOI: 10.1080/02773819708003127 
Demirbas, A. (2005). "Potential applications of renewable energy sources, biomass combustion problems in boiler power systems and combustion related environmental issues," Prog. Energy Comust. Sci. 31(2), 171-192. DOI: 10.1016/j.pecs.2005.02.002

Dhiman, S., and Mukherjee, G. (2018). "Recent advances and industrial applications of microbial xylanases: A review," in: Fungi and Their Role in Sustainable Development: Current Perspectives, P. Gehlot and J. Singh (ed.), pp. 329-348. DOI: 10.1007/978-981-13-0393-7_19

Diez, M. C., Castillo, G., Aguilar, L., Vidal, G., and Mora, M. L. (2002). “Operational factors and nutrient effects on activated sludge treatment of Pinus radiata kraft mill wastewater," Bioresour. Technol. 83(2), 131-138. DOI: 10.1016/S09608524(01)00204-8

Dincer, I., and Rosen, M. A. (2021). Exergy: Energy, Environments, and Sustainable Development, $3^{\text {rd }}$ Ed., Elsevier, Amsterdam. DOI: 10.1016/B978-0-12-8243725.00004-X

Dong, C. X., Song, D. L., Patterson, T., Ragauskas, A., and Deng, Y. L. (2008). "Energy saving in papermaking through filler addition," Indust. Eng. Chem. Res. 47(21), 8430-8435. DOI: 10.1021/ie8011159

Ekstrand, E. M., Larsson, M., Truong, X. B., Cardell, L., Borgstrom, Y., Bjorn, A., Ejlertsson, J., Svensson, B. H., Nilsson, F., and Karlsson, A. (2013). "Methane potentials of the Swedish pulp and paper industry - A screening of wastewater effluents," Appl. Energy 112, 507-517. DOI: 10.1016/j.apenergy.2012.12.072

Empie, H. J. (2009). Fundamentals of the Kraft Recovery Process, TAPPI Press, Atlanta.

Erixon, M., and Bjorklund, P. (2017). "Steam exploded pellets made from bark and residues - A new possible value stream for the pulp and paper industry," APPITA $J$. 71(3), 236-241.

Esteves Costa, C. A. E., Pinto, P. C. R., and Rodrigues, A. E. (2018). "Lignin fractionation from $E$. globulus kraft liquor by ultrafiltration in a three stage membrane sequence," Separ. Purif. Technol. 192, 140-151. DOI: 10.1016/j.seppur.2017.09.066

Fardim, P., and Duran, N. (2003). "Modification of fibre surfaces during pulping and refining as analysed by SEM, XPS and ToF-SIMS," Colloids Surf. A-Physicochem. Eng. Aspects 223, 263-276. DOI: 10.1016/S0927-7757(03)00149-3

Farla, J., Blok, K., and Schipper, L. (1997). "Energy efficiency developments in the pulp and paper industry: A cross-country comparison using physical production data," Energy Policy 25, 745-758. DOI: 10.1016/S0301-4215(97)00065-7

Finnveden, G., Johansson, J., Lind, P., and Moberg, A. (2005). "Life cycle assessment of energy from solid waste - Part 1: General methodology and results," J. Cleaner Prod. 13(3), 213-229. DOI: 10.1016/j.jclepro.2004.02.023

Fleiter, T., Fehrenbach, D., Worrell, E., and Eichhammer, W. (2012). "Energy efficiency in the German pulp and paper industry - A model-based assessment of saving potentials," Energy 40(1), 84-99. DOI: 10.1016/j.energy.2012.02.025

Francey, S., Tran, H., and Berglin, N. (2011). "Global survey on lime kiln operation, energy consumption, and alternative fuel usage," TAPPI J. 10(8), 19-26. DOI: 10.32964/TJ10.8.19

Garvin, S. P., and Pantaleo, P. F. (1970). "Measurements and evaluation of dryer section performance," TAPPI Engineering Conf., Book 2, pp. 125-133.

Gaudreault, C., Samson, R., and Stuart, P. R. (2010). "Energy decision making in a pulp and paper mill: Selection of LCA system boundary," Int. J. Life Cycle Assess. 15(2), 198-211. DOI: 10.1007/s11367-009-0125-1 
Gavrileseu, D. (2008). "Energy from biomass in pulp and paper mills," Environ. Eng. Manag. J. 7(5), 537-546. DOI: 10.30638/eemj.2008.077

Gharehkhani, S., Sadeghinezhad, E., Kazi, S. N., Yarmand, H., Badarudin, A., Safaei, M. R., and Zubir, M. N. M. (2015). "Basic effects of pulp refining on fiber properties - A review," Carbohydr. Polym. 115, 785-803. DOI: 10.1016/j.carbpol.2014.08.047

Gherghel, A., Teodosiu, C., and De Gisi, S. (2019). "A review on wastewater sludge valorisation and its challenges in the context of circular economy," J. Cleaner Production 228, 244-263. DOI: 10.1016/j.jclepro.2019.04.240

Gilbreath, K. R. (2019). "Pulp mill energy audit pays off," Paper 360 2019(July/Aug.).

Gong, M. (2005). "Exergy analysis of a pulp and paper mill," Int. J. Energy Res. 29(1), 79-93. DOI: $10.1002 / \mathrm{er} .1041$

Gregory, J. (1976). "The effect of cationic polymers on the colloidal stability of latex particles," J. Colloid Interface Sci. 55(1), 35-44. DOI:10.1016/0021-9797(76)90006-0

Grønli, M. (2021). "Solid fuel characterization," http://web.abo.fi

Gruber, E., Gelbrich, M., and Schempp, W. (1997). "Morphological and chemical effects on drainage," Wochbl. Papierfabr. 125(2), 66-72.

Hamaguchi, M., Kautto, J., and Vakkilainen, E. (2013). "Effects of hemicellulose extraction on the kraft pulp mill operation and energy use: Review and case study with lignin removal," Chem. Eng. Res. Design 91(7), 1284-1291. DOI:

10.1016/j.cherd.2013.02.006

Hamm, U., and Gottsching, L. (1998). "Wet oxidation of deinking sludges," Wochenblatt fur Papierfabrikation 126(1), 15-23.

Hart, P. W. (2011). "The chemical versus energy cost tug of war: A pulp mill perspective," TAPPI J. 10(7), 37-42. DOI: 10.32964/tj10.7.37

Hart, P. W. (2020a). “Alternative 'green' lime kiln fuels: Part I - Pulping/recovery byproducts, TAPPI J. 19(5), 263-269. DOI: 10.32964/TJ19.5.263

Hart, P. W. (2020b). “Alternative 'green' lime kiln fuels: Part II - Woody biomass, biooils, gasification, and hydrogen," TAPPI J. 19(5), 271-279. DOI: 10.32964/TJ19.5.271

Hart, P. W., Waite, D. M., Thibault, L., Tomashek, J., Rousseau, M. E., Hill, C., and Sabourin, M. J. (2009). "Refining energy reduction and pulp characteristic modification of alkaline peroxide mechanical pulp (APMP) through enzyme application," TAPPI J. 8(5), 19-25. DOI: 10.32964/TJ8.5.19

Herrmann-Heber, R., Reinecke, S. F., and Hampel, U. (2020). "Dynamic aeration for improved oxygen mass transfer in the wastewater treatment process," Chem. Eng. J. 386, article no. 122068. DOI: 10.1016/j.cej.2019.122068

Hii, C., Gregersen, O. W., Chinga-Carrasco, G., Eriksen, O., and Toven, K. (2012). "The web structure in relation to the furnish composition and shoe press pulse profiles during wet pressing," Nordic Pulp Paper Res. J. 27(4), 798-805. DOI: 10.3183/npprj2012-27-04-p798-805

Hinds, G. R., Mussoline, W., Casimir, L., Dick, G., Yeh, D. H., and Ergas, S. J. (2016). "Enhanced methane yields in high-solids anaerobic digestion through inoculation with pulp and paper mill sludge," Environ. Eng. Sci. 33(11), 907-917. DOI: 10.1089/ees.2016.0129

Holmberg, J. M., and Gustavsson, L. (2007). "Biomass use in chemical and mechanical pulping with biomass-based energy supply," Resour. Conserv. Recyc. 52(2), 331-350. DOI: 10.1016/j.resconrec.2007.05.002 
Holmberg, K., Siilasto, R., Laitinen, T., Andersson, P., and Jasberg, A. (2013). "Global energy consumption due to friction in paper machines," Tribol. Int. 62, 58-77. DOI: 10.1016/j.triboint.2013.02.003

Hong, G. B., Ma, C. M., Chen, H. W., Chuang, K. J., Chang, C. T., and Su, T. L. (2011). "Energy flow analysis in pulp and paper industry," Energy 36(5), 3063-3068. DOI: 10.1016/j.energy.2011.02.051

Hubbe, M. A. (2005). "Microparticle programs for drainage and retention," in Rodriguez, J. M. (ed.), Micro and Nanoparticles in Papermaking, TAPPI Press, Atlanta, Chapter $1,1-36$.

Hubbe, M., Alén, R., Paleologou, M., Kannangara, M., and Kihlman, J. (2019). "Lignin recovery from spent alkaline pulping liquors using acidification, membrane separation, and related processing steps: A Review," BioResources 14(1), 23002351. DOI: 10.15376/biores.14.1.2300-2351

Hubbe, M. A., Becheleni, E. M. A., Lewis, A. E., Peters, E. M., Gan, W., Nong, G., Mandal, S., and Shi, S. Q. (2018a). "Recovery of inorganic compounds from spent alkaline pulping liquor by eutectic freeze crystallization and supporting unit operations: A Review," BioResources 13(4), 9180-9219. DOI: 10.15376/biores.13.4.Hubbe

Hubbe, M. A., and Dölle, K. (2018). "Drainage strategies and micro- or nanoparticle systems," in: Advances in Papermaking Wet End Chemistry Application Technologies, M. A. Hubbe and S. Rosencrance (eds.), TAPPI Press, Atlanta, Chapter 8, pp. 185-206.

Hubbe, M. A., and Gill, R. A. (2016). "Fillers for papermaking: A review of their properties, usage practices, and their mechanistic role," BioResources 11(1), 28862963. DOI: 10.15376/biores.11.1.2886-2963

Hubbe, M. A., and Heitmann, J. A. (2007). "Review of factors affecting the release of water from cellulosic fibers during paper manufacture," BioResources 2(3), 500-533. DOI: 10.15376/biores.2.3.500-533

Hubbe, M. A., and King, K. (2009). Cost-saving Strategies in Papermaking Chemistry, TAPPI Press, Atlanta, 237 pp.

Hubbe, M. A., Metts, J. R., Hermosilla, D., Blanco, M. A., Yerushalmi, L., Haghighat, F., Lindholm-Lehto, P., Khodaparast, Z., Kamali, M., and Elliott, A. (2016).

"Wastewater treatment and reclamation: A review of pulp and paper industry practices and opportunities," BioResources 11(3), 7953-8091. DOI:

10.15376/biores.11.3.Hubbe

Hubbe, M. A., Nazhad, M., and Sánchez, C. (2010). "Composting as a way to convert cellulosic biomass and organic waste into high-value soil amendments: A review," BioResources 5(4), 2808-2854. DOI: 10.15376/biores.5.4.2808-2854

Hubbe, M. A., Powell, J. S., and Delozier, G. (2018b). "Enzymatic technology for wetend implementation," in: Advances in Papermaking Wet End Chemistry Application Technologies, TAPPI Press, Atlanta, Ch. 12, p. 269.

Hubbe, M. A., Sjöstrand, B., Nilsson, L., Kopponen, A., and McDonald, J. D. (2020). "Rate-limiting mechanisms of water removal during the formation, vacuum dewatering, and wet-pressing of paper webs: A review," BioResources 15(4), 96729755. DOI: 10.15376/biores. 15.4.Hubbe

Humpert, D., Ebrahimi, M., and Czermak, P. (2016). "Membrane technology for the recovery of lignin: A review," Membranes 6(3), article no. 42. DOI: 10.3390/membranes6030042 
IPCC (1996). "Climate change 1995: Impacts, adaptation and mitigation of climate change: Scientific-technical analysis. Contribution of working group II to the Second assessment report of the Intergovernmental Panel Climate Change (IPCC). R. T. Watson, M. C. Zinoyowera, and R. H. Moss (eds.), Cambridge University Press, Cambridge, UK.

Jarvensivu, M., Saari, K., and Jamsa-Jounela, S. L. (2001). "Intelligent control system of an industrial lime kiln process," Control Eng. Practice 9(6), 589-606. DOI: 10.1016/S0967-0661(01)00017-X

Jin, W., Tolba, R., Wen, J. L., Li, K. C., and Chen, A. C. (2013). "Efficient extraction of lignin from black liquor via a novel membrane-assisted electrochemical approach," Electrochimica Acta 107, 611-618. DOI: 10.1016/j.electacta.2013.06.031

Joelsson, J. M., and Gustavsson, L. (2008). " $\mathrm{CO}_{2}$ emission and oil use reduction through black liquor gasification and energy efficiency in pulp and paper industry," Resources, Conservation and Recycling 52(5), article no. 747e63. DOI: 10.1016/j.resconrec.2007.11.002

Johal, S., Yuen, B., and Watson, P. (2006). "The effects of species on the thermomechanical pulping of balsam fir, black spruce, red spruce, and white spruce," Pulp Paper Canada 107(7/8), 41-45.

Johansson, A. (1982). "By-product recovery and valorization in the kraft industry - A review of current trends in the recovery and use of turpentine and tall oil derivatives," Biomass 2(2), 103-113. DOI: 10.1016/0144-4565(82)90020-8

Johansson, B., Mjöberg, J., Sandström, P., and Teder, A. (1984). "Modified continuous kraft pulping - Now a reality," Svensk Papperstidning - Nordisk Cellulosa 87(10), 30-35.

Johansson, L., Hill, J., Gorski, D., and Axelsson, P. (2011). "Improvement of energy efficiency in TMP refining by selective wood disintegration and targeted application of chemicals," Nordic Pulp Paper Res. J. 26(1), 31-46. DOI: 10.3183/npprj-2011-2601-p031-046

Johnston, J. H., Milestone, C. B., Northcote, P. T., and Wiseman, N. (2000). "The alkaline digestion of reject fibre in deinking sludge as a precursor to filler recovery by wet air oxidation," APPITA J. 53(1), 54-58.

Karlsson, M. (ed). (2000). Papermaking. Part 2, Drying, Fapet Oy, Helsinki, Finland, TAPPI Press, Atlanta.

Keller, D. S. (2018). "Paper drying in the manufacturing process," in: Paper and Water, $2^{\text {nd }}$ Revised and Enlarged Ed., Anton Siegl Fachbuchhandlung GmbH.

Kerekes, R. J. (2005). “Characterizing refining action in PFI mills," TAPPI J. 4(3), 9-14.

Kerekes, R. J. (2010). "Energy and forces in refining," J. Pulp Paper Sci. 36, 10-15.

Khan, A. A., de Jong, W., Jansens, P. J., and Spliethoff, H. (2009). "Biomass combustion in fluidized bed boilers: Potential problems and remedies," Fuel Proc. Technol. 90(1), 21-50. DOI: 10.1016/j.fuproc.2008.07.012

Khanam, S., and Mohanty, B. (2010). "Energy reduction schemes for multiple effect evaporator systems," Appl. Energy 87(4), 1102-1111. DOI:

10.1016/j.apenergy.2009.05.003

Kim, H. J., Jo, B. M., and Lee, S. H. (2006). "Potential for energy saving in refining of cellulase-treated kraft pulp," J. Indust. Eng. Chem. 12(4), 578-583.

Klass, C. P. (1990). "Trends and developments in size press technology," TAPPI J. 73(12), 69-75. 
Kohl, C., Lex, R., Sommer, H., ter Veer, B. C. A., and Wanzek, C. (1999). "Replacing the size press by the metered size press - Its economic end quality aspects," Wochenblatt fur Papierfabrikation 127(6), 394-396.

Koleff, A. M. (1998). "Energy efficiency in the US pulp and paper industry - Impacts on greenhouse gas emissions," Proc. International Environmental Conference \& Exhibit, TAPPI, pp. 237-244.

Kong, L. B., Hasanbeigi, A., and Price, L. (2016). "Assessment of emerging energyefficiency technologies for the pulp and paper industry: A technical review," $J$. Cleaner Produc. 122, 5-28. DOI: 10.1016/j.jclepro.2015.12.116

Koufos, D., and Retsina, T. (2001). "Practical energy and water management through pinch analysis for the pulp and paper industry," Water Sci. Technol. 43(2), 327-332. DOI: 10.2166/wst.2001.0107

Kouisni, L., Holt-Hindle, P., Maki, K., and Paleologou, M. (2012). "The Lignoforce system (TM): A new process for the production of high-quality lignin from black liquor," J-FOR-J. Sci. Technol. For. Prod. Proc. 2(4), 6-10.

Krook, R., Hollmark, H., and Stenström, S. (1996). "Some effects of press drying on paper properties," Nordic Pulp Pap. Res. J. 11(3), 141-151. DOI: 10.3183/npprj1996-11-03-p141-145

Kuokkanen, M., Vilppo, T., Kuokkanen, T., Stoor, T., and Niinimaki, J. (2011). "Additives in wood pellet production - A pilot-scale study of binding agent usage," BioResources 6(4), 4331-4355.

Laine, C., Wang, X. S., Tenkanen, M., and Varhimo, A. (2004). "Changes in the fiber wall during refining of bleached pine kraft pulp," Holzforschung 58(3), 233-240. DOI: $10.1515 /$ HF.2004.036

Langdon, E. (1991). "Advances in hot pressing technology," APPITA J. 44(4), 245-246.

Laurijssen, J., De Gram, F. J., Worrell, E., and Faaij, A. (2010a). "Optimizing the energy efficiency of conventional multi-cylinder dryers in the paper industry," Energy 35(9), 3738-3750. DOI: 10.1016/j.energy.2010.05.023

Laurijssen, J., Marsidi, M., Westenbroek, A., Worrell, E., and Faaij, A. (2010b). "Paper and biomass for energy? The impact of paper recycling on energy and $\mathrm{CO}_{2}$ emissions," Recour. Conserv. Recyc. 54(12), 1208-1218. DOI: 10.1016/j.resconrec.2010.03.016

Lawrence, A., Thollander, P., and Karlsson, M. (2018). "Drivers, barriers, and success factors for improving energy management in the pulp and paper industry," Sustain. 10, article no. 1851. DOI: 10.3390/su10061851

Lecourt, M., Meyer, V., Sigoillot, J. C., and Petit-Conil, M. (2010). “Energy reduction of refining by cellulases," Holzforschung 64(4), 441-446. DOI: 10.1515/HF.2010.066

Lee, H. S., Carr, W. W., Beckham, H. W., and Leisen, J. (2002). "A model of through-air drying of tufted textile materials," Int. J. Heat Mass Trans. 45(2), 357-366. DOI: 10.1016/S0017-9310(01)00130-2

Lee, S. Y., Hubbe, M. A., and Saka, S. (2006). "Prospects for biodiesel as a byproduct of wood pulping - A review," BioResources 1(1), 150-171. DOI: 10.15376/biores.1.1.150-171

Lehtikangas, P. (2001). "Quality properties of pelletised sawdust, logging residues and bark," Biomass Bioenergy 20(5), 351-360. DOI: 10.1016/S0961-9534(00)00092-1

Lehtinen, E. (ed.) (2000). Pigment Coating and Surface Sizing of Paper, Fapet Oy, Helsinki, Finland, TAPPI, Atlanta, GA, USA. 
Lelieveld, J., Crutzen, P. J., and Dentener, F. J. (1998). "Changing concentration, lifetime and climate forcing of atmospheric methane," Tessus Ser. B-Chem. Phys. Meteorol. 50(2), 128-150. DOI: 10.1034/j.1600-0889.1998.t01-1-00002.x

Li, W. W., Siddhu, M. A. H., Amin, F. R., He, Y. F., Zhang, R. H., Liu, G. Q., and Chen, C. (2018). "Methane production through anaerobic co-digestion of sheep dung and waste paper," Energy Conver. Manag. 156, 279-287. DOI: 10.1016/j.enconman.2017.08.002

Liew, Y. X., Chan, Y. J., Manickam, S., Chong, M. F., Chong, S., Tiong, T. J., Lim, J. W., and Pan, G. T. (2020). "Enzymatic pretreatment to enhance anaerobic bioconversion of high strength wastewater to biogas: A review," Science Total Environ. 713, article no. 136373. DOI: 10.1016/j.scitotenv.2019.136373

Linderoth, C. E. (1986). "Why dry hog fuel?" Pulp Paper Can. 87(6), 103-106.

Lindqvist, S. (1980). "Flakt float dryers, the flexible drying system," British Paper and Board Industry Federation (BPBIF), 24 pp., Nov. 19-20, 1980; Conference: BPBIF

Lindström, T. (1989). "Some fundamental chemical aspects of paper forming," in Fundamentals of Papermaking, Trans. ${ }^{\text {th }}$ Fund. Res. Symp., Cambridge, C. F. Baker and V. W. Punton (eds.), Mechanical Engineering Publ., Ltd., London, 311-412.

Luis, P., and Van der Bruggen, B. (2014). "Exergy analysis of energy-intensive production processes: Advancing towards a sustainable chemical industry," J. Chem. Technol. Biotech. 89(9), 1288-1303. DOI: 10.1002/jctb.4422

Lundberg, V., Bood, J., Nilsson, L., Axelsson, E., Berntsson, T., and Svensson, E. (2014). "Converting a kraft pulp mill into a multi-product biorefinery: Technoeconomic analysis of a case mill," Clean Technol. Environ. Policy 16(7), 1411-1422. DOI: $10.1007 / \mathrm{s} 10098-014-071-8$

Ma, X. T., Shen, X. X., Qi, C. C., Ye, L. P., Yang, D. L., and Hong, J. L. (2018). "Energy and carbon coupled water footprint analysis for kraft wood pulp paper production," Renew. Sustain. Energy Rev. 96, 253-261. DOI: 10.1016/j.rser.2018.07.054

MacCallum, C. (1983). "Controlled combustion-zone firing of hogged fuel in new and retrofit boiler applications," TAPPI J. 66(9), 111-114.

MacLeod, M. (2007). "The top ten factors in kraft pulp yield," Paperi Puu 89(4), 1-7.

MacLeod, M., Dougall, I., and Fowler, L. (2010). "Thinking inside the box: How the tensile strength of kraft pulp changes on pulp drying machines," APPITA J. 63(2), 108-112, 130.

Mahmood, T., and Elliott, A. (2006). "A review of secondary sludge reduction technologies for the pulp and paper industry," Water Res. 40(11), 2093-2112. DOI: 10.1016/j.watres.2006.04.001

Man, Y., Han, Y. L., Li, J. G., and Hong, M. N. (2019). "Review of energy consumption research for papermaking industry based on life cycle analysis," Chinese J. Chem. Eng. 27(7), 1543-1553. DOI: 10.1016/j.cjche.2018.08.017

Man, Y., Shen, W. H., Chen, X. Q., Long, Z., and Corriou, J. P. (2018). “Dissolved oxygen control strategies for the industrial sequencing batch reactor of the wastewater treatment process in the papermaking industry," Environ. Sci. - Water Res. Technol. 4(5), 654-662. DOI: 10.1039/c8ew00035b

Manorma, Ferreira, I., Alves, P., Gil, M. H., and Gando-Ferreira, L. M., (2021). "Lignin separation from black liquor by mixed matrix polysulfone nanofiltration membrane filled with multiwalled carbon nanotubes," Separ. Purif. Technol. 260, article no. 118231. DOI: 10.1016/j.seppur.2020.118231 
Mao, C. L., Feng, Y. Z., Wang, X. J., and Ren, G. X. (2015). "Review on research achievements of biogas from anaerobic digestion," Renew. Sustain. Energy Rev. 45, 540-555. DOI: 10.1016/j.rser.2015.02.032

Marinova, M., Mateos-Espejel, E., Jemaa, N., and Paris, J. (2009). “Addressing the increased energy demand of a kraft mill biorefinery: The hemicellulose extraction case," Chem. Eng. Res. Design 87(9A), 1269-1275. DOI:

10.1016/j.cherd.2009.04.017

Marshman, D. J., Chmelyk, T., Sidhu, M. S., Gopaluni, R. B., and Dumont, G. A. (2010). "Energy optimization in a pulp and paper mill cogeneration facility," Applied Energy 87(11), 3514-3525. DOI: 10.1016/j.apenergy.2010.04.023

Martin-Gamboa, M., Marques, P., Freire, F., Arroja, L., and Dias, A. C. (2020). "Life cycle assessment of biomass pellets: A review of methodological choices and results," Renew. Sustain. Energy Rev. 133, article no. 110278. DOI: 10.1016/j.rser.2020.110278

Martinez, D. M., and Kerekes, R. J. (1994). "Forces on fibers in low-consistency refining," TAPPI J. 77(12), 119-123.

Martinez-Gutierrez, E. (2018). "Biogas production from different lignocellulosic biomass sources: Advances and perspectives," 3 Biotech 8(5), article no. 233. DOI: 10.1007/s13205-018-1257-4

Martin-Sampedro, R., Eugenio, M. E., Moreno, J. A., Revilla, E., and Villar, J. C. (2014). "Integration of a kraft pulping mill into a forest biorefinery: Pre-extraction of hemicellulose by steam explosion versus steam treatment," Bioresour. Technol. 153, 236-244. DOI: 10.1016/j.biortech.2013.11.088

Matúš, M., Križan, P., Šooš, L., and Beniak, J. (2018). "The effect of papermaking sludge as an additive to biomass pellets on the final quality of the fuel," Fuel 219, 196-204. DOI: 10.1016/j.fuel.2018.01.089

McCabe, W. L., Smith, J. C., and Harriott, P. (2001). "Drying of solids," in: Unit Operations of Chemical Engineering, Sixth Ed., McGraw Hill, Boston, Chapter 24, pp. 773-811.

McCoy, M. (2000). "Tall (oil) tale of pine chemicals," Chem. Eng. News 78(13), 13-15. DOI: 10.1021/cen-v078n042.p013

McDermott, R. J., Morris, K. W., and Sanderson, J. G. (1981). "Better boiler for wet hog fuel," Pulp Paper Canada 82(6), 133-135, 137-138.

McDonald, J. D. (2020). "Wet pressing and product quality: Review of previous pilot machine trials," TAPPI J. 19(7), 369-374. DOI: 10.32964/TJ19.7.369

McDonald, J. D., and Kerekes, R. J. (2017). "Estimating limits of wet pressing on paper machines," TAPPI J. 16(2), 81-87. DOI: 10.32964/TJ16.2.81

McDonald, J. D., and Kerekes, R. J. (2018). "Rewet in wet pressing of paper," TAPPI J. 17(9), 479-487. DOI: 10.32964/TJ17.09.479

McDonald, D., Miles, K., and Amiri, R. (2004). "The nature of the mechanical pulping process," Pulp Paper - Canada 105(8), 27-32.

Merrild, H., Damgaard, A., and Christensen, T. H. (2008). "Life cycle assessment of waste paper management: The importance of technology data and system boundaries in assessing recycling and incineration," Resour. Conserv. Recyc. 52(12), 1391-1398. DOI: 10.1016/j.resconrec.2008.08.004

Michell, A. J. (1984). "Press drying of paper - An overview," APPITA 37(4), 325-329.

Miles, K. B., May, W. D., and Karnis, A. (1991). "Refining intensity, energyconsumption, and pulp quality in 2-stage chip refining," TAPPI J. 74(3), 221-230. 
Miller, M., Luukkonen, A., and Olson, J. A. (2017). "Effect of LC refining intensity on fractionated and unfractionated mechanical pulp," Nordic Pulp Paper Res. J. 32(3), 386-394. DOI: 10.3183/npprj-2017-32-03-p386-394

Miranda, T., Montero, I., Sepulveda, F. J., Arranz, J. I., Rojas, C. V., and Nogales, S. (2015). "A review of pellets from different sources," Materials 8(4), 1413-1427. DOI: $10.3390 / \mathrm{ma} 8041413$

Mobini, M., Sowlati, T., and Sokhansanj, S. (2013). "A simulation model for the design and analysis of wood pellet supply chains," Appl. Energy 111, 1239-1249. DOI: 10.1016/j.apenergy.2013.06.026

Mohammadi, A., Sandberg, M., Venkatesh, G., Eskandari, S., Dalgaard, T., Joseph, S., and Granstrom, K. (2019). "Environmental performance of end-of-life handling alternatives for paper-and-pulp-mill sludge: Using digestate as a source of energy or for biochar production," Energy 182, 594-605. DOI: 10.1016/j.energy.2019.06.065

Mohlin, U. B. (1997). "Fibre development during mechanical pulp refining," J. Pulp Paper Sci. 23(1), J28-J33.

Molino, A., Chianese, S., and Musmarra, D. (2016). "Biomass gasification technology: The state of the art overview," J. Energy Chem. 25(1), 10-25. DOI: 10.1016/j.jechem.2015.11.005

Mollersten, K., Gao, L., Yan, J. Y., and Obersteiner, M. (2004). "Efficient energy systems with $\mathrm{CO}_{2}$ capture and storage from renewable biomass in pulp and paper mills," Renew. Energy 29(9), 1583-1598. DOI: 10.1016/j.renene.2004.01.003

Moshkelani, M., Marinova, M., Perrier, M., and Paris, J. (2013). "The forest biorefinery and its implementation in the pulp and paper industry: Energy overview," Appl. Thermal Eng. 50(2), 1427-1436. DOI: 10.1016/j.applthermaleng.2011.12.038

Mostafa, M. E., Hu, S., Wang, Y., Su, S., Hu, X., Elsayed, S. A., and Xiang, J. (2019). "The significance of pelletization operating conditions: An analysis of physical and mechanical characteristics as well as energy consumption of biomass pellets," Renew. Sustain Energy Rev. 105, 332-348. DOI: 10.1016/j.rser.2019.01.053

Mussoline, W., Esposito, G., Lens, P., Spagni, A., and Giordano, A. (2013). "Enhanced methane production from rice straw co-digested with anaerobic sludge from pulp and paper mill treatment process," Bioresour. Technol. 148, 135-143. DOI: 10.1016/j.biortech.2013.08.107

Naqvi, M., Yan, J., and Dahlquist, E. (2010). "Black liquor gasification integrated in pulp and paper mills: A critical review," Bioresource Technology 101(21), 8001-8015. DOI: 10.1016/j.biortech.2010.05.013

Nelson, L., Park, S., and Hubbe, M. A. (2018). "Thermal depolymerization of biomass with emphasis on gasifier design and best method for catalytic hot gas conditioning," BioResources 13(2), 4630-4727. DOI: 10.15376/biores.13.2.Nelson

Neshat, S. A., Mohammadi, M., Najafpour, G. D., and Lahijani, P. (2017). "Anaerobic co-digestion of animal manures and lignocellulosic residues as a potent approach for sustainable biogas production," Renew. Sustain. Energy Rev. 79, 308-322. DOI: 10.1016/j.rser.2017.05.137

Nosek, R., Holubcik, M., Jandacka, J., and Radacovska, L. (2017). “Analysis of paper sludge pellets for energy utilization," BioResources 12(4), 7032-7040. DOI: 10.15376/biores. 12.4.7032-7040

Obando, J., Cadavid, Y., and Amell, A. (2015). "Theoretical, experimental and numerical study of infrared radiation heat transfer in a drying furnace," Appl. Thermal Eng. 90, 395-402. DOI: 10.1016/j.applthermaleng.2015.06.087 
Ocko, I. B., Naik, V., and Paynter, D. (2018). "Rapid and reliable assessment of methane impacts on climate," Atmos. Chem. Phys. 18(21), 15555-15568. DOI: 10.5194/acp18-15555-2018

Oksanen, T., Buchert, J., and Viikari, L. (1997). "The role of hemicelluloses in the hornification of bleached kraft pulps," Holzforschung 51(4), 355-360. DOI: 10.1515/hfsg.1997.51.4.355

Paulapuro, H. (ed.) (2000). Papermaking. Part 1. Stock Preparation and Wet End, Fapet Oy, Helsinki, Finland; TAPPI Press, Atlanta.

Paulapuro, H., and Nordman, L. (1991). "Wet pressing: History and future trends," Pulp Paper Can. 92(1), 41-44, 47-50; T1-T8.

Peng, L. H., Zeng, X. L., Wang, Y. J., and Hong, G. B. (2015). "Analysis of energy efficiency and carbon dioxide reduction in the Chinese pulp and paper industry," Energy Policy 80, 65-75. DOI: 10.1016/j.enpol.2015.01.028

Persson, J., and Bertsson, T. (2009). "Influence of seasonal variations on energy-saving opportunities in a pulp mill," Energy 34(10), 1705-1714. DOI:

10.1016/j.energy.2009.07.023

Philp, R. J., and Azarniouch, M. K. (1984). "Wood residues as fuel source for lime kilns Phase II: Pilot kiln trials," Pulp Paper Canada 85(12), 114-116.

Picchio, R., Latterini, F., Venanzi, R., Stefanoni, W., Suardi, A., Tocci, D., and Pari, L. (2020). "Pellet production from woody and non-woody feedstocks: A review on biomass quality evaluation," Energies 13(11), article no. 2937. DOI: 10.3390/en13112937

Precci Lopes, A. D., Silva, C. M., Rosa, A. P., and Rodrigues, F. D. (2018). “Biogas production from thermophilic anaerobic digestion of kraft pulp mill sludge," Renew. Energy 124, 40-49. DOI: 10.1016/j.renene.2017.08.044

Ramos, V. F., Pinheiro, O. S., da Costa, E. F., and da Costa, A. O. S. (2019). "A method for exergetic analysis of a real kraft biomass boiler," Energy 183, 946-957. DOI: 10.1016/j.energy.2019.07.001

Rao, P. V., Baral, S. S., Dey, R., and Mutnuri, S. (2010). "Biogas generation potential by anaerobic digestion for sustainable energy development in India," Renew. Sustain. Energy Rev. 14(7), 2086-2094. DOI: 10.1016/j.rser.2010.03.031

Raskin, N., Palonen, J., and Nieminen, J. (2001). "Power boiler fuel augmentation with a biomass fired atmospheric circulating fluid-bed gasifier," Biomass Bioenergy 20(6), 471-481. DOI: 10.1016/S0961-9534(00)00056-8

Reese, D. (2005). "Low-cost dryer upgrade opportunities offer efficiency gains, energy saving," Pulp Pap. 79(3), 54-58.

Reese, J. R. (1988). "High humidity hoods conserve energy and improve runnability, TAPPI Engineering Conference, p. 653.

Reese, R. (2018). "Practical strategies to reduce pulp and paper mill energy use," Paper 3602018 (July/Aug.).

Reese, R., and Deodar, S. (2018). "Using common sense and emerging technologies to reduce energy use," PaperCon 2018, Technical Association of the Pulp and Paper Industry (TAPPI), Vol. 2, pp. 970-982.

Reese, R., Gilbreath, D., and Fochs, J. (2020). "Total pulp and paper mill energy evaluations," PEERS/IBBC Virtual Conference 2020, pp. 636-646,

Rinaldi, R., Jastrzebski, R., Clough, M. T., Ralph, J., Kennema, M., Bruijnincx, P. C. A., and Weckhuysen, B. M. (2016). "Paving the way for lignin valorisation: Recent 
advances in bioengineering, biorefining and catalysis," Angew. Chemie - Int. Ed. 55(29), 8164-8215. DOI: 10.1002/anie.201510351

Robert, D. R., Bardet, M., Gellerstedt, B., and Lindfords, E.-L. (1984). "Structural changes in lignin during kraft cooking. 3. On the structure of dissolved lignins," $J$. Wood Chem. Technol. 4(3), 239-263. DOI: 10.1080/02773818408070647

Rodriguez, C., Alaswad, A., El-Hassan, A., and Olabi, A. G. (2017). "Mechanical pretreatment of waste paper for biogas production," Waste Manag. 68, 157-164. DOI: 10.1016/j.wasman.2017.06.040

Rogers, J. G., Cooper, S. J., and Norman, J. B. (2018). "Uses of industrial energy benchmarking with reference to the pulp and paper industries," Renew. Sustain. Energy Rev. 95, 23-37. DOI: 10.1016/j.rser.2018.06.019

Roy, M. M., Islam, M. S., and Alam, M. N. (2021). "Biodiesel from crude tall oil and its NOx and aldehydes emissions in a diesel engine fueled by biodiesel-diesel blends with water emulsions," Processes 9(1), article no. 126. DOI: 10.3390/pr9010126

Russell, D. L. (2019). Practical Wastewater Treatment, Wiley, Hoboken, NJ, USA.

Ryan, M., Modak, A., Zuo, H., Ramaswamy, S., and Worry, G. (2003). "Through air drying," Drying Tech. 21(4), 719-734. DOI: 10.1081/DRT-120019059

Sabourin, M., Xu, E., Cort, B., Boileau, I., and Waller, A. (1997). "Optimizing residence time, temperature and speed to improve TMP pulp properties and reduce energy," Pulp Paper Canada 98(4), 38-45.

Saidur, R., Abdelaziz, E. A., Demirbas, A., Hossain, M. S., and Mekhilef, S. (2011). "A review on biomass as a fuel for boilers," Renew. Sustain Energy Rev. 15(5), 22622289. DOI: 10.1016/j.rser.2011.02.015

Sain, M. M., Marchildon, L., Daneault, C., Pendault, C., and Robard, S. (1995). "Infrared energy - Transfer mechanism in constant and falling rate periods of paper drying," APPITA J. 48, 351-357.

Sandberg, C., Berg, J. E., and Engstrand, P. (2019). "Low consistence refining combined with screen fractionation: Reduction of mechanical pulping process complexity," BioResources 14(1), 882-894.

Sandberg, C., Hill, J., and Jackson, M. (2020). "On the development of the refiner mechanical pulping process - A review," Nordic Pulp Paper Res. J. 35(1), 1-17. DOI: 10.1515/npprj-2019-0083

Sarimveis, H. K., Angelou, A. S., Retsina, T. R., Rutherford, S. R., and Bafas, G. V. (2008). "Optimal energy management in pulp and paper mills," Energy Convers. Manag. 44(10), 1707-1718. DOI: 10.1016/S0196-8904(02)00165-6

Savulescu, L. E., and Alva-Argaez, A. (2008). "Direct heat transfer considerations for improving energy efficiency in pulp and paper kraft mills," Energy 33(10), 15621571. DOI: 10.1016/j.energy.2008.07.015

Sayegh, N. N., Azarniouch, M. K., and Prahacs, S. (1983). "Evaluation of infrared moisture analyzers for hog fuel," Pulp Paper Canada 84(4), 35-39.

Servaes, K., Varhimo, A., Dubreuil, M., Bulut, M., Vandezande, P., Siika-aho, M., Sirvio, J., Kruus, K., Porto-Carrero, W., and Bongers, B. (2017). "Purification and concentration of lignin form the spent liquor of the alkaline oxidation of woody biomass through membrane separation technology," Indust. Crops Prod. 106, 86-96. DOI: 10.1016/j.indcrop.2016.10.005

Sherlaw, L. A. (1980). "How to reduce energy consumption in a paper machine dryer section," Pulp Paper 54(1), 160-163. 
Sibiya, N. T., Muzenda, E., and Mbohwa, C. (2017). "Evaluation of potential substrates for biogas production via anaerobic digestion: A review," in: World Cong. Eng. Computer Sci. WCECS, Vol. 2, pp. 583-588.

Silva Rabelo, C. A. B., Soares, L. A., Sakamoto, I. K., and Varesche, M. B. A. (2018). "Bioconversion of cellulose into hydrogen, biogas and organic acids using microbial consortium from a pulp and paper mill wastewater treatment plant," Quimica Nova 41(2), 169-175. DOI: 10.21577/0100-4042.20170157

Sivill, L., Ahtila, P., and Taimisto, M. (2005). "Thermodynamic simulation of dryer section heat recovery in paper machines," Appl. Thermal. Eng. 25(8-9), 1273-1292. DOI: 10.1016/j.applthermaleng.2004.09.002

Smook, G. A. (1992). "Paper manufacture - Dry end operations," in: Handbook for Pulp and Paper Technologists, G. A. Smook, Angus Wilde Publ., Vancouver.

Sricharoenchaikul, V., Frederick, W. J., and Agrawal, P. (2002). "Black liquor gasification characteristics. 2. Measurement of condensable organic matter (tar) at rapid heating conditions," Indust. Eng. Chem. Res. 41(23), 5650-5658. DOI: 10.1021/ie020208o

Sricharoenchaikul, V., Frederick, W. J., and Agrawal, P. (2003). "Carbon distribution in char residue from gasification of kraft black liquor," Biomass Bioenergy 25(2), 209220. DOI: 10.1016/S0961-9534(02)00193-9

Stenström, S. (2020). "Drying of paper: A review 2000-2018," Drying Technol. 38, 825845. DOI: $10.1080 / 07373937.2019 .1596949$

Stoica, A., Sandberg, M., and Holby, O. (2009). "Energy use and recovery strategies within wastewater treatment and sludge handling at pulp and paper mills," Bioresour. Technol. 100(14), 3497-3505. DOI: 10.1016/j.biortech.2009.02.041

Sun, M. X., Wang, Y. T., Shi, L., and Klemes, J. J. (2018). "Uncovering energy use, carbon emissions and environmental burdens of pulp and paper industry: A systematic review and meta-analysis," Renew. Sustain. Energy Rev. 92, 823-833. DOI: $10.1016 /$ j.rser.2018.04.036

Sweet, R. N. (1991). “Ketchikan pulps hog-fuel-boiler energy retrofits,” TAPPI J. 74(9), 79-83.

Szabó, L., Soria, A., Forsström, J., Keränen, J. T., and Hytönen, E. (2009). “A world model of the pulp and paper industry: Demand, energy consumption and emission scenarios to 2030," Environ. Sci. Policy 12, 257-269. DOI: 10.1016/j.envsci.2009.01.011

Szikla, Z. (1991). "Role of felt in wet pressing. 2. Movement of water during the separation of paper from felt," Paperi Puu 73(2), 160-166.

Takizawa, S., Baba, Y., Tada, C., Fukuda, Y., and Nakai, Y. (2018). "Pretreatment with rumen fluid improves methane production in the anaerobic digestion of paper sludge," Waste Manag. 78, 379-384. DOI: 10.1016/j.wasman.2018.05.046

TAPPI TIP 0404-63 (2021). "Paper machine energy conservation," Technical Assoc. Pulp Paper Ind., Atlanta.

Taylor, C. J. (2011). "Drying paper: More than a choice of fabric for dryer section solutions," APPITA J. 64(4), 310-313.

Thollander, P., and Ottosson, M. (2008). "An energy efficient Swedish pulp and paper industry - Exploring barriers to and driving forces for cost-effective energy efficiency investments," Energy Effic. 1(1), 21-34. DOI: 10.1007/s12053-007-9001-7 
Thollander, P., and Ottosson, M. (2010). "Energy management practices in Swedish energy-intensive industries," J. Cleaner Produc. 18(12), 1125-1133. DOI: 10.1016/j.jclepro.2010.04.011

Tikka, P. (ed.) (2008). Chemical Pulping. Part 2, Recovery of Chemicals and Energy, book series: Papermaking Science and Technology, book 6, Paper Engineer's Assoc., Paperi ja Puu.

Timmons, D. S., Buchholz, T., and Veeneman, C. H. (2016). "Forest biomass energy: Assessing atmospheric carbon impacts by discounting future carbon flows," Global Change Biol. Bioenergy 8(3), 631-643. DOI: 10.1111/gcbb.12276

Tofani, G., de Nys, J., Cornet, I., and Tavernier, S. (2021). "Alternative filler recovery from paper waste stream," Waste Biomass Valoriz. 12(1), 503-514. DOI: 10.1007/s12649-020-01011-7

Torres, C. E., Negro, C., Fuente, E., and Blanco, A. (2012). "Enzymatic approaches in paper industry for pulp refining and biofilm control," Appl. Microbiol. Biotech. 96(2), 327-344. DOI: 10.1007/s00253-012-4345-0

Turconi, R., Boldrin, A., and Astrup, T. (2013). "Life cycle assessment (LCA) of electricity generation technologies: Overview, comparability and limitations," Renew. Sustain. Energy Rev. 28, 555-565. DOI: 10.1016/j.rser.2013.08.013

Uimonen, J. (2017). "Energy savings in paper machine vacuum system - How to utilize modern vacuum and nip dewatering technology," IPPTA: Quarterly Journal of Indian Pulp and Paper Technical Association 29(1), 67-74.

Utlu, Z., and Kincay, O. (2013). "An assessment of a pulp and paper mill through energy and exergy analyses," Energy 57, 565-573. DOI: 10.1016/j.energy.2013.05.054

Vaxelaire, J., and Olivier, J. (2006). "Conditioning for municipal sludge dewatering. From filtration compression cell tests to belt press," Drying Technol. 24(10), 1225 1233. DOI: $10.1080 / 07373930600838090$

Veluchamy, C., Raju, V. W., and Kalamdhad, A. S. (2018). "Electrohydrolysis pretreatment for enhanced methane production from lignocellulose waste pulp and paper mill sludge and its kinetics," Bioresour. Technol. 252, 52-58. DOI: 10.1016/j.biortech.2017.12.093

Verma, O. P., Manik, G., and Sethi, S. K. (2019). "A comprehensive review of renewable energy source on energy optimization of black liquor in MSE using steady and dynamic state modeling, simulation and control," Renew. Sustain. Energy Rev. 100, 90-109. DOI: 10.1016/j.rser.2018.10.002

Villanueva, A., and Wenzel, H. (2007). "Paper waste - Recycling, incineration or landfilling? A review of existing life cycle assessments," Waste Manag. 27(8), S29S46. DOI: 10.1016/j.wasman.2007.02.019

Voss, M., Ramthun, J., Tadjbach, S., Lamprecht, J. C., and Tietz, M. (2002). "Metered size press - Fluid mechanics and rheology of coating colours," Wochenblatt fur Papierfabrikation 130(11-12), 782.

Vukoje, M., and Rozic, M. (2018). "Various valorisation routes of paper intended for recycling - A review," Cellulose Chem. Technol. 52(7-8), 515-541.

Walker, K. (1990). "Advances in hot pressing technology," Tappi J. 73(8), 99-101.

Walker, P. (1977). "Dryer section energy losses and how to control them," Pulp \& Paper Canada 78(11), T260-263.

Wallmo, H., Richards, T., and Theliander, H. (2009). "An investigation of process parameters during lignin precipitation from kraft black liquors: A step towards an 
optimised precipitation operation," Nordic Pulp Paper Res. J. 24(2), 158-164. DOI: 10.3183/NPPRJ-2009-24-02-p158-164

Wang, L., Riva, L., Skreiberg, O., Khalil, R., Bartocci, P., Yang, Q., Yang, H. P., Wang, X. B., Chen, D. Y., Rudolfsson, M., and Nielsen, H. K. (2020). "Effect of torrefaction on properties of pellets produced from woody biomass," Energy Fuels 34(12), 1534315354. DOI: 10.1021/acs.energyfuels.0c02671

Wejkowski, R. (2016). “Triple-finned tubes - Increasing efficiency, decreasing $\mathrm{CO}_{2}$ pollution of a steam boiler," Energy 99, 304-314. DOI: 10.1016/j.energy.2016.01.073

Welf, E. S., Venditti, R. A., Hubbe, M. A., and Pawlak, J. (2005). "The effects of heating without water removal and drying on the swelling as measured by water retention value and degradation as measured by intrinsic viscosity of cellulose papermaking fibers," Prog. Paper Recycling 14(3), 1-9.

Wilhelmsson, B. I., McKibben, J. F., Stenstrom, S. G., and Aidun, C. K. (1995). "Condensate flow inside paper dryer cylinders," J. Pulp Paper Sci. 21(1), J1-J9.

Wising, U., Berntsson, T., and Stuart, P. (2005). "The potential for energy savings when reducing the water consumption in a kraft pulp mill," Appl. Thermal Eng. 25(7), 1057-1066. DOI: 10.1016/j.applthermaleng.2004.07.023

Wolf, A., Vidlund, A., and Andersson, E. (2006). "Energy-efficient pellet production in the forest industry - A study of obstacles and success factors," Biomass Bioenergy 30(1), 38-45. DOI: 10.1016/j.biombioe.2005.09.003

Wong, K. K. Y., and Mansfield, S. D. (1999). "Enzymatic processing for pulp and paper manufacture - A review," APPITA J. 52(6), 409-418.

Xing, R., Qi, W., and Huber, G. W. (2011). "Production of furfural and carboxylic acids from waste aqueous hemicellulose solutions from the pulp and paper and cellulosic ethanol industries," Energy Environ. Sci. 4(6), 2193-2205. DOI: 10.1039/c1ee01022k

$\mathrm{Xu}, \mathrm{C}$. B., and Lancaster, J. (2009). "Treatment of secondary sludge for energy recovery," in: Energy Recovery, E. DuBois and A. Mercier (eds.), pp. 187-212.

Xu, Y. J., Wang, J. Y., Qian, X., Zuo, L. G., and Yue, X. P. (2016). "Effects of supplementary alkali after alkaline peroxide treatment on the properties of bleached kraft pine fluff pulp," BioResources 11(1), 336-353. DOI: 10.15376/biores.11.1.336353

Yang, G. H., Lucia, L. A., Chen, J. C., Cao, X. D., and Liu, Y. (2011). "Effects of enzyme pretreatment on the beatability of fast-growing poplar APMP pulp," BioResources 6(3), 2568-2580.

Yang, Q., Wu, B., Yao, F. B., He, L., Chen, F., Ma, Y. H., Shu, X. Y., Hou, K. J., Wang, D. B., and Li, X. M. (2019). "Biogas production from anaerobic co-digestion of waste activated sludge: Co-substrates and influencing parameters," Rev. Environ. Sci.

Biotech. 18(4), 771-793. DOI: 10.1007/s11157-019-09515-y

Yerushalmi, L., Ashrafi, O., and Haghighat, F. (2013). "Reductions in greenhouse gas (GHG) generation and energy consumption in wastewater treatment plants," Water Sci. Technol. 67(5), 1159-1164. DOI: 10.2166/wst.2013.681

Yoon, S. H., and van Heiningen, A. (2008). "Kraft pulping and papermaking properties of hot-water pre-extracted loblolly pine in an integrated forest products biorefinery," TAPPI J. 7(7), 22-27.

Yuan, Z., Heitner, C., and McGarry, P. (2006). "Evaluation of the APMP process for mature and juvenile loblolly pine," TAPPI J. 5(7), 24-32.

Zaki, G. M., and Al-Turki, A. M. (2000). "Optimization of multilayer thermal insulation for pipelines,” Heat Transf. Eng. 21(4), 63-70. DOI: 10.1080/01457630050144514 
Zhao, C. X., Jiang, E. C., and Chen, A. H. (2017). "Volatile production from pyrolysis of cellulose, hemicellulose and lignin," J. Energy Inst. 90(6), 902-913. DOI: 10.1016/j.joei.2016.08.004

Zhu, W. Z., Westman, G., and Theliander, H. (2014). "Investigation and characterization of lignin precipitation in the LignoBoost process," J. Wood Chem. Technol. 34(2), 7797. DOI: $10.1080 / 02773813.2013 .838267$ 


\section{APPENDIX}

\section{Glossary of Technical Terms}

Activated sludge: Settled solids that accumulate during wastewater treatment under aerated conditions, with the understanding that some of the material is continually recirculated back to the intake of the unit operation to provide inoculation with a stable community of microorganisms

Air-impingement drying: System for evaporative removal of water from a paper web in which initially dry heated air contacts the paper, but is not forced through the paper

Alkaline peroxide mechanical pulping (APMP): System for converting wood chips into separate cellulosic fibers in which the mixture is first treated with hydrogen peroxide and $\mathrm{NaOH}$ solution before it is passed between a rotor and stator of a refiner

Anaerobic: A process carried out in the relative absence of oxygen

Ash content: The mass of mineral, in comparison to the initial dry-basis mass of a specimen, after combustion at a specified temperature and time period

Belt press: A device in which a material is squeezed between two fabric belts as a means to remove water and increase the percent solids

Benchmarking: Systematic comparison of a factory's operations with the performance of selected reference operations that are believed to represent leadership in an industry

Biomass: Lignocellulosic material, which may include wood, bark, branches, stalks, crop residues, etc.

Biorefinery: A system of processing biomass in which one or more non-cellulose components (e.g. lignin or hemicellulose) is isolated

Black liquor: Spent pulping liquor from a kraft pulping operation, usually rich in lignin byproducts, sodium sulfate, and very high $\mathrm{pH}$

Blowbox: A device that injects relatively dry air, approximately matching the temperature of other air within the pockets of a conventional dryer section on a paper machine

Blow-through steam: An excess volume of steam, beyond that which is required for condensation and transfer of heat within a dryer can, such that non-condensible gases (such as nitrogen and oxygen) do not accumulate within dryer cans

Boiler: A device in which a combustible fuel is burned and heat from the combustion is transferred to water, within metal tubes, producing steam

Carbon footprint: The computed environmental impact of a process in terms of the net amount of carbon dioxide produced per unit of production

Cellulase: An enzyme that facilitates the hydrolytic cleavage of the cellulose macromolecule into smaller units

Chemical pulping: A process, such as the kraft process, in which a mixture of chemicals works to break down and solubilize the lignin component of wood, so that 
the fibers easily can be separated from each other without mechanical damage to them

Coefficient of friction: The result of dividing the force required to move something by the perpendicular force pushing that item toward a surface

Condebelt drying: A process by which a paper sheet is dried between two continuously moving steel belts, together with plastic fabric (on the cooled side), where one of the belts is continuously heated and the other is continuously cooled

Counter-current washing: A process in which papermaking pulp is washed by passing relatively clean water through a mat of relatively clean fibers, then using the filtrate to carry out a similar operation on intermediate-clean fibers, and so on

Combustion: A process in which material is burned in the presence of sufficient oxygen to achieve relatively complete transformation into carbon dioxide

Dryer section: Part of a paper machine in which water is removed from the continuous sheet by evaporation

Economizer: Device that collects most of the usable heat from flue gas and transfers it to incoming air or water for a process

Effect (in black liquor evaporation): Unit within a system for evaporation of water from spent pulping liquor in which each successive unit in a set is run at a lower pressure

Effective heating value: The amount of enthalpy that can be generated by complete combustion of a unit amount of water-containing material, based on its dry mass

Efficiency: The amount of output, compared to a theoretical maximum output

Energy-intensive: Requiring a high amount of energy expenditure in comparison to the amount of production

Environmental impacts: Undesired changes to the surrounding natural environment, such as generation of greenhouse gases, toxic substances, noise, etc., due to the running of a specified process

Energy: A quantity of heat and ability to do work, when the fixed reference temperature is absolute zero

Enzyme: A specific protein structure in a folded conformation that is able to catalyze the breakage or assembly of covalent bonds within certain organic molecules

Exergy: A quantity of heat and ability to do work, when the fixed reference temperature is representative of the ambient (outdoor) temperature

Extended nip press: A device on a paper machine in which the wet-web of paper, while sandwiched between a pair of continuous felts, passes through a nip between a press roll and a backing having a concave shape that conforms to the roll curvature

Flue gas: Hot flow that is on its way to a smokestack, usually after a combustion process

Friction (dynamic): Resistance to motion on account of rubbing against a surface, past which something is moving 
Fuel: A substance that is suitable for generation of heat and power upon combustion, but which also can be stored conveniently until its energy content is needed

Furnish: The fiber-rich solids content from which paper is made

Gasification: A process in which biomass is strongly heated with much less oxygen than is needed for full combustion, with process conditions chosen to favor mainly the production of gaseous products such as carbon monoxide, hydrogen, methane, water, and carbon dioxide

Grate: A set of parallel metal supports, with spaces between them, which is able to hold combustible solid materials within an area where combustion occurs

Greenhouse effect: A tendency for the plant Earth to have a higher average temperature due to a process in which increased concentrations of gases such as carbon dioxide, methane, and nitrogen oxides prevent infrared rays coming from the Earth's surface to pass unobstructed into space

Greenhouse gases: Carbon dioxide, methane, nitrogen oxides, and some minor gases, which have the net effect of increasing the world's average temperature when they are present at increased concentrations in the atmosphere

Green liquor: The result of dissolving the solid byproducts of combustion in a kraft pulping process (i.e. smelt from the chemical recovery boiler) in water

Heat: Thermal energy that is characterized by rapid motions of the molecules making up a substance

Heat capacity: The quantity of heat that is associated with a unit change of temperature of a specified amount of material

Heat exchanger: A device that transfers energy from a source stream (being cooled) to a sink stream (being heated)

Hemicellulose pre-extraction: A process strategy by which hemicellulose is extracted from wood chips prior to chemical pulping, with potential high-value usage of the hemicellulose and potential savings in bleaching costs of pulp

Higher heating value: The maximum amount of heat that can be obtained from combustion of a unit mass of specified material if it is completely dried before the combustion

Hog fuel: Chopped biomass, such as bark or branches, that can be fed to a boiler for generation of electricity or process steam

Hood: A mostly sealed set of roof and side-walls enclosing a set of evaporative dryer cans in a paper machine system, making possible the later recovery of much of the latent heat content in the evaporated water from the paper

Incineration: A process in which a sufficient amount of oxygen is employed in order to fully burn selected material at a high temperature, i.e. high-temperature combustion

Insulation: The use of a layer of material having low thermal conductivity as a means to decrease the rate of heat transfer, as in the case of a pipe carrying steam

Kraft pulping: A process in which a solution containing sodium hydroxide and sodium sulfide, at high temperature and pressure, is used to break down and dissolve the 
lignin component within wood chips such that cellulosic fibers can be separated easily from each other

Landfilling: The disposal of solid or semi-solid waste materials in the ground, ideally in a site that has a sealed floor and is fitted with devices to capture any methane that results from anaerobic decomposition

Latent heat: Energy that is associated with the change of phase within a material, as in the case of steam vapor that can be condensed to liquid water

Life cycle assessment: An accounting system that attempts to quantify the environmental impacts of a proposed or actual change in a process or system, including such changes as production of greenhouse gases, depletion of resources, eutrophication of water, emission of toxic gases, etc.

Lignin: The component of woody material that is made up of phenolpropane subunits and serves as a stiff binder joining cellulosic fibers to each other in the wood

Lime kiln: A very large, slowly rotating steel cylinder device, positioned at a shallow descending angle, that is strongly heated while damp calcium carbonate, added at its upward end, is gradually being transformed to calcium oxide (burnt lime), which comes out of its lower end

Loss: An amount of heat or material that become no longer available as heat or product as a result of processing or leakage

Mechanical pulping: A process in which lignocellulosic material is transformed into fibers, where mechanical energy plays the dominant role

Modeling: The use of systematic mathematic expressions and calculations to estimate the outcomes of a process, making it possible to address "what-if" type questions

Pellet: A piece of lignocellulosic material that has been compressed into a cylinder shape about 3 to $6 \mathrm{~mm}$ in diameter and often about 10 to $20 \mathrm{~mm}$ long

Photosynthesis: A natural process by which carbon dioxide from the atmosphere, together with some water, is converted into sugars that thereafter can be converted into other organic compounds

Pinch analysis: An engineering strategy involving graphical plots having change of temperature on one axis, enthalpy on the other axis, and a pair of curves, one representing the cumulative streams being cooled (source streams) and the other representing the streams being heated (sink streams)

Pocket ventilation: Injection of relatively dry air into locations within a dryer section where vapor otherwise can be expected to accumulate

Power: An amount of energy usage or production per unit of time

Primary treatment of wastewater: A process in which wastewater is placed near the center of a circular container under quasi-static flow conditions, thus allowing particles of solid materials to settle, such that relatively solids-free water can be collected at the upper outside edges of the container and sludge can be collected at its base 
Process integration: A program of systematic changes to heat flows within a process, such that heat can be utilized more efficiently

Pulp: Cellulosic fibers, often obtained from wood or other plant materials, either in their dry form or suspended in water

Pyrolysis: A process in which material is subjected to strong heating in the presence of much less oxygen than would be needed to fully react and produce carbon dioxide, with temperature conditions favoring the production of bio-oil, together with some char and syngas

Radiant energy: The transport of energy through space as electromagnetic waves, not dependent on diffusion or convection, which often is proportional to the absolute temperature of a surface raised to the fourth power

Recovery boiler: A device within which spent pulping liquor, e.g. strong black liquor, is incinerated, resulting in heat that is used to generate high-pressure steam, while reducing most of the sulfate present to the sulfide form

Recovery of heat: The transfer of heat content from a hot stream (a source stream) so that it can be used in a process, for instance for the heating up of air or water (a sink stream)

Refining: Passage of wet cellulosic material between a rotor and a stator having rectangular bars on their surfaces such that bunches of fibers encounter multiple events of squeezing and shearing, yielding individual fibers that have been internally delaminated, become more swollen with water, and have an increased tendency to form bonded area when the material is dried

Refrigeration: Usage of a device in which a cycle of evaporation and condensation is used to convert electrical energy into removal of heat from a material or process

Rotor: A disc-like or conical section of a device that turns around on a shaft

Saveall: A device within a paper machine system that is intended to collect fine suspended solids from excess process water, usually by means of filtration, but sometimes by a floatation mechanism

Secondary treatment of wastewater: A process in which wastewater is subjected to protracted aeration, with the recycling of sludge, such that a microbial population is able to grow and consume organic compounds in the water, thus reducing the biological oxygen demand (BOD). Alternatively, an anaerobic process designed to perform the same function

Self-sufficiency (in terms of energy): The ability of a process to power itself by using a portion of the energy present in the raw materials that are being consumed

Sensible heat: Heat that is associated with the heating or cooling of a material, without changing its phase

Shoe press: A device on a paper machine designed to squeeze water out of paper as it passes (within a sandwich comprised of felt-paper-felt) through a nip between a hard roll and a surface that has a convex shape in the squeezed zone 
Simulation: Carrying out a system of calculations and tabulation, making it possible to predict the outcomes of a process, as in the carrying out of calculations for a mathematical model

Sink stream: Flowing material (often a liquid, a gas, or a suspension) that is in the process of being heated

Size press: A device on a paper machine in which an aqueous solution (often a starch solution) is applied to paper's surface as the wet web passes through a nip between two rolls

Sludge, primary: The wet, solid material that settles by gravity during use of an initial clarification, often with assistance of a coagulant and an optional flocculant

Sludge, secondary: The wet, solid material that settles by gravity during use of a second clarification operation, usually after the wastewater has been aerated, with the recycling of some of the same sludge (activated sludge) to the aeration stage of the process

Solids: Contents of a mixture that can be weighed after full evaporation of water, e.g. at $105{ }^{\circ} \mathrm{C}$

Source stream: Flowing material (often a liquid, a gas, or a suspension) that is in the process of being cooled

Stator: A disc-like or conical section of a device that faces the surface of a rotor (see earlier)

Steam box: A rectangular enclosure that allows steam to come into contact with a wet paper sheet, often immediately before it enters the nip of a wet-press

Sustainability: The ability of a process to be carried out repeatedly without accumulated damage to the environment

Tall oil: A mixture of oil-loving compounds that can be skimmed from the surface of spent kraft pulping liquor (black liquor), often when it is part way through the evaporation process on its way to the recovery boiler

Thermocompresser: A device that blends steam streams having two different levels of temperature and pressure

Thermomechanical pulping: A process of preparing cellulosic fibers from wood chips in which the chips are steam-treated under pressure and then passed through an initial refiner

Through-air drying (TAD): A system for evaporation of water from tissue or towel paper grades in which a stream of relatively dry, hot air passes from a pressurized hood enclosure through the paper and then through a large cylindrical screen

Torrefaction: Exposure of lignocellulosic material to temperatures in the general range of 200 to $300{ }^{\circ} \mathrm{C}$, such that some of the hemicellulose is decomposed and the resulting material has less tendency to take up water

Underutilized resources: In the case of lignocellulosic materials, such items as bark, branches, residues from lumber mills, crop residues, and some lignin streams 
Vacuum flatbox (suction box): A device designed to such water from a wet web of paper in the later part of its formation on a paper machine

Water footprint: The amount of fresh water that is removed from the ecosystem surrounding a process of interest due to that operation

Wet-press: A device on a paper machine designed to squeeze water out of paper as it passes (adjacent to one felt or within a sandwich comprised of felt-paper-felt) through a nip between two hard rolls

White liquor: A mixture of sodium hydroxide and sodium sulfide in a water solution, which can be used in a pressurized reactor with wood chips for kraft pulping

White water: Process water within a paper machine system that carries the fibers, allows them to be formed into a sheet, and most of which is recirculated multiple times so that it can dilute incoming pulp 